\title{
Human Exploration Using Real-Time Robotic Operations (HERRO)—Crew Telerobotic Control Vehicle (CTCV) Design
}

\author{
Steven R. Oleson, ${ }^{1}$ Melissa L. McGuire, ${ }^{2}$ Laura Burke, ${ }^{3}$ David Chato, ${ }^{4}$ James Fincannon, ${ }^{5}$ \\ Geoff Landis, ${ }^{6}$ Carl Sandifer, ${ }^{7}$ Joe Warner, ${ }^{8}$ and Glenn Williams ${ }^{9}$ \\ NASA Glenn Research Center, Cleveland, Ohio 44135 \\ Tony Colozza, ${ }^{10}$ Jim Fittje, ${ }^{11}$ Mike Martini, ${ }^{12}$ Tom Packard ${ }^{13}$ \\ Analex Corporation, Cleveland, Ohio 44135 \\ Dave McCurdy ${ }^{14}$ and John Gyekenyesi ${ }^{15}$ \\ ASRC Engineering, Cleveland, Ohio 44135
}

\begin{abstract}
The HERRO concept allows real time investigation of planets and small bodies by sending astronauts to orbit these targets and telerobotically explore them using robotic systems. Several targets have been put forward by past studies including Mars, Venus, and near Earth asteroids. A conceptual design study was funded by the NASA Innovation Fund to explore what the HERRO concept and it's vehicles would look like and what technological challenges need to be met. This design study chose Mars as the target destination. In this way the HERRO studies can define the 'endpoint' design concepts for an 'all-up' telerobotic exploration of the number one target of interest-Mars. This endpoint design will serve to help planners define combined precursor telerobotics science missions and technology development flights. A suggested set of these technologies and demonstrator missions is shown in Appendix B.

The HERRO concept includes a crewed telerobotics orbit vehicle as well three Truck rovers, each supporting two teleoperated geologist robots 'Rockhounds' (each truck/Rockhounds set is landed using a commercially launched aeroshell landing system.) Options include a sample ascent system teamed with an orbital telerobotic sample rendezvous and return spacecraft $(\mathrm{S} / \mathrm{C})$ (yet to be designed). Each truck rover would be landed in a science location with the ability to traverse a $100 \mathrm{~km}$ diameter area, carrying the Rockhounds to $100 \mathrm{~m}$ diameter science areas for several week science activities. The truck is not only responsible for transporting the Rockhounds to science areas, but also for relaying telecontrol and high-res communications to/from the Rockhound and powering/heating the Rockhound during the non-science times (including night-time). The Rockhounds take the place of human geologists by providing an agile robotic platform with real-time telerobotics control to the Rockhound
\end{abstract}

${ }^{1}$ COMPASS Lead, DSB0, 21000 Brookpark Road, and AIAA Senior Member.

${ }^{2}$ COMPASS Integration Lead, Mission Design, 21000 Brookpark Road, Non-Member.

${ }^{3}$ Mission Designer, Mission Design, 21000 Brookpark Road, and Non-Member.

${ }^{4}$ Mechanical Engineer, Fluid Systems 21000 Brookpark Road, and AIAA Senior Member.

${ }^{5}$ Electrical Engineer, Power Systems, 21000 Brookpark Road, and Non-Member.

${ }^{6}$ Physicist, Power Research, 21000 Brookpark Road, and AIAA Senior Member.

${ }^{7}$ Aerospace Engineer, Mission Design, 21000 Brookpark Road, and Non-Member.

${ }^{8}$ Electrical Engineer, Communications Branch, 21000 Brookpark Road, and Non-Member.

${ }^{9}$ Electronics Engineer, Avionics Branch, 21000 Brookpark Road, and Non-Member.

${ }^{10}$ Electrical Engineer, Thermal Systems, 21000 Brookpark Road, and AIAA Senior Member.

${ }^{11}$ Aerospace Engineer, Propulsion Systems, 21000 Brookpark Road, and AIAA Senior Member.

${ }^{12}$ Aerospace Engineer, Mission Solutions Group, 21000 Brookpark Road, and AIAA Senior Member.

${ }^{13}$ Aerospace Engineer, Missions Solutions Group, 21000 Brookpark Road, and Non-Member.

${ }^{14}$ Senior Structural Engineer, Missions Solutions Group, 21000 Brookpark Road, and Non-Member.

${ }^{15}$ Senior Structural Engineer, Missions Solutions Group, 21000 Brookpark Road, and Non-Member. 
from the crew telerobotics orbiter. The designs of the Truck rovers and Rockhounds will be
described in other publications. This document focuses on the CTCV design.

\section{Study Background and Assumptions}

\section{A. Background}

$\mathrm{T}$

HE HERRO design was awarded as part of the NASA's 2009 Innovative Partnerships Program. The Innovative Partnerships Program (IPP) website characterizes the program as follows: http://www.nasa.gov/offices/ipp/ about us/index.html.

\section{B. Study Overview}

From the IPP proposal submission, the Human Exploration Using Real-Time Robotic Operations (HERRO) architecture concept description is as follows:

This effort will evaluate Human Exploration Using Real-Time Robotic Operations (HERRO)—an exploration strategy combining the best features of human and robotic spaceflight into a single architecture. HERRO enables human exploration of the solar system without landing astronauts on the surface of the Moon or Mars. Instead, a piloted S/C orbits scientifically interesting planetary bodies such as Mars, Phobos and Deimos, Near Earth Objects (NEOs), or Venus. From the vantage point of planetary orbit, the crew explores via telepresence, using telerobotic systems deployed on the surface. It is very similar to the way scientists use telerobotic submersibles to explore the oceans. This proposed 3-month proof-of-concept effort will compare HERRO with conventional architectures for crew-to-surface missions for a Mars mission.

HERRO enables human exploration of the solar system without landing astronauts on the body surface. Instead, a piloted S/C orbits scientifically interesting planetary bodies such as Mars, Phobos and Deimos, Near Earth Objects (NEOs), Venus. HERRO is a new approach to exploration. This was inspired as a sort of 'Star-Trek' approach. In the HERRO architecture, the crew remains in orbit and probes the planet with probes and sensors. The crew only shuttle or "beam" down to the surface if the environment has been deemed safe. From the vantage point of planetary orbit, the crew explores via telepresence, using telerobotic systems deployed on the surface. It is very similar to the way scientists use telerobotic submersibles to explore the oceans.

1. Architecture Components and Concept of Operations (CONOPS) Overview

For the HERRO concept designed in this report, the COMPASS team chose Mars as the target of interest. The mission follows one similar to the Mars DRA 5.0 recently completed by a NASA study team (Ref. 1). The following elements shown in Figure 1 make up the architecture of this HERRO architecture concept.

First three truck rovers (each carrying two Rockhounds) are launched using three separate EELVs and sent to Mars and landed using proven aerocapture techniques at three different locations of scientific interest at disparate locations around the Mars globe. Once these systems are checked out and operational, the CTCV departs Earth, coasts to and captures at Mars using nuclear thermal propulsion. Operating in its highly elliptic 12-hr retrograde Molniya Mars science orbit, the CTCV beings to spin at $2.7 \mathrm{rpm}$ to provide Mars' g level artificial gravity. Once the astronauts have acclimatized, they begin to operate the Trucks and Rockhounds, with the former serving as a transporter and the latter serving as the geologists on the surface. The 12-hr Molniya orbit allows for two shifts of scientists to operate two trucks with their Rockhounds each Mars day. The Trucks transport and charge the Rockhounds as well as perform their own science experiments. The Rockhounds depart the Truck and are telerobotically driven around the surface performing science and collecting samples from the surface before returning to the Truck for charging and transport to the next area of scientific interest.

The science mission duration will approach 500 days in Mars orbit. After completing the telerobotic science, samples collected by the Rockhounds will be shuttled to Mars ascent vehicles, which will launch the samples into Mars orbit for pickup, by an as yet undefined collection vehicle and taken to the CTCV. Once the science mission is complete the CTVC despins and begins the return to Earth using a nuclear thermal rocket burn. Final return of the crew is performed using the Orion vehicle on a hyperbolic trajectory. After the Orion vehicle had been jettisoned, the CTCV flies by Earth. Options to return the CTCV for future missions exist. 


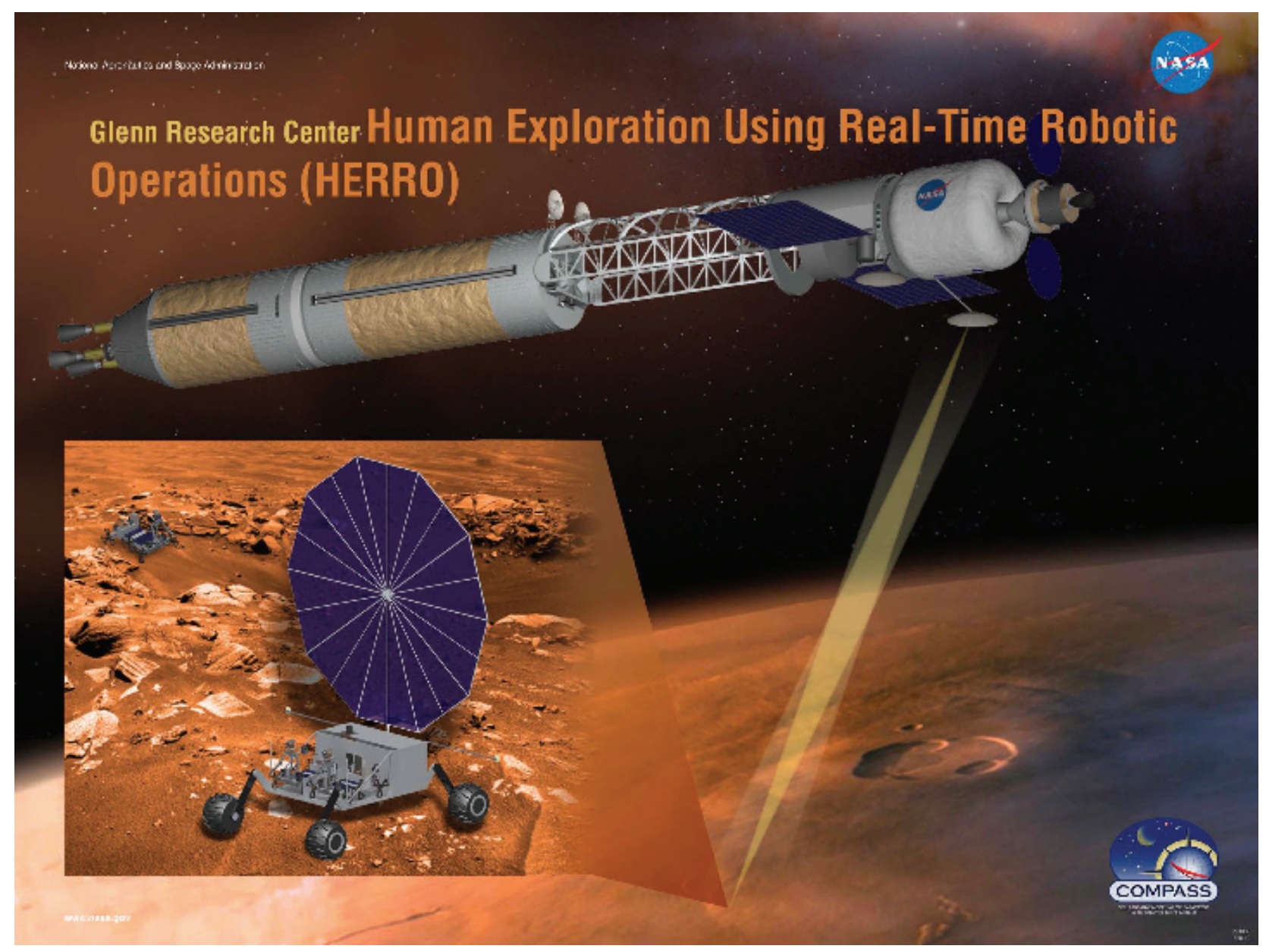

Figure 1. HERRO mission concept architecture

\section{CTCV Design and Functions}

The CTCV is divided into four elements. Each element is launched separately and docked together in LEO to form the assembled CTCV. The definition of each element is show in Table 1. The elements are listed in the table in order of launch with the TransHab element launched first.

Table 1. CTCV Element Definitions

\begin{tabular}{l|l}
\hline \hline \multicolumn{1}{c|}{ Element } & \multicolumn{1}{c}{ Purpose } \\
\hline $\begin{array}{l}\text { TransHab Element } \\
\text { Dropped Tank Element }\end{array}$ & $\begin{array}{l}\text { Contains the crew quarters and all the components necessary to provide a safe haven for the crew. } \\
\text { Contains the propellant to perform the first TMI burn. Once the TMI 1 is performed, the tank is dropped, leaving } \\
\text { the saddle truss structure behind. } \\
\text { Contains much of the TMI 2 and MOC burn propellant. } \\
\text { Contains the NTR engines and reactors along with the structure and tankage to carry the propellant for TEI. } \\
\text { Core Element }\end{array}$ \\
\hline \hline
\end{tabular}

\section{DRA 5.0 Background}

The crewed mission designed during the NASA DRA 5.0 activity had the following highlights. The crew is set to six. The trajectory option is a long duration stay mission, in which the astronauts will be at Mars for roughly 500 days and fly a type II trajectory to Mars from the Earth. A type II trajectory in one in which Mars and the Earth start on the same side of the Sun in the ecliptic plane at the time the astronauts depart Earth. Cargo and some of the assets necessary are pre-deployed to Mars' surface before the crew leave Earth orbit.

The DRA 5.0 mission is a split sprint mission in which the cargo elements are sent out prior to the crew leaving Earth and is illustrated in the graphic in Figure 2. Two cargo vehicles are sent to Mars. Each cargo vehicle is assembled using two Ares V launches each to LEO. The crewed NTR vehicle is also assembled in LEO over a series 
of three Ares V launches. A fourth launch, this time of the Ares I delivers the Orion vehicle containing the crew up to the assembled and powered NTR vehicle. The crew flies on a type II trajectory to Mars, stays on the Martian surface for approximately $500 \mathrm{~d}$ in the predeployed cargo and habitat elements. Once the mission time on the surface is complete, the crew uses the ascent vehicle predeployed on the surface to return to the orbiting NTR crewed vehicle. This vehicle then propels them to a hyperbolic Earth return trajectory. The Orion capsule enters on a direct Earth return while the NTR vehicle flies by.

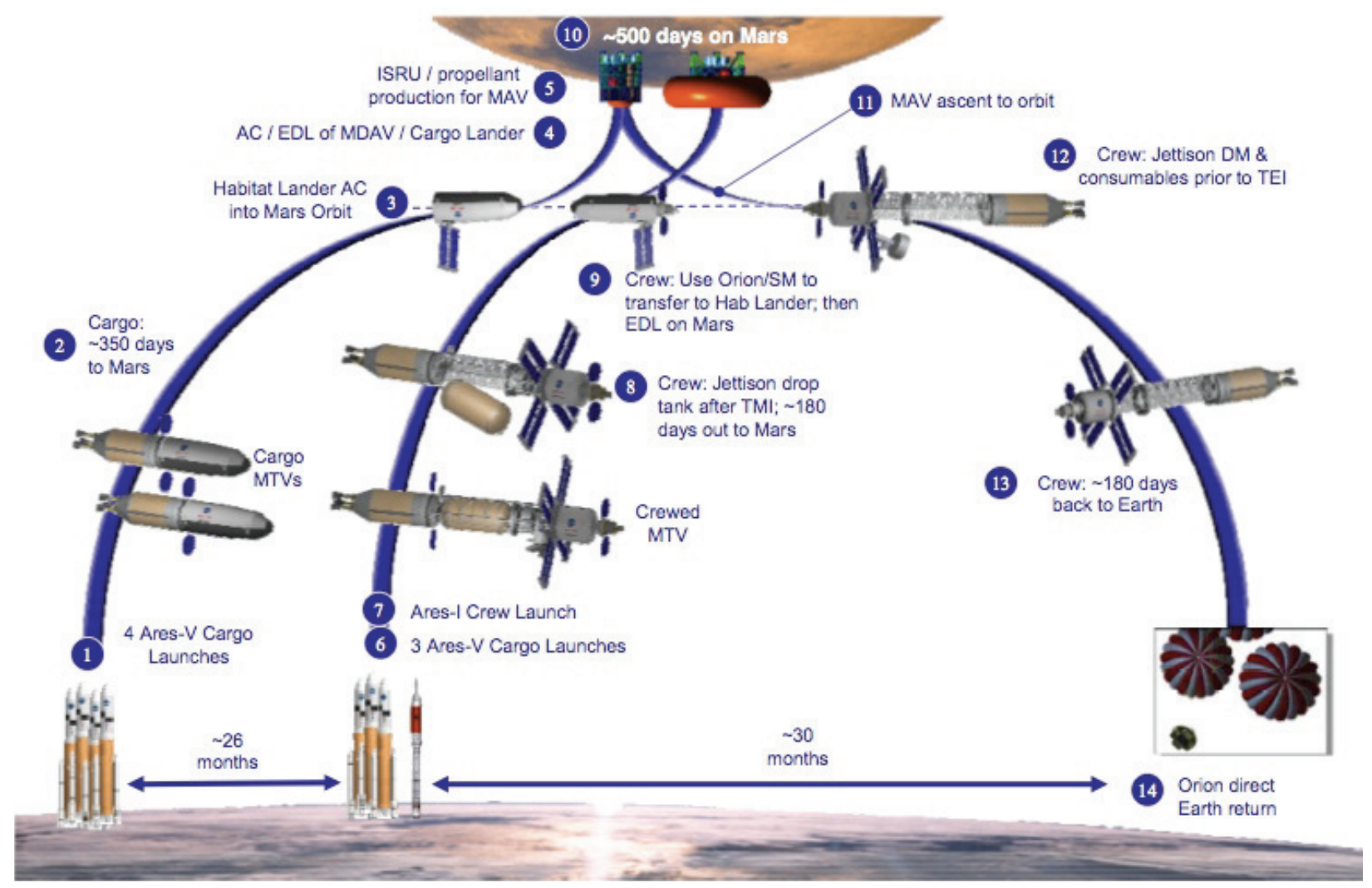

Figure 2. DRM 5.0 mission layout.

\section{Assumptions}

Where the DRA mission lands the crew on the surface of the planet Mars, the HERRO mission leaves them in orbit to control landed Trucks and Rockhounds on the surface. This is similar to the current NASA exploration option being called the Flexible Path option (Ref. 2, HSF Final Report Oct 2009). This option allows for investigation of other worlds while saving the cost and propellant necessary to land and launch again the elements to the surface of that world. In the HERRO mission, the landed elements are predeployed and controlled from orbit from the CTCV which is launched to the target planet (in this case Mars) on the next available trajectory opportunity.

\section{E. Growth, Contingency and Margin Policy}

\section{Mass Growth}

The COMPASS team uses the AIAA S-120-2006, Standard Mass Properties Control for Space Systems (Ref. 3). Mass Growth Allowance (MGA) is defined as the predicted change to the basic mass of an item based on an assessment of the design maturity and fabrication status of the item, and an estimate of the in-scope design changes that may still occur.

The percent growth factors are applied to each subsystem, after which the total system growth of the design is calculated. The COMPASS design team designed to a total growth of $30 \%$ or less. An additional growth is carried at the system level in order to add up to a total system growth of a maximal $30 \%$ limit on the dry mass of the system. Note that growth in propellant is either carried in the propellant calculation itself or in the $\Delta \mathrm{V}$ used to calculate the propellant required to fly a mission. 


\section{Power Growth}

The COMPASS team uses a $30 \%$ margin on the bottoms up power requirements in modeling the power system.

\section{F. Redundancy Assumptions}

The following assumptions of redundancy in the design of the subsystems were used in this design study.

- Single fault tolerant where possible in the design of the subsystems (Double fault tolerance used in some crew systems for safety).

- Exceptions

- Propellant tanks

- Radiators

\section{G. Mission Definition}

The 2033 Earth to Mars transit opportunity was chosen for this study because of the achievable low departure energies and associated departure declinations that were within $28.5^{\circ}$. Type I transfers (as opposed to Type II) were chosen for both the inbound and outbound legs of the transit. Injection into the Earth to Mars transfer ellipse is done with a two-burn trans-Mars injection (TMI) sequence. At Mars arrival, a Mars orbit insertion (MOI) burn is performed to capture into a nearly Sun synchronous Molniya orbit. The CTCV and crew remain in this orbit for 549 days telerobotically operating the rovers on the surface of Mars. Following the stay time in Mars orbit, the CTCV performs a trans-Earth injection (TEI) burn to return the crew to Earth. The NTR engine on the CTCV performs all large burn maneuvers. Smaller maneuver burns including the trajectory correction maneuvers (TCM) during the inbound and outbound transits are performed using the RCS engines.

\section{Mission Design Analytical Methods}

The impulsive trajectory mission was optimized using Copernicus, a generalized trajectory design and optimization program. The impulsive trajectory was analyzed in two separate parts, the outbound leg and the inbound leg. The outbound leg was modeled as an Earth to Mars transfer with the two-burn TMI sequence of maneuvers and the MOI (Mars Orbit Insertion) maneuver at Mars. The inbound leg was modeled as a single TEI maneuver followed by a coast trajectory to Earth. The TMI burns as well as the TEI burn were modeled as finite burns within Copernicus in order to model the effect of gravity loss for varying CTCV mass. The MOI burn was modeled impulsively as it was assumed that the gravity losses would be small capturing into Mars with the large thrust NTR engine.

Optimization was performed on the outbound leg of the trajectory such that the launch energy as well as total impulsive MOI Delta-V were minimized. The analysis was performed using Copernicus which allowed the TMI sequence to be split (into TMI 1 and TMI 2) optimally for Delta-V. The TMI 1 maneuver results in an approximately 10-hr intermediate elliptical orbit before TMI 2 puts the CTCV on the trajectory to Mars. Propellant for TMI 1 is stored in the saddle tank and propellant for TMI 2 and remaining burns during the mission is stored in the core tank. In order to assure that the core tank was filled fully and that the mass post CTCV assembly was within mass limits, it was necessary to adjust the Delta-V split of the TMI burn sequence and force more of the burn to be performed during TMI 2 . When optimally split, $66 \%$ of the total Delta-V for TMI is performed during TMI 1. It was found necessary to reduce this percentage to $48 \%$ in order to force the propellant used during TMI 1 to be approximately $80 \mathrm{mt}$. This limit on propellant was due to the limits of the tank capacity in the dropped saddle truss tank in the Saddle Tank element. The limits of tank capacity in the element were due to the volume/dimension limits of the tank as dictated by the payload fairing of the Ares V launch vehicle (in this case a stretched version from that previously planned). In addition, a $2 \%$ increase in total Delta- $\mathrm{V}$ was assumed to account for Delta- $\mathrm{V}$ increases incurred from not splitting the burns optimally. Optimization was done on the inbound leg of the mission such that the total Delta-V for the TEI maneuver was minimized.

\section{Trajectory Details}

The baseline mission initiates its departure from Earth April 20, 2033, by performing the TMI 1 maneuver to move from a circular parking orbit around Earth into an elliptical orbit. For a 400 MT vehicle in LEO, when optimally performed, TMI 1 is approximately $45 \mathrm{~min}$ in duration and provides a Delta-V of $2.66 \mathrm{~km} / \mathrm{s}$. TMI 2 is performed when the vehicle travels one revolution in this elliptical orbit and again reaches perigee. When done optimally, TEI 2 is approximately 45 minutes in duration and provides a Delta-V of $1.3 \mathrm{~km} / \mathrm{s}$. The CTCV and crew arrive at Mars after 199 days on November 5, 2033. At this time, MOI is performed to capture into the desired Mars orbit. The impulsive Delta-v used in this analysis for MOI is $1.389 \mathrm{~km} / \mathrm{s}$, a Mars stay time of at least 500 days was desired to complete the telerobotic exploration of the surface. The optimal departure date from Mars results in a 549-day stay in Mars orbit for the CTCV and crew. The TEI chemical departure maneuver is initiated on May 8, 
2035. The Delta-V for TEI is $1.75 \mathrm{~km} / \mathrm{s}$ for a $185 \mathrm{MT}$ vehicle with an approximate burn time of $158 \mathrm{~min}$. The Mars to Earth Transfer time is 198 days with an Earth arrival date of November 22, 2035.

Figure 3 shows the minimum energy Hohmann transfer type I trajectory of the Earth to Mars leg of the mission. The trajectory from Earth to Mars is shown in aqua. Earth's orbit is the dark cobalt blue and Mars' orbit is the red. Figure 4 shows the textbook minimum energy Hohmann transfer type I trajectory of the Mars to Earth leg of the mission. The trajectory from Mars to Earth is shown in magenta. Earth's orbit is the dark cobalt blue and Mars' orbit is the red. Figure 5shows the MOI maneuver to capture into the elliptical orbit about the planet Mars. The Hohmann transfer orbit incoming to mars is shown in purple. The Martian orbit into which the CTCV will insert is show in Aqua. The MOI burn is labled and pointed out by the arrow.

The nearly Sun synchronous Molniya orbit was chosen for this mission because of the zero rate-of-change of argument of perigee, allowing apogee passage to remain over one hemisphere throughout the entire Mars stay time. Additionally, since this orbit is nearly Sun synchronous, the CTCV is able to follow the Sun track on the surface for the majority of its orbit. The right ascension of the ascending node of this orbit does process at a slightly slower rate than that of a true Sun synchronous orbit. In order to have the S/C pass through apogee while the ground beneath was sunlit, the orbit was biased such that apogee passage occurred in the morning when the Sun just breaks the horizon. Halfway into the mission (approximately 250 days), apogee passage will occur during midday and at the end of the mission (approximately 550 days) apogee passage will occur in the evening.

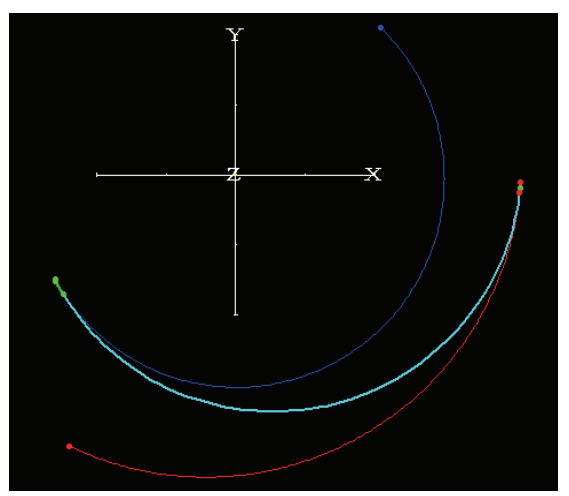

Figure 3. Earth to Mars type I transfer trajectory.

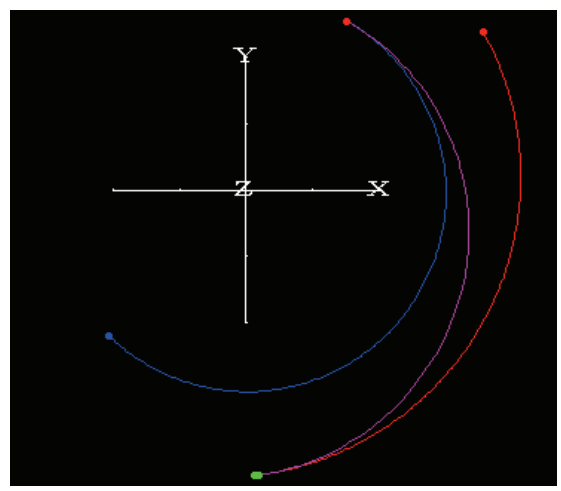

Figure 4. Mars to Earth type I transfer trajectory.

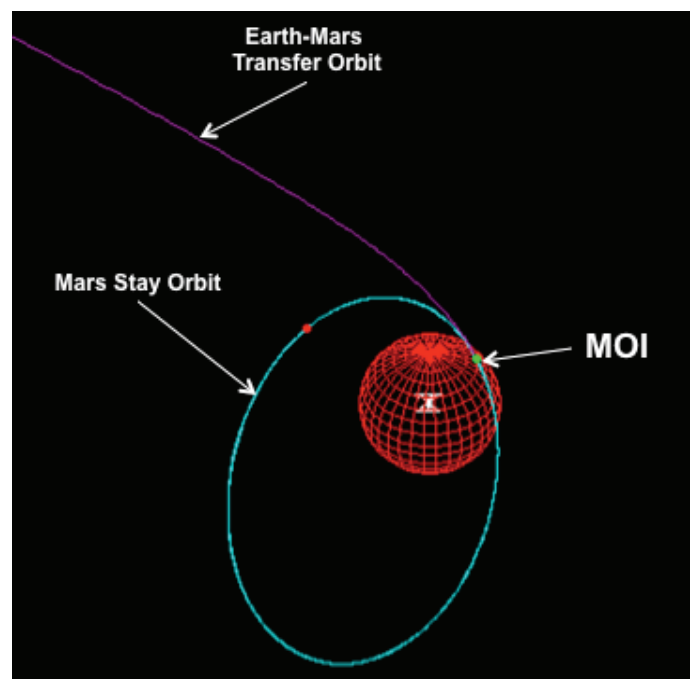

Figure 5. Model of impulsive MOI capture burn into Mars orbit.

Figure 6 shows the TEI burn to change from the Mars elliptical orbit onto the Earth return trajectory. The Mars orbit is shown in aqua, and the TEI burn is labeled and pointed out by the arrow. The Mars-Earth transfer orbit is shown in green. 


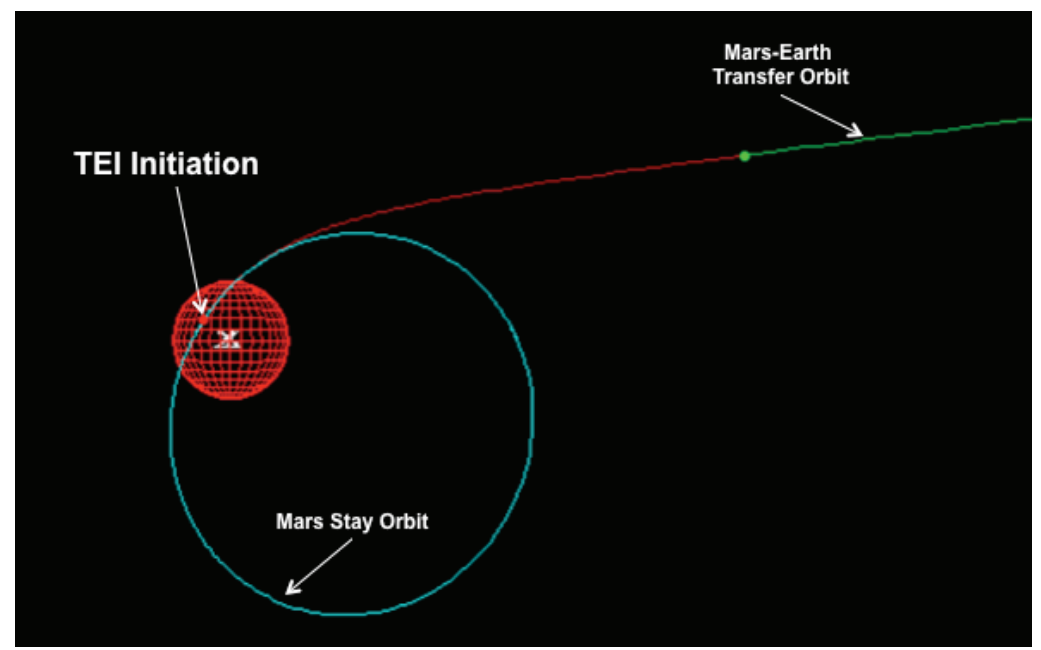

Figure 6. Model of finite TEI burn to inject into Mars-Earth transfer ellipse.

\section{Gravity Losses}

The gravity losses to escape from Earth with such a large vehicle are significant, even with the high thrust of the NTR. Injection a 400 MT vehicle into the required Earth-Mars transfer orbit with a single TMI burn results in a Delta-V of over $4.3 \mathrm{~km} / \mathrm{s}$ with $0.8 \mathrm{~km} / \mathrm{s}$ being due to gravity losses. For this reason the TMI maneuver was split into a two burn sequence such that an intermediate highly elliptical orbit is achieved prior to final transfer orbit insertion. Splitting the TMI maneuver will reduce the effects of gravity loss by nearly half, thus lowering the Delta-V required for TMI to just over $3.9 \mathrm{~km} / \mathrm{s}$ for a $400 \mathrm{MT}$ CTCV.

Figure 7 shows the total Delta-V and gravity losses for a single burn and two-burn TMI sequence for varying IMLEO mass. Figure 8shows the total Delta-V for a two-burn TMI sequence as well as the individual Delta-V's for each of the TMI burns for varying IMLEO mass.

Although there is some gravity loss during escape from Mars, the additional propellant required for gravity loss during TEI fit within mass limits for the launch vehicles. Thus the complexity of adding a second TEI burn to the mission was unnecessary. It is possible to reduce the effects of gravity loss during Mars departure by splitting the TEI maneuver into two burns. Figure 9 shows the total Delta-V and gravity losses for a single burn TEI sequence for varying mass in Mars orbit prior to TEI initiation.

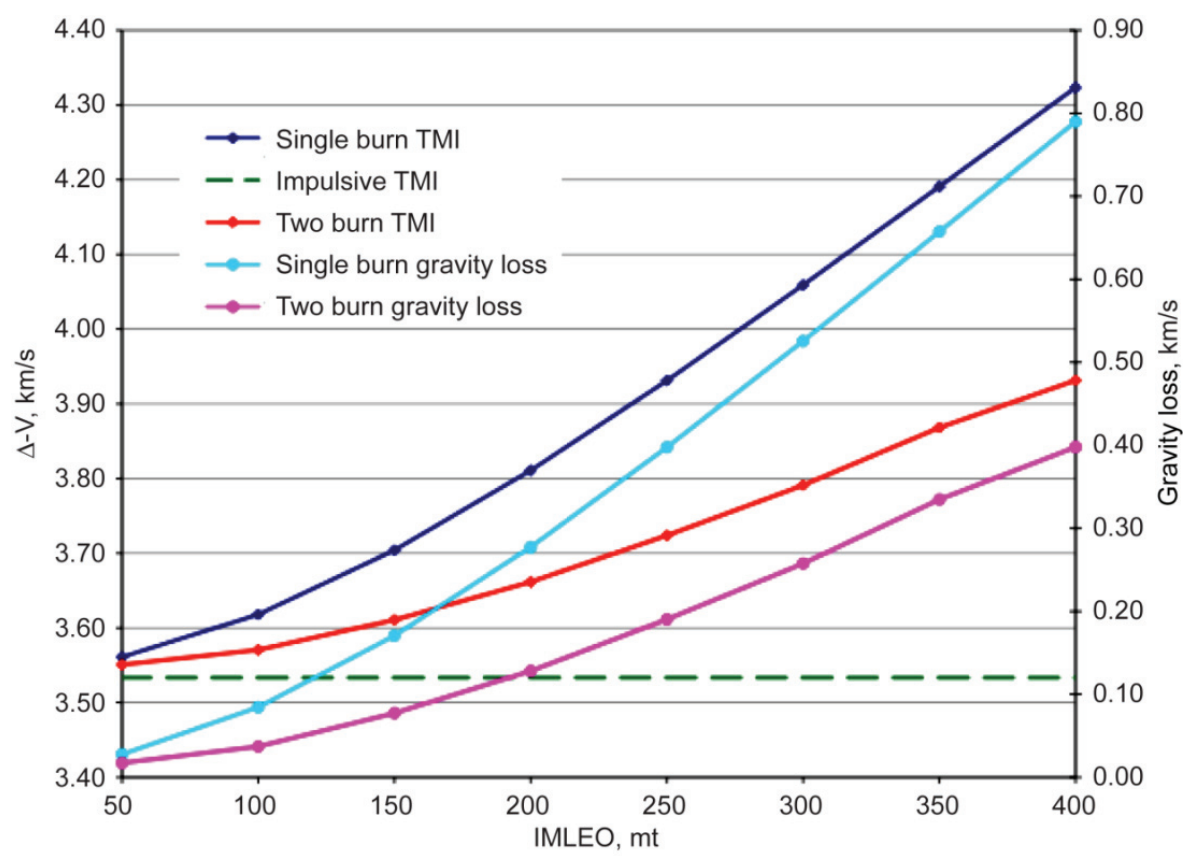

Figure 7. Delta-V of single burn and two burn TMI with gravity losses for range of IMLEO. 


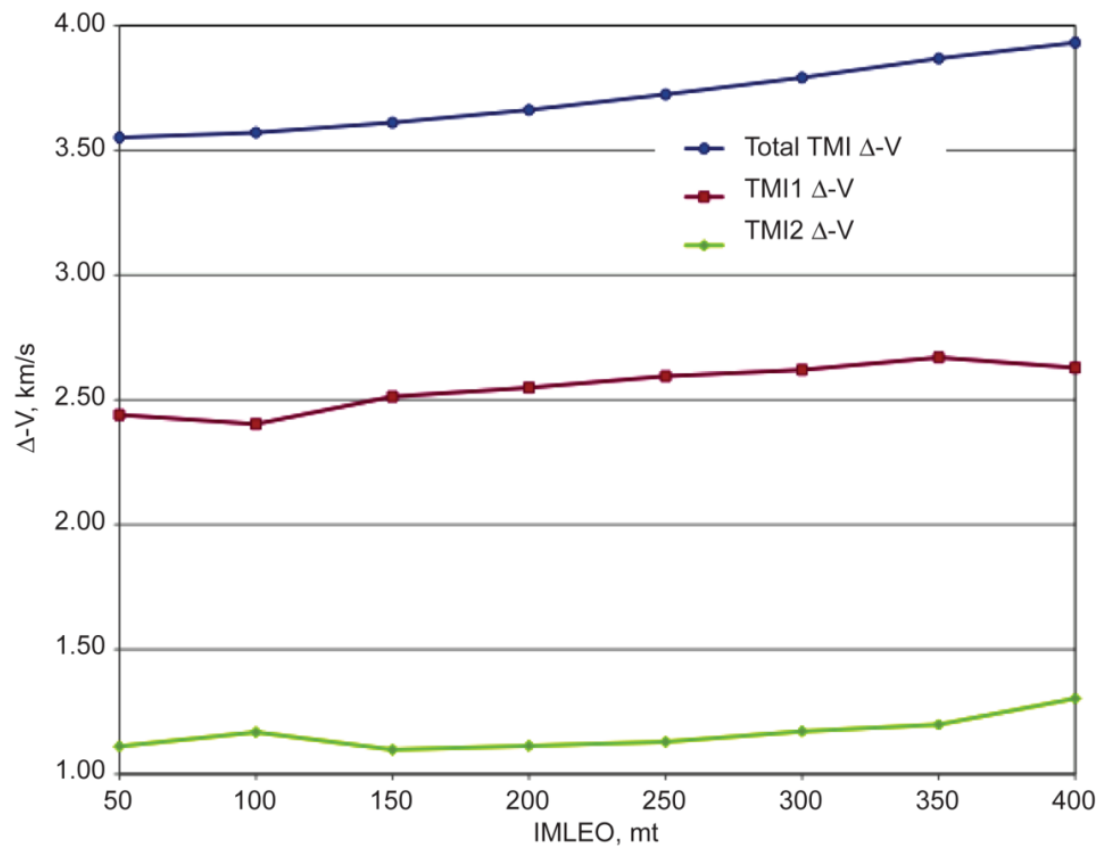

Figure 8. Delta-Vs of TMI burns with gravity losses for range of IMLEO.

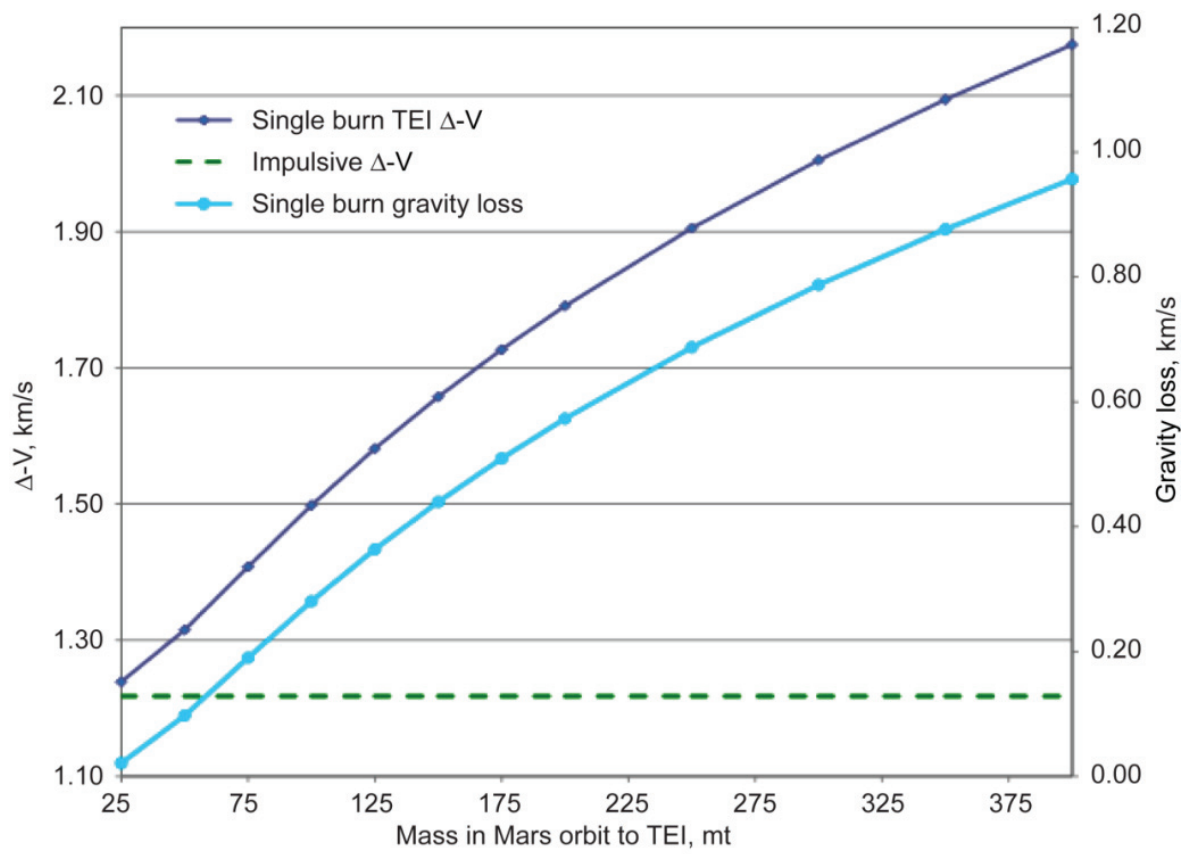

Figure 9. Delta-V of TEI burn with gravity losses for range of masses in Mars orbit prior to burn initiation.

\section{Mission Phases}

\section{LEO Assembly}

The four elements are assembled autonomously in LEO. The TransHab is the first part to be assembled. In doing this, the design did not have to add arrays to each of the subsequent sections and thus the main arrays provide power for everything while in LEO. By launching the TransHab first, the Earth antennas can be used rather than adding communications equipment to each of the other sections. The Core element is the last part to be launched into LEO. Once the TransHab has been inflated, the crew is launched in the Orion vehicle on an Ares I and docks with the TransHab, in the fully assembled vehicle pre-Earth departure as shown in Figure 10. 


\section{TMI Burn 1}

The departure burn to Mars, called the TMI burn is separated into two burns in order to reduce gravity losses. In order to benefit from staging and reducing the amount of mass that the propulsion system has to push, the propellant for the TMI burn 1 is contained in the tank held in the Saddle truss element of the CTCV. Once this first burn is completed, the empty tank is dropped. Therefore, the second TMI burn no longer has to push the empty tank's mass. The mass of the tank includes the MLI covering it as well as the micrometeoroid debris (MMOD) protection, tank lines, heaters, trapped residual propellants, etc. After performing TMI 1, the CTCV is on a 12.5-hr period elliptical intermediate orbit. This intermediate orbit has a radius of perigee of roughly $1000 \mathrm{~km}$. Recall that the ratio of TMI 1 to TMI 2 was optimized on ideal delta V but was also constrained by the amount of propellant that the Saddle tank could not exceed.

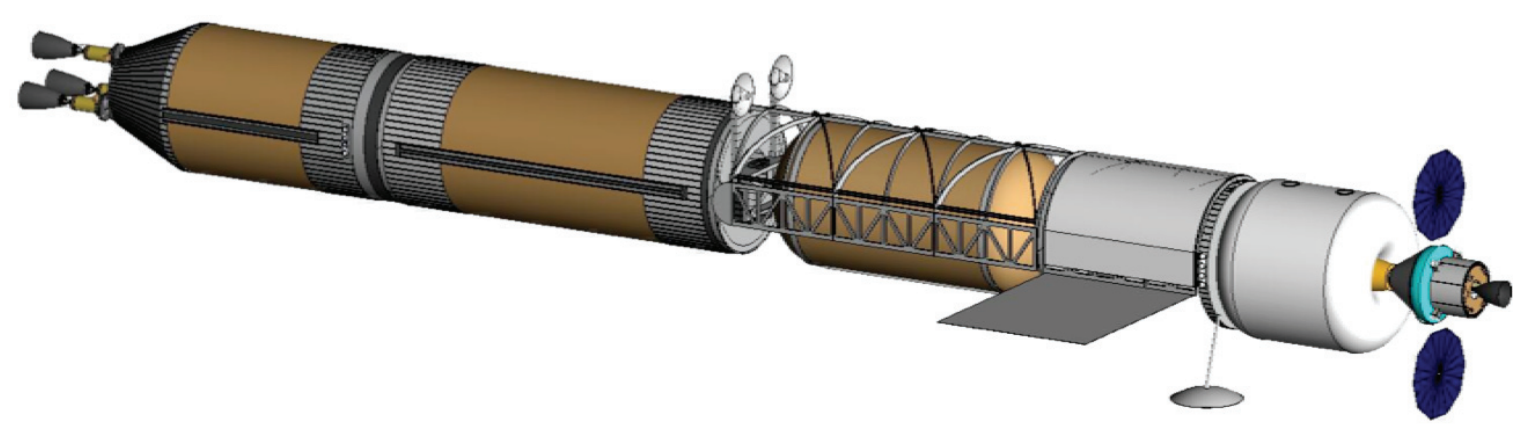

Figure 10. CTCV in LEO (predeparture)—View 1.

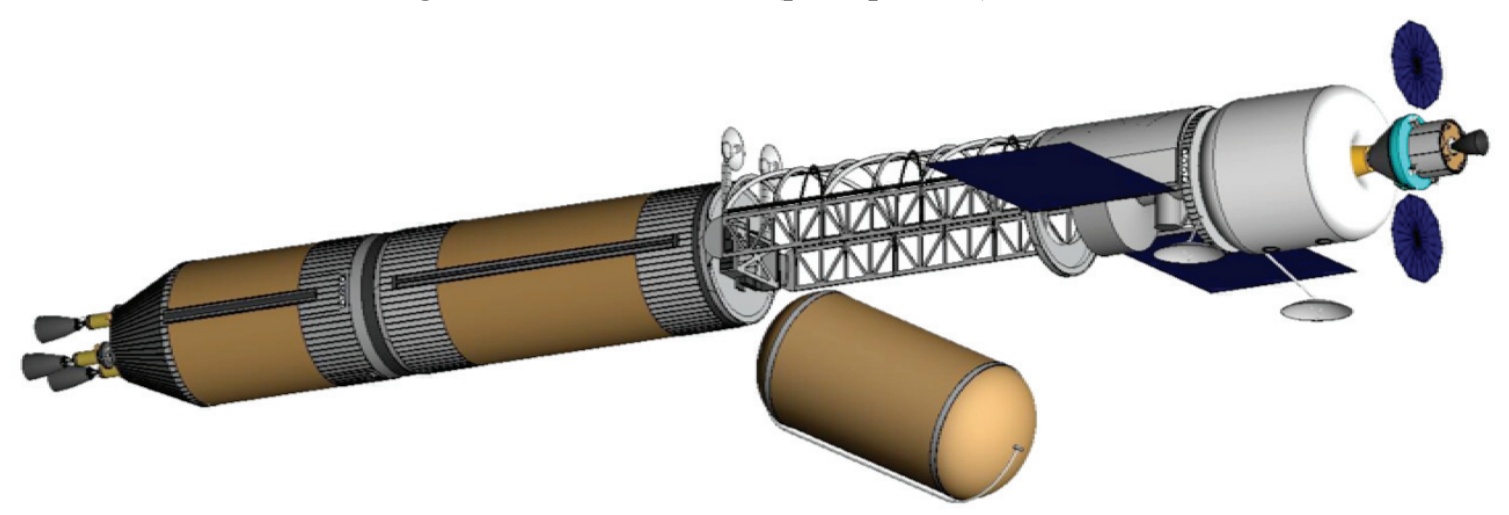

Figure 11. CTCV in LEO (post TMI burn 1)—View 3.

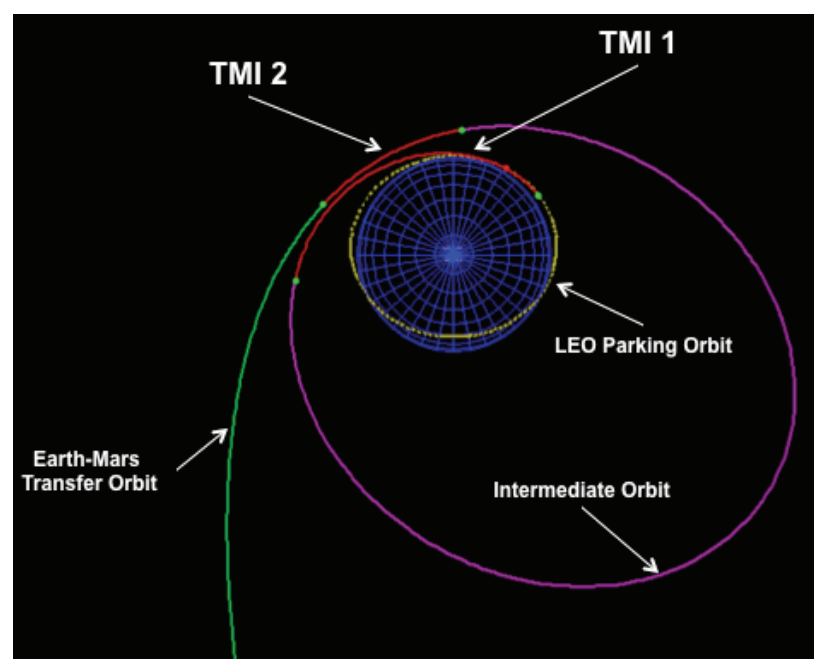

Figure 12. Optimally split finite burn model of TMI sequence. 


\section{TMI Burn 2}

The second burn to put the CTCV on its trajectory to Mars takes place after the TMI 1 intermediate burn and inserts the crew after departing the Earth, into a 190 day final Earth to Mars transfer trajectory. Splitting the TMI burn into two burns reduces the gravity loss effects on the departure trajectory.

\section{In-Transit to Mars}

During the transit to Mars, the Saddle truss-dropped tank has been jettisoned. The solar arrays are deployed and the Ka-band antennas are articulated to face the Earth to provide communication between the Earth and the astronauts in the TransHab. The CTCV in transit to Mars can be seen in Figure 13 and it should be noted that the dropped tank has been jettisoned.

\section{MOI (Mars Orbit Insertion)}

The CTCV performs a burn to insert into an elliptical orbit at Mars. This burn is derived using the ideal Delta V calculations from the mission analysis optimal trajectory. The total Delta-V for the MOI is $1389 \mathrm{~m} / \mathrm{s}(1.39 \mathrm{~km} / \mathrm{s})$. The initial orbit into which the CTCV is captured at Mars had a 96-hr period. The MOI capture burns were optimally split based on ideal Delta V and staging with the Rocket equation, since there were no tank capacity constraints for the vehicle at this stage of the mission. No more tanks were being dropped.

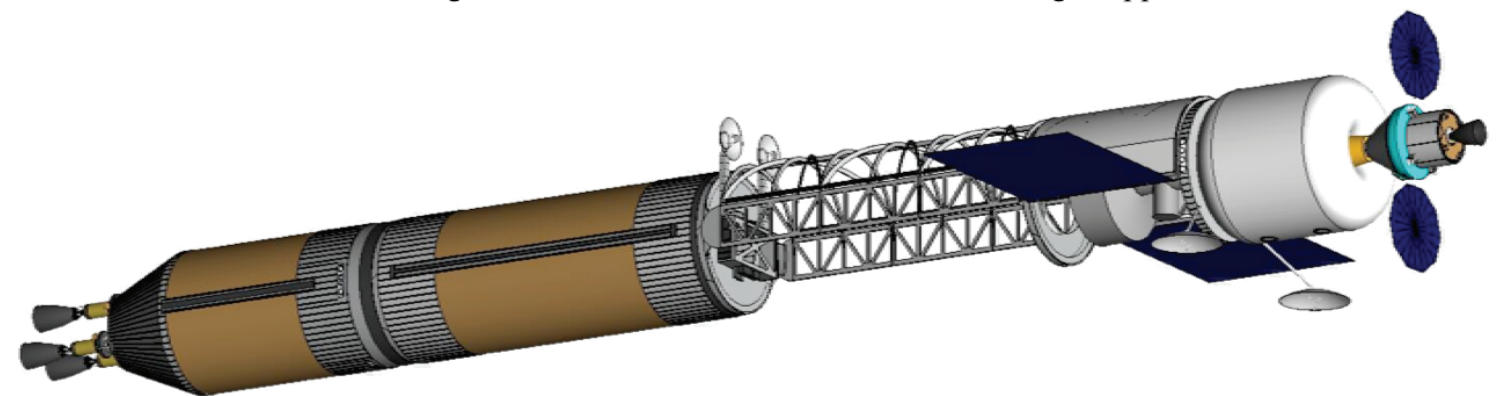

Figure 13. CTCV in-transit to Mars.

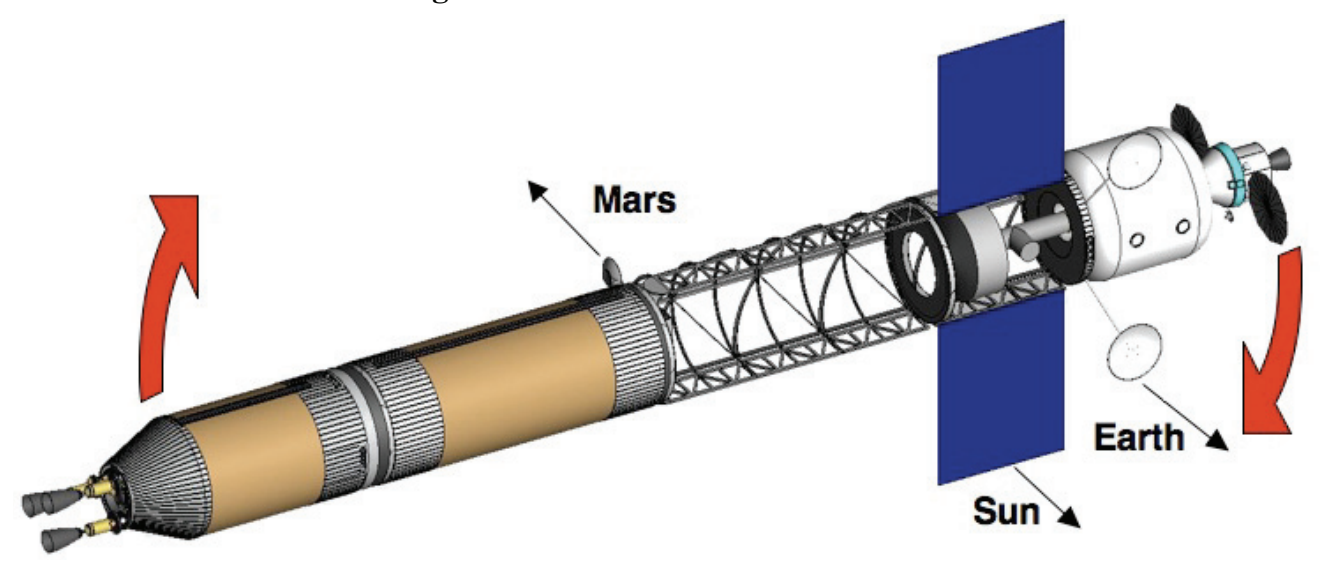

Figure 14. CTCV in Mars orbit.

\section{In Mars Orbit}

The CTCV rotates in Mars orbit in order to provide the astronauts $0.38 \mathrm{~g}$ (Mars' gravity) of gravity during the approximately 500-d stay at Mars. The CTCV rotates at the rate of $2.7 \mathrm{rpm}$. Figure 14 shows the configuration of the CTCV as it rotates end over end about the normal to the center of the vehicle as shown in Figure 14 to provide simulated gravity to the crew. The CTCV rotates around the vector to the Sun and Earth in order to maintain communications.

\section{TEI Burn}

Prior to performing the burn to return to Earth, also called the TEI burn, the food canister and the tunnel connecting the TransHab to the food canister is jettisoned. It is expected that the canister only contain waste at this point. The food for the return trip of 198 days to the Earth is contained with the astronauts in the TransHab. Because the canister and tunnel are jettisoned before the TEI is performed, the propellant used in that burn does not have to push the mass of the canister and tunnel as well as the waste assumed to be inside the canister. The dropping of the food canister is shown in Figure 15. 


\section{In Transit to Earth}

Figure 16 shows the CTCV as it appears in transfer from Mars on its return to the Earth. Note that the dropped tank and food canister have been jettisoned. The crew will return to the Earth in the Orion capsule docked to the end of the TransHab at end opposite the NTR thrusters. The rest of the CTCV will be put on a trajectory with an infinitesimal chance of crossing that of the Earth.

5. Dropped Elements

In order to run the end-to-end mission analysis, the elements, which were to be dropped at major mission milestones, were estimated. After TMI burn 1, the Saddle Tanks and associated hardware were dropped (as shown in Figure 16). Those sums are shown in Table 2. Before TEI, the tunnel, food canister, contingency food, and waste is also jettisoned (as shown in Figure 16).

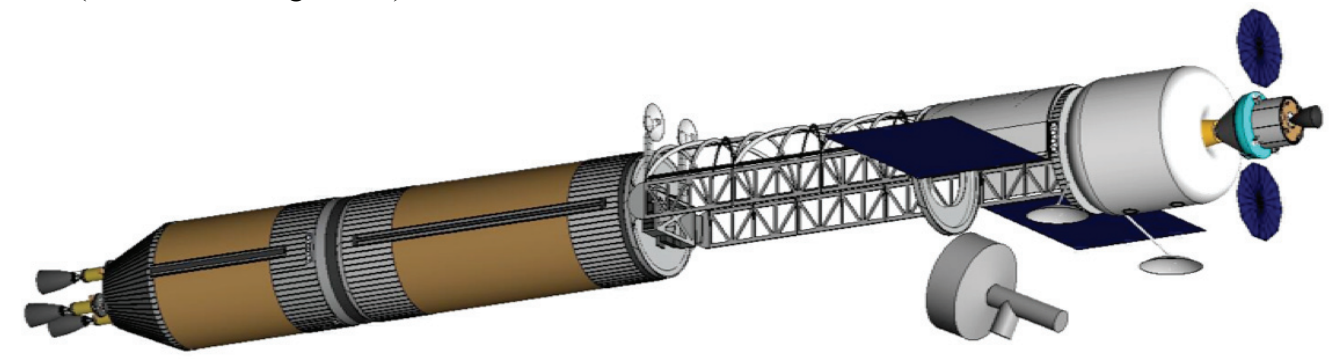

Figure 15. CTCV pre-TEI burn.

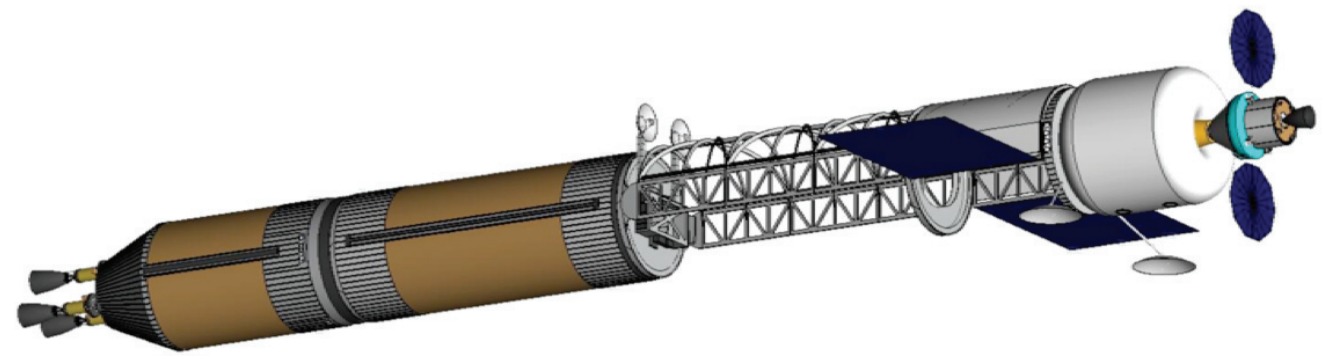

Figure 16. CTCV transit to Earth.

Table 2. HERRO CTCV Dropped Elements

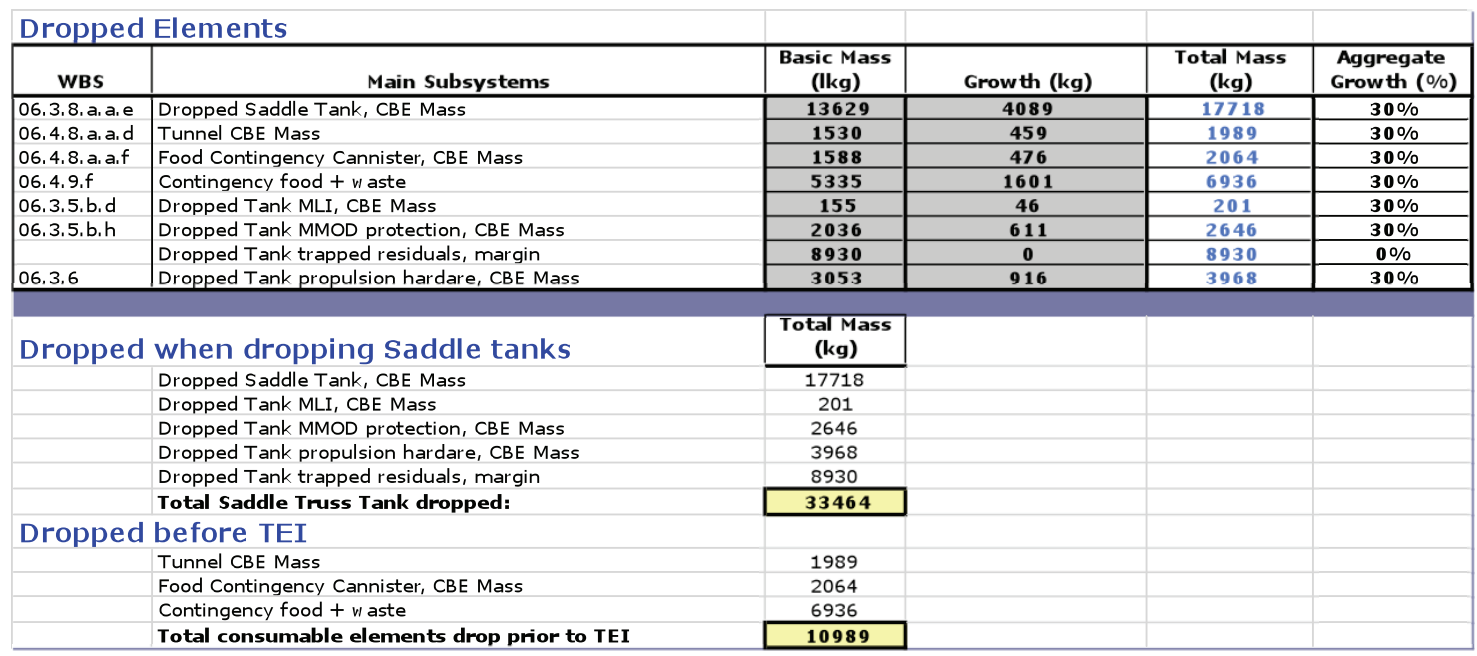

Table 3 lists the assumed inert element mass for the CTCV and the CEV, the required main engine propellant, the required RCS propellant, and the total dropped mass. The total mass for each element includes the inert mass and the required propellant mass. The dropped mass is included within the inert mass. The propellant necessary to perform some of the on-orbit maneuvers (spin-up/spin-down and precession) was tracked as a negative dropped mass rather than accumulating from a Delta-V. 
Table 3. CTCV Propellant and Dropped Mass Totals

\begin{tabular}{|c|c|c|c|c|c|}
\hline Element number & $\begin{array}{c}\text { Inert element mass (includes } \\
\text { boiloff, dropped masses and } \\
\text { unusable propellant) } \\
(\mathrm{kg})\end{array}$ & $\begin{array}{c}\text { Required main } \\
\text { engine usable } \\
\text { propellant } \\
(\mathbf{k g})\end{array}$ & $\begin{array}{c}\text { Required RCS } \\
\text { engine usable } \\
\text { propellant } \\
(\mathbf{k g})\end{array}$ & $\begin{array}{c}\text { Total mass } \\
\text { dropped } \\
\text { (kg) }\end{array}$ & $\begin{array}{c}\text { Total element } \\
\text { mass } \\
\text { (kg) }\end{array}$ \\
\hline 1-CTCV & 186054 & $\begin{array}{r}205294 \\
0\end{array}$ & 5583 & 57317 & $\begin{array}{r}396932 \\
10000\end{array}$ \\
\hline
\end{tabular}

\section{Launch Vehicle Details}

The Ares V launch vehicle is baselined as the launcher for the four elements assembled in LEO to create the $\mathrm{CTCV}$. The projected performance of the Ares V launch vehicle for the purpose of this design is $140,000 \mathrm{~kg}$ to a $28.5^{\circ}$ inclined LEO.

\section{Launch Vehicle Packaging}

During the course of the CTCV design, it was decided to split the entire vehicle into four sections, a TransHab section, drop tank section, in-line tank section, and core section, each requiring their own launch. Given the large diameter and long length of each of the four sections, a modified Ares V Payload shroud is required for launch. While each of the four sections were designed to maximize the launch mass to near the Ares V performance while maintaining good staging points during the Mars mission profile, the desire to utilize, and maximize the volume capability of a common payload fairing for all four launch sections was also considered.

Given the $10 \mathrm{~m}$ external diameter of the large $\mathrm{LH}_{2}$ tanks, an $11 \mathrm{~m}$ static envelope diameter was selected to allow room for tank insulation and shielding, and the saddle truss used to encapsulate the drop tank and cargo canister. The length of the cylindrical section of the fairing was driven by the length of the in-line and drop tank sections, both of which came in at a total length of $26.6 \mathrm{~m}$, including the interface rings at each end of the sections. The overall length of the TransHab section fits well within the $26.6 \mathrm{~m}$ length of cylindrical portion of the fairing. For the core section, it was decided to launch with the engines on top. This orientation allows for easier mating to the launch vehicle, and allows the $\mathrm{LH}_{2}$ tank to be maximized by utilizing the conical section of the fairing to encapsulate the engine nozzles.

Two of the four sections require deployable components to allow them to fit within the fairing for launch. On the TransHab section the two Earth pointing antennas, solar arrays, and the TransHab itself (inflatable) require deployment, while on the drop tank section the two Mars pointed antennas require deployment. Figure 17 through Figure 20 show each of the four CTCV sections stowed within the modified fairing.
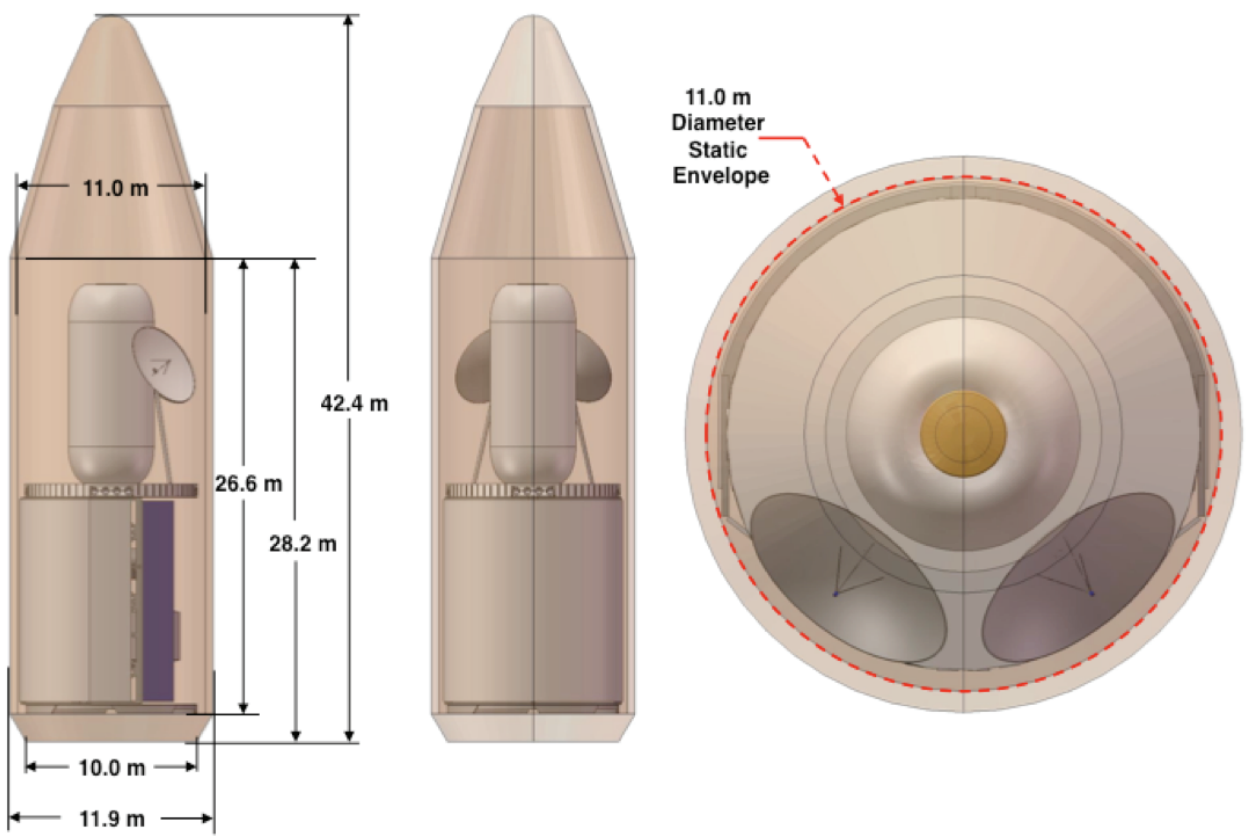

Figure 17. TransHab section stowed within the modified Ares V payload fairing. 

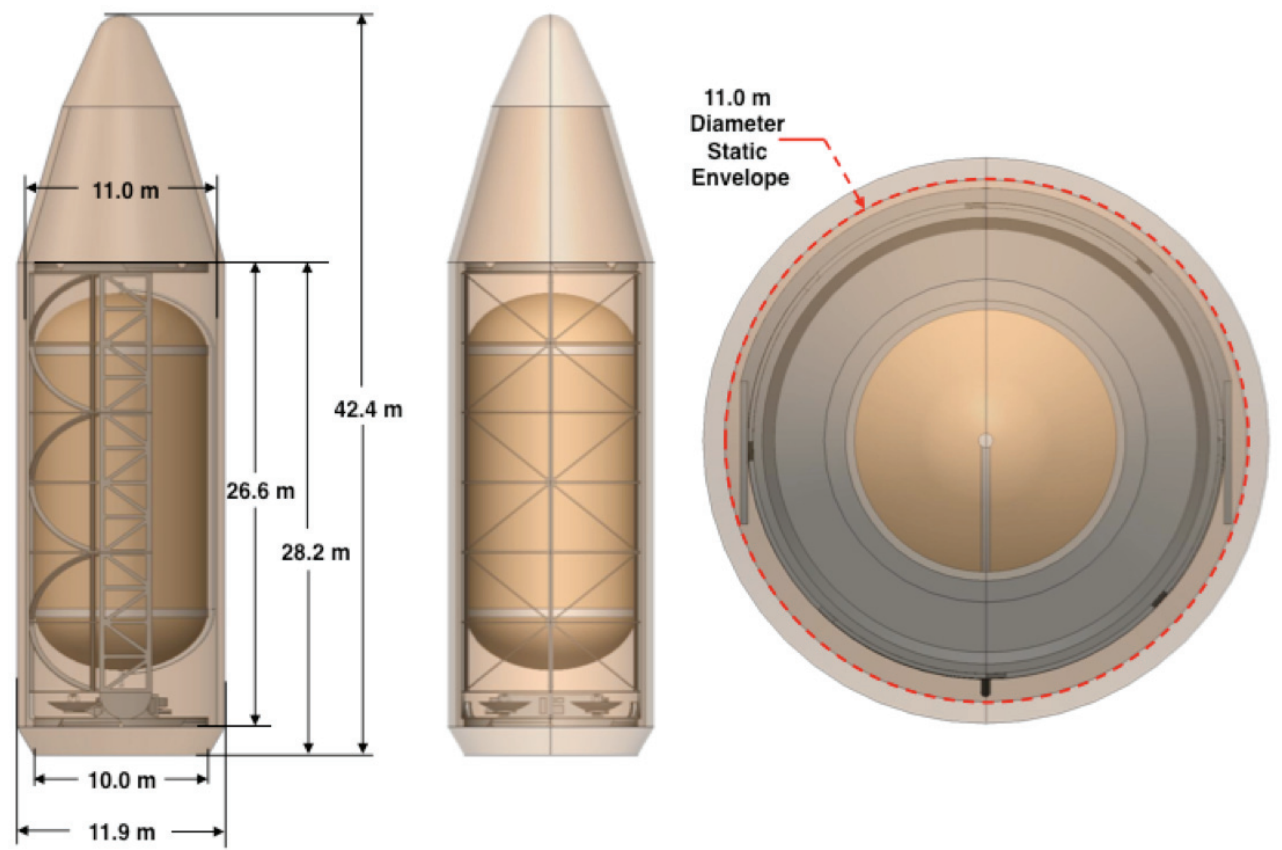

Figure 18. Drop tank section stowed within the modified Ares V payload fairing.
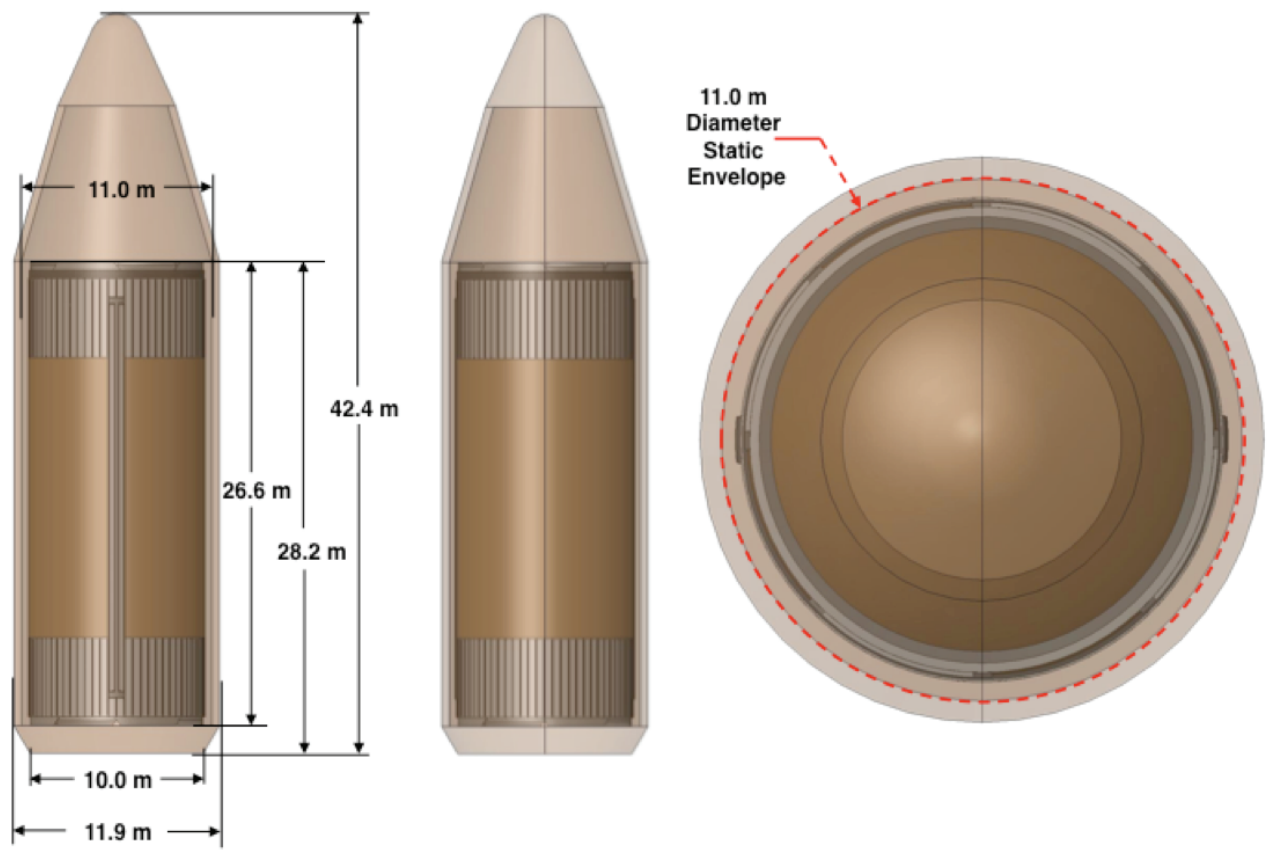

Figure 19. In-line tank section stowed within the modified Ares V payload fairing. 

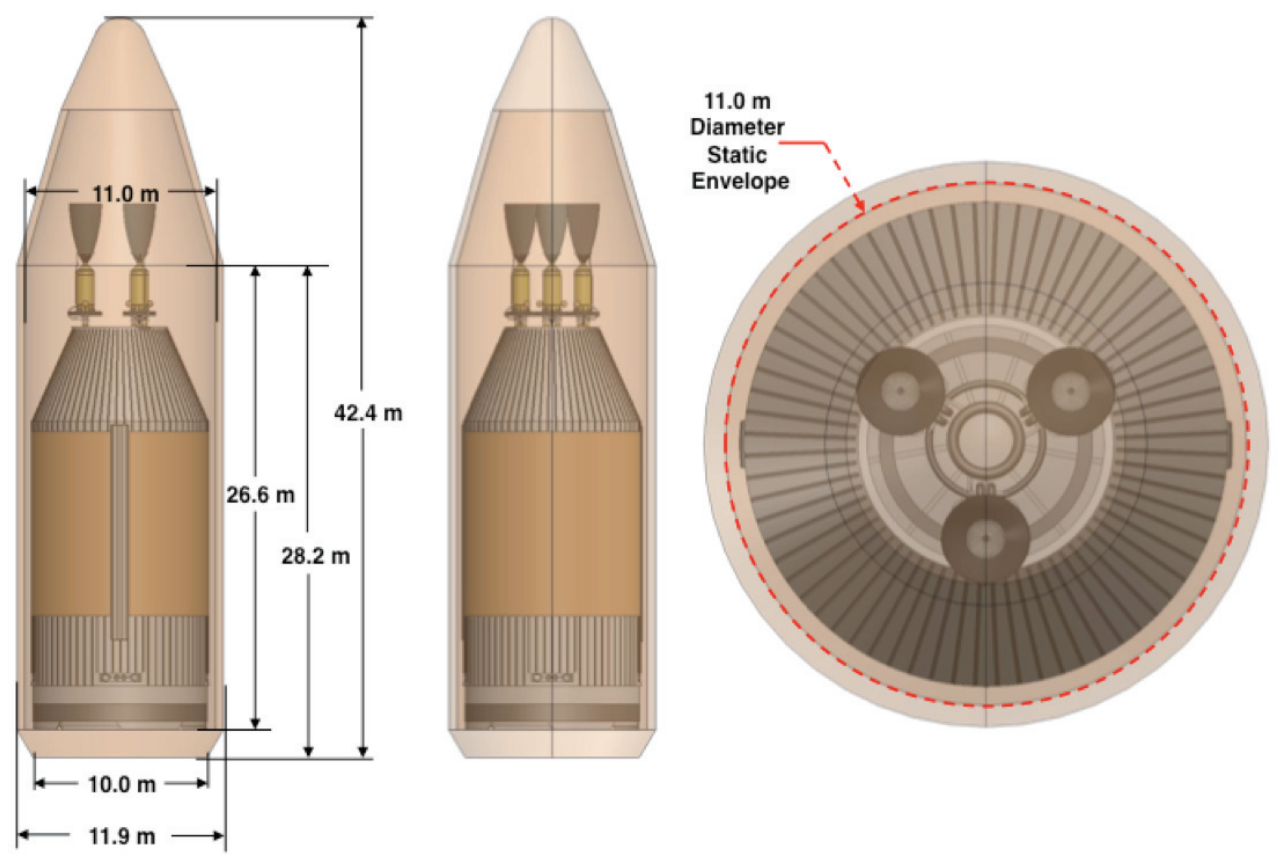

Figure 20. Core section stowed within the modified Ares V payload fairing.

\section{H. Baseline CONOPS}

The baseline CONOPS of the HERRO mission roughly follows that laid out in the DRA 5.0 mission. Recall that the DRA mission is a landing mission while the HERRO concept is an orbiter only.

For the HERRO concept, the landed objects are launched first, 2 years prior to the crew departing Earth. These three launches use an Atlas V, or Delta IV H, to send the Truck with two Rockhounds directly to the Martian surface. An Ares V is then used to launch the vehicle elements to LEO for on orbit assembly.

- A total of eight launches are needed to complete the mission

- $\quad$ Each truck requires a launch, so three Trucks = three launches of Atlas V

- CTCV takes five launches total: Four to assemble the CTCV, one launch of Ares I to bring the crew via Orion to the assembled CTCV in orbit

- Cargo launches will occur at least 2 yr prior to crew launches

- Approximately 500 day Mars stay

- Explore three regions simultaneously (based on Sun synchronous frozen orbit)

- Crew can communicate with each truck $8 \mathrm{hr} / \mathrm{d}$

- $\quad$ Three science regions (explore each region for months)

- Science region: $100 \mathrm{~km}$ diameter: $20 \mathrm{~km}$ traverse to a new location (at $1 \mathrm{~m} / \mathrm{s}$ ): $3.6 \mathrm{~km} / \mathrm{hr}$, can get to next location in one shift: 3 months stay

- Science location: $1 \mathrm{~km}$ diameter: 2-wk stay time

- Science sites: $10 \mathrm{~m}$ diameter, 1 day

Figure 22 offers an illustration of the above science area notation. The science region is the largest physical location; each region is subdivided into locations of interest. The Truck drives between locations within the region. The locations are subdivided into Sites of interest. These sites are then scouted out and examined by the Rockhounds.

The Mars Science Laboratory (MSL) S/C landing site candidates were used as the potential science regions for the Trucks carrying the rovers from the areas under consideration. The final four candidates for the MSL landing site were decided in November of 2009 and include Mawrth, and Eberswalde as shown in Figure 23. http:/www.nasa.gov/images/content/291983main final4-516.jpg. 


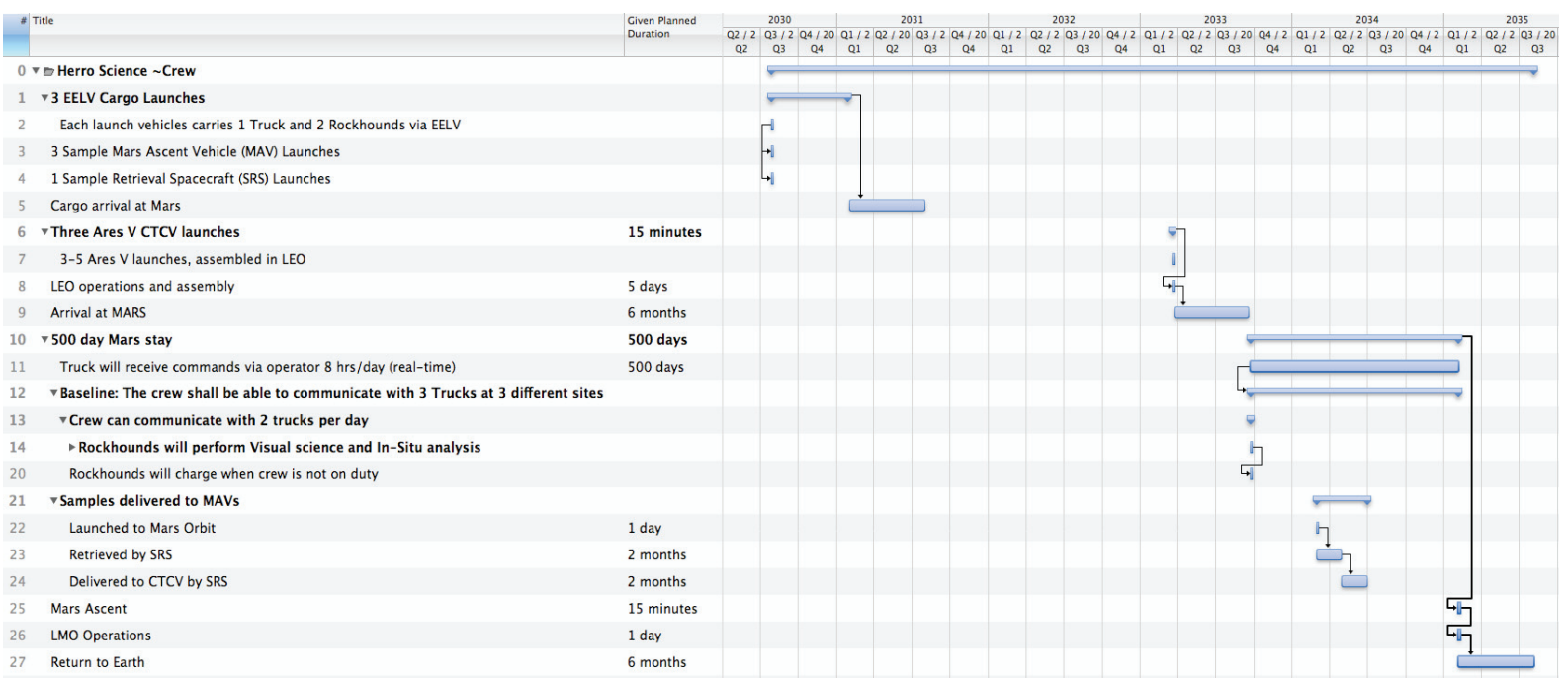

Figure 21. CTCV human mission CONOPS Timeline.

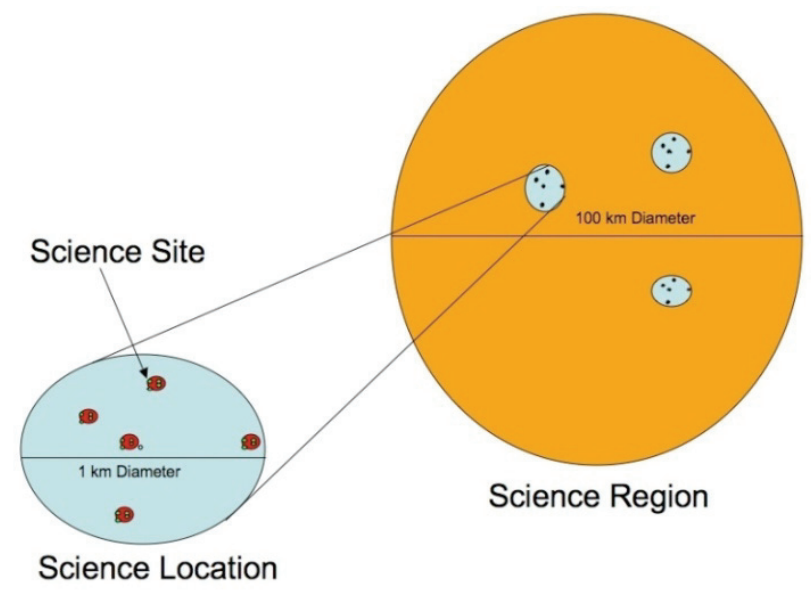

Figure 22. Science area definitions.

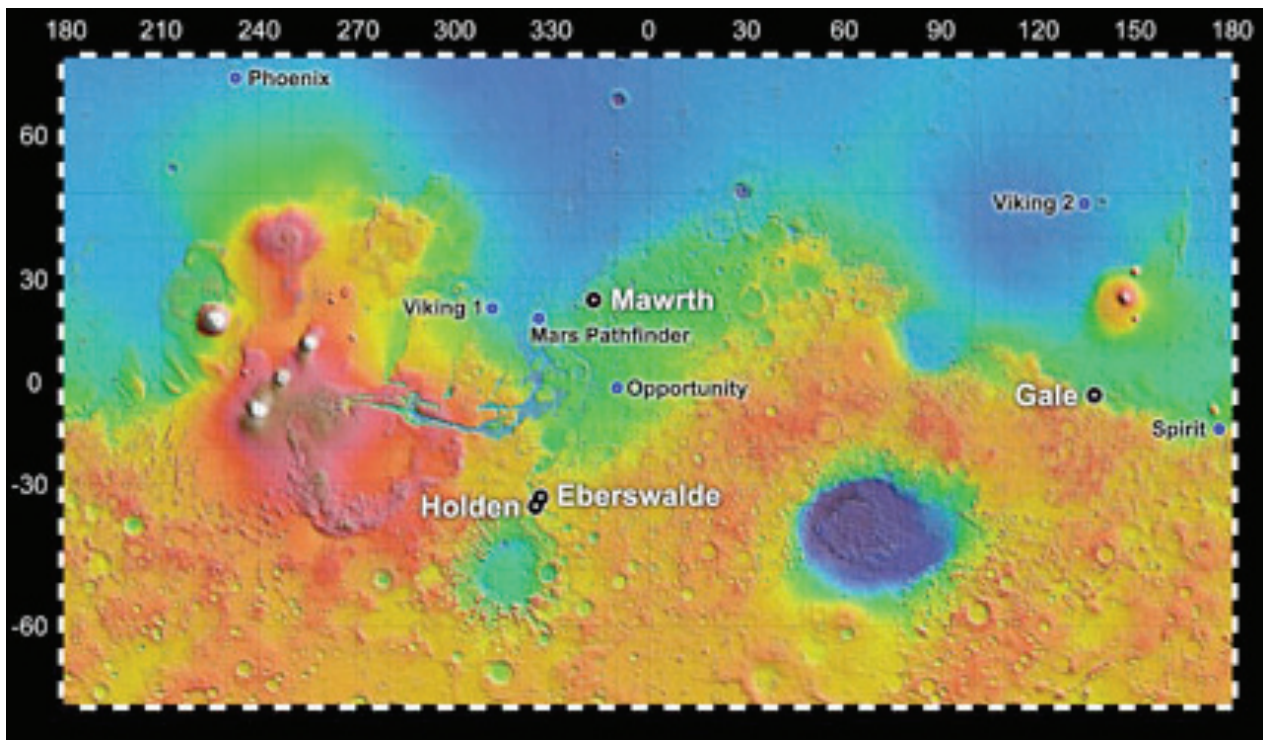

Figure 23. Potential science regions from MSL candidates. 


\section{Science Definition}

Design reference science, telerobotic systems, and concept of operations for general options.

1. Teleoperation Orbit

The CTCV performs science in a $12 \mathrm{hr}$ Molniya type orbit, at an inclination of $116^{\circ}$ to keep apoapsis in daylight for the $500 \mathrm{~d}$ stay, point of periapse at equator. The CTCV crew will work shifts for 5 to $8 \mathrm{hr}$. There will be two shifts per day - two teleoperations crews (of two operators each). The forward section (rover antennas) points antiSun. The Earth antenna(s) point off of Sun direction to Earth (within $\sim 30^{\circ}$ to $40^{\circ}$ ). The Rover operations always occur during daylight (evening, noon, morning during $500 \mathrm{~d}$ due to right ascension drift). In this configuration, solar power is easier to implement-flat panels, little cosine loss during work shift. There will be three sites of interest: one on each side of Mars and one near south Polar Regions. The CTCV astronauts will run two sites a day, South Pole site during southern summer.

2. Ground Site Contact Analysis and On-Orbit Operations

Throughout the 500-day mission there are three sites that are of interest for science. The sites that the Rockhounds will perform science include Mawrth Vallis, the South Pole, and the Gale Crater. Analysis was done using the Satellite Orbit Analysis Program (SOAP) to determine the most convenient times to perform science. It is necessary for the CTCV to have an available line of sight with the Truck/Rockhounds. In addition, the elevation angle from each site to the CTCV should be greater than $10^{\circ}$ to account for unlevel terrain. The following two charts provide examples of the different types of analysis that were completed to estimate the durations that science can be achieved.

Figure 24 shows the ground site elevation angle to the CTCV from the surface. The $10^{\circ}$ margin for unstable terrain is also taken into account. Figure 25 shows the total angle to the Sun and each of the surface science locations as seen from the CTCV in order to show which locations are in sunlight. The Truck and Rockhounds require sunlight for power during operations.

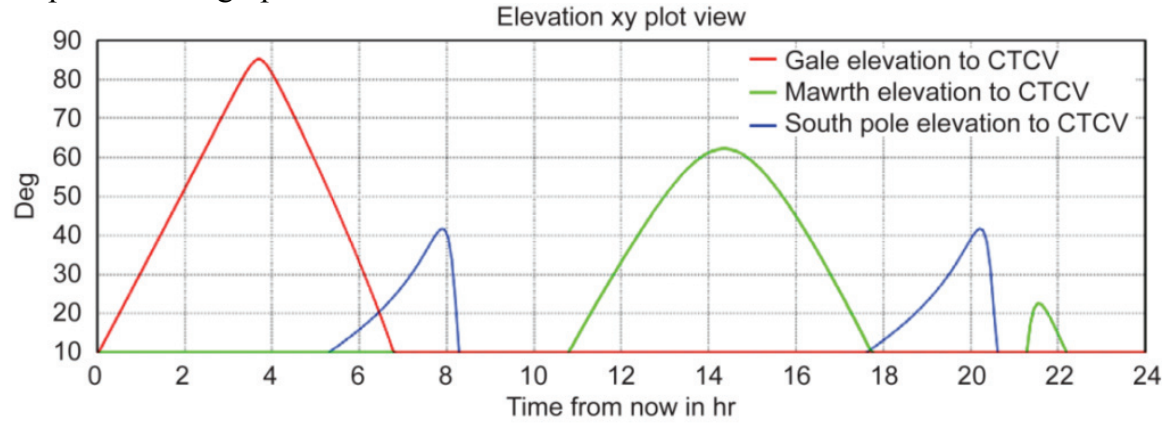

Figure 24. Ground site elevation view from the surface site to CTCV.

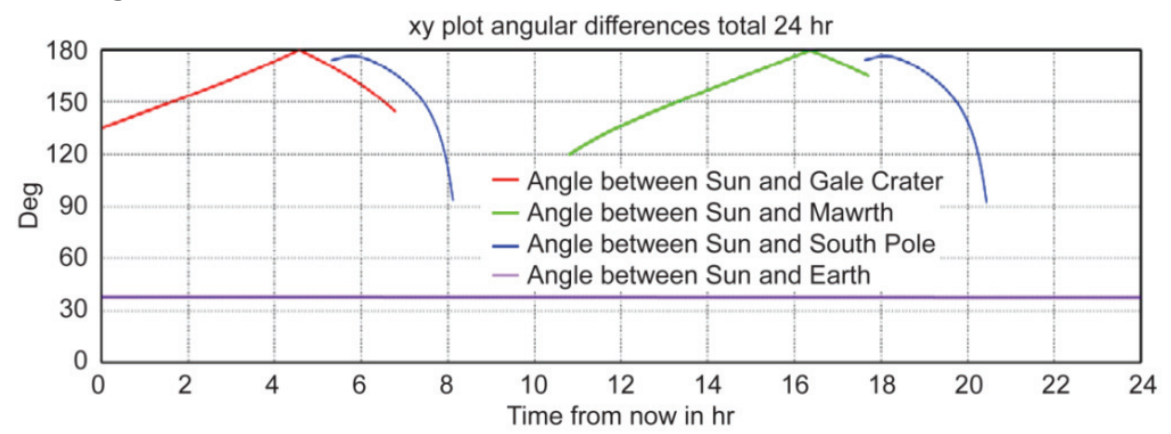

Figure 25. Ground site total angular difference between Sun vector and ground site over $24 \mathrm{hr}$.

Figure 26 gives an example of science that can be done over the period of a week based on the communications view of the surface from the orbiting CTCV over the span of a week. Mawrth Vallis and the Gale Crater would be candidates for science during this sample week. Figure 27 shows the CTCV in orbit about Mars and illustrates the communications line of site links to the Sun, Mars surface, and to the Earth. This analysis was used for power system sizing and communications analysis. Figure 28 is close up view of Figure 27 of the CTCV in orbit about Mars and illustrates the viewing angles to the Mars surface. 
xy plot view total $24 \mathrm{hr}$

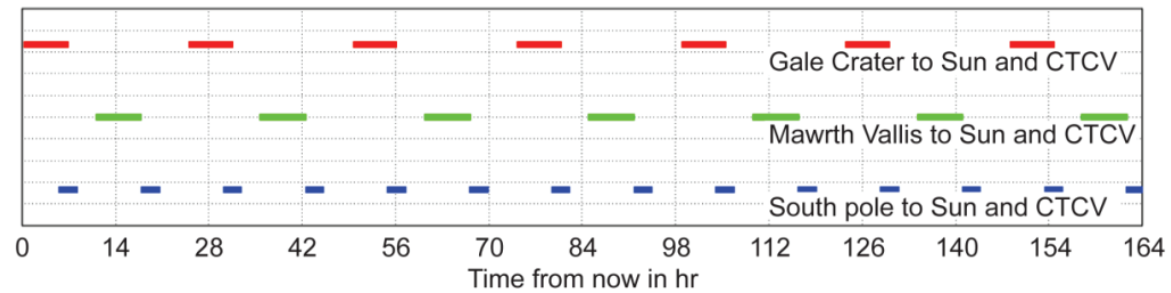

Figure 26. Science site view over 1 wk.

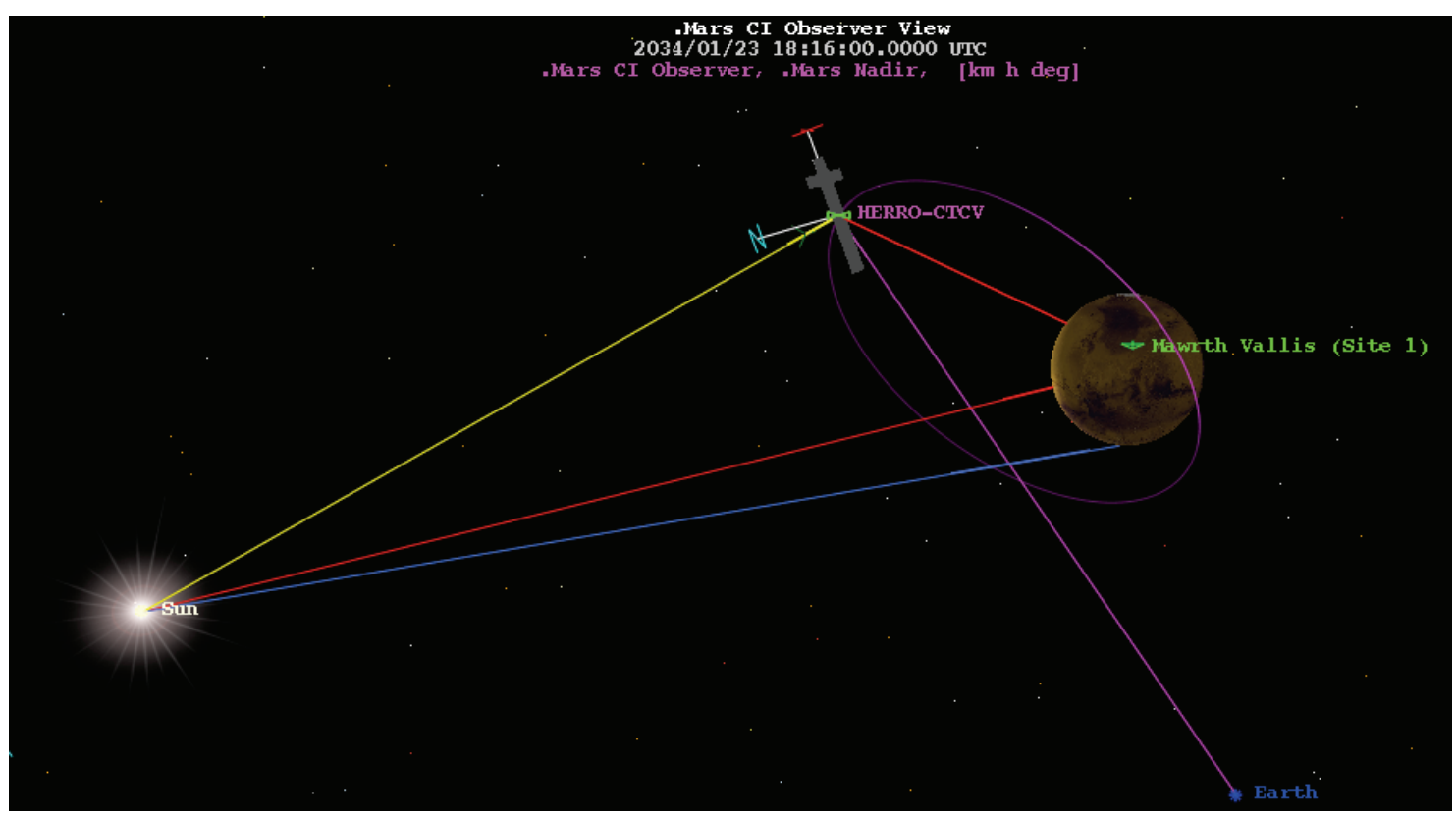

Figure 27. CTCV in orbit, views to Sun, Mars surface, and Earth.

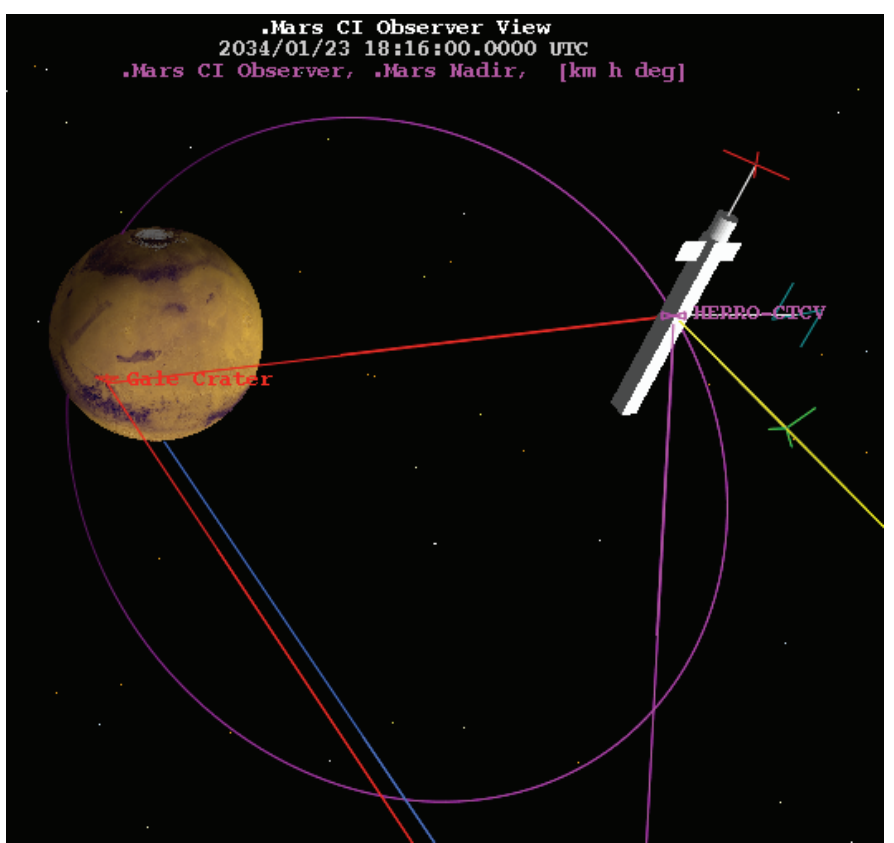

Figure 28. CTCV in orbit, close up views to Sun, Mars surface, and Earth. 
During the initial 166 days of the mission, the CTCV can access the South Pole on the average of $4.5 \mathrm{hr}$ for two contacts per day. Using two views of $4.5 \mathrm{hr}$ each for a total of $9 \mathrm{hr}$. The CTCV can access Mawrth Vallis for about $6.5 \mathrm{hr}$ once per day. The Gale Crater can access the CTCV $5 \mathrm{hr}$ once per day.

Throughout the middle $166 \mathrm{~d}$ of the mission, the CTCV can access the South Pole a maximum of $5.3 \mathrm{hr}$ for two contacts per day for a total of $10.6 \mathrm{hr}$. The CTCV can access Mawrth Vallis for about $4 \mathrm{hr}$ once twice per day. The Gale Crater can access the CTCV $3.5 \mathrm{hr}$ twice per day.

During the final $166 \mathrm{~d}$ of the mission, the CTCV cannot access the South Pole to perform science due to lack of sunlight during the communication periods. Conversely, The CTCV can access Mawrth Vallis for about $3 \mathrm{hr}$ nearly twice per day for a total of $6 \mathrm{hr}$. The Gale Crater can access the CTCV $3 \mathrm{hr}$ once per day.

\section{Baseline Design}

\section{A. Top Level Design (MEL and PEL)}

The following section describes the engineering theory behind the design of the CTCV S/C line element Work Breakdown Structure (WBS) Master Equipment List (MEL). It also goes through the power equipment listing (PEL) and the definition of power modes of operation used to size the power requirements from the subsystems to the power system.

\section{Master Equipment List (MEL). CTCV}

Table 4 lists the top level of the MEL of the design with all the subsystem line elements hidden such that only the top-level masses are shown. The total growth on the dry mass of the $\mathrm{S} / \mathrm{C}$ is then rolled up to find a total growth mass and growth percentage. Engineers enter in the CBE mass for each of their line elements, as well as quantity. The MEL takes all of the items and racks them up into totals and calculates a total CBE mass, a Total mass and a total Growth Mass.

Table 4. MEL-CTCV

\begin{tabular}{|c|c|c|c|c|c|c|c|}
\hline WBS & Description & QTY & $\begin{array}{r}\text { Unit } \\
\text { Mass }\end{array}$ & Basic Mass & Growth & Growth & $\begin{array}{l}\text { Total } \\
\text { Mass }\end{array}$ \\
\hline Number & Crew Telerobotic Control Vehicle (CTCV) & & (kg) & (kg) & $(\%)$ & (kg) & (kg) \\
\hline 06 & Crew Telerobotic Control Vehicle & & & 435329 & & 20034 & 455362 \\
\hline 06.1 & Core Element & & & 126473 & & 5521 & 131994 \\
\hline 06.1 .1 & Attitude Determination and Control & & & 8 & $15.0 \%$ & 1 & 9 \\
\hline 06.1 .2 & Command and Data Handling & & & 333 & $19.3 \%$ & 64 & 398 \\
\hline 06.1 .3 & Communications and Tracking & & & 20 & $10.0 \%$ & 2 & 22 \\
\hline 06.1 .4 & Electrical Power Subsystem & & & 221 & $34.9 \%$ & 77 & 298 \\
\hline 06.1 .5 & Environmental Control (Non-Propellant) & & & 1735 & $15.0 \%$ & 260 & 1995 \\
\hline 06.1 .6 & Propulsion Hardware & & & 20263 & $4.2 \%$ & 843 & 21106 \\
\hline 06.1 .7 & Propellant & & & 81839 & $0.0 \%$ & $\mathbf{0}$ & 81839 \\
\hline 06.1 .8 & Structures and Mechanisms & & & 22053 & $19.4 \%$ & 4273 & 26326 \\
\hline 06.2 & In Line Tank & & & 131885 & & 4156 & 136041 \\
\hline 06.2 .1 & Attitude Determination and Control & & & 0 & 0 & 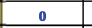 & 0 \\
\hline 06.2 .2 & Command and Data Handling & & & 91 & $17.2 \%$ & 16 & 107 \\
\hline $06.2,3$ & Communications and Tracking & & & 0 & 0 & 0 & 0 \\
\hline 06.2 .4 & Electrical Power Subsystem & & & 102 & $43.7 \%$ & 45 & 147 \\
\hline $06.2,5$ & Environmental Control (Non-Propellant) & & & 1735 & $15.0 \%$ & 260 & 1995 \\
\hline 06.2 .6 & Propulsion Hardware & & & 3192 & $20.0 \%$ & 638 & 3831 \\
\hline 06.2 .7 & Propellant & & & 105451 & $0.0 \%$ & 0 & 105451 \\
\hline 06.2 .8 & Structures and Mechanisms & & & 21313 & $15.0 \%$ & 3197 & 24510 \\
\hline 06.3 & Saddle Truss and dropped Tank & & & 129547 & & 6225 & 135772 \\
\hline 06.3 .1 & Attitude Determination and Control & & & 0 & 0 & 0 & 0 \\
\hline 06.3 .2 & Command and Data Handling & & & 91 & $17.2 \%$ & 16 & 107 \\
\hline 06.3 .3 & Communications and Tracking & & & 0 & 0 & 0 & $\mathbf{0}$ \\
\hline 06.3 .4 & Electrical Power Subsystem & & & 103 & $45.3 \%$ & 47 & 150 \\
\hline 06.3 .5 & Environmental Control (Non-Propellant) & & & 2322 & $15.0 \%$ & 348 & 2670 \\
\hline 06.3 .6 & Propulsion Hardware & & & 3053 & $20.0 \%$ & 611 & 3663 \\
\hline 06.3 .7 & Propellant & & & 98554 & $0.0 \%$ & $\mathbf{0}$ & 98554 \\
\hline 06.3 .8 & Structures and Mechanisms & & & 25425 & $20.5 \%$ & 5204 & 30629 \\
\hline 06.4 & TransHAB and Payload & & & 47425 & & 4132 & 51555 \\
\hline 06.4 .1 & Attitude Determination and Control & & & 1088 & $15.0 \%$ & 163 & 1251 \\
\hline 06.4 .2 & Command and Data Handling & & & 1112 & $17.5 \%$ & 194 & 1307 \\
\hline 06.4 .3 & Communications and Tracking & & & 1039 & $26.1 \%$ & 271 & 1310 \\
\hline 06.4 .4 & Electrical Power Subsystem & & & 1413 & $32.0 \%$ & 452 & 1865 \\
\hline 06.4 .5 & Environmental Control (Non-Propellant) & & & 15500 & $1.2 \%$ & 186 & 15685 \\
\hline 06.4 .6 & Propulsion Hardware & & & 194 & $15.0 \%$ & 29 & 223 \\
\hline 06.4 .7 & Propellant & & & 3788 & $0.1 \%$ & 3 & 3791 \\
\hline 06.4 .8 & Structures and Mechanisms & & & 8092 & $20.7 \%$ & 1678 & 9770 \\
\hline 06.4 .9 & ECLSS & & & 15200 & $7.6 \%$ & 1154 & 16353 \\
\hline
\end{tabular}

The MEL was designed in order to group elements per stage. Each stage is that which is launched by a single Ares V launch vehicle. The stages are then docked and assembled in LEO. Once the TransHab is docked, inflated and powered up, the crew is launched on a LEO launch vehicle inside the Orion capsule. Figure 29 shows the four 
elements as they are assembled in LEO, and the table below each element in the figure outlines what subsystems are in each of those major elements.

The Propulsion engineer models the propulsion hardware and propellant. ECLSS was grouped with the Environmental Control subsystem and given to the thermal engineer for design.

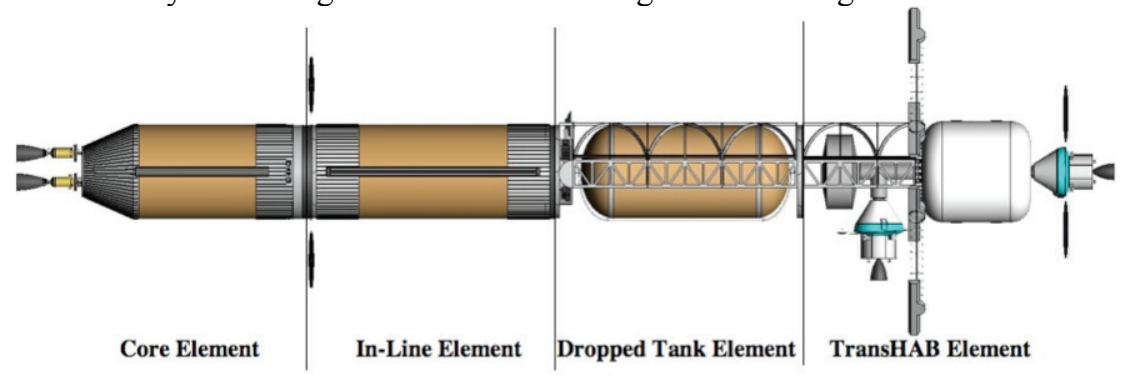

\begin{tabular}{l} 
Core Element \\
\hline Avionics - processor, etc. \\
GN\&C - star trackers, sun \\
sensors, IMU \\
Comm. - antenna(s) \\
Power - Orion arrays, batteries \\
Propulsion - NTR (engines, \\
reactor, radiation shield), tanks, \\
ZBO, RCS, MLI for tanks \\
Environment Control - MLI for \\
avionics, MMOD protection, \\
sensors \\
Structures \& Mechanisms - \\
dock adaptor, truss, Forward \\
skirt, aft thrust structure, etc.
\end{tabular}

\begin{tabular}{l} 
In-Line Element \\
\hline Avionics - processor, etc. \\
GN\&C - star trackers, sun \\
sensors, IMU \\
Comm. - antenna(s) \\
Power - Orion arrays, \\
batteries \\
Propulsion - tanks, ZBO, \\
RCS, MLI for tanks \\
Environment Control - MLI \\
for avionics, MMOD \\
protection, sensors \\
Structures \& Mechanisms - \\
dock adaptor, truss,
\end{tabular}

Dropped Tank Element

Avionics - processor, etc.

GN\&C - star trackers, sun sensors, IMU

Comm. - antenna(s)

Power - Orion arrays,

batteries, fuels cells

Propulsion -tanks, ZBO,

RCS, MLI for tanks

Environment Control - MLI

for avionics, MMOD

protection, sensors

Structures \& Mechanisms -

dock adaptor, truss, saddle

truss
TransHAB Element

Avionics - crew needs, processors,

etc.

GN\&C - CMG, star trackers, sun

sensors, IMU, etc.

Comm. - antenna(s)

Power - Orion arrays, deployed ISS

arrays, batteries

Propulsion - RCS, MLI for tanks

Environment Control - MLI for

avionics, MMOD protection,

Radiation protection, radiator,

ECLSS, food canister, crew

Structures \& Mechanisms - dock

adaptor, truss, TransHAB structure, tunnel

Figure 29. CTCV MEL layout details by subsystem.

\section{Power Equipment List (PEL) - CTCV}

Bottoms up requirements for the subsystem-by-subsystem power requirements were gathered in order to size the power system. To derive the maximum power loads, a set of operating modes for the Rockhound was identified. These modes and their definitions would tell the subsystem designers which of their equipment line items needed to be powered on and which were off based on the mission operations. The definitions and operating elements are detailed in Table 5.

Table 5. System Operations by Mission Mode

\begin{tabular}{|c|c|c|c|c|c|}
\hline \multicolumn{6}{|c|}{ Systems in operation (CTCV) by mode } \\
\hline Mode Number & 1 & 2 & 3 & 4 & 5 \\
\hline Mode Name & $\begin{array}{c}\text { LEO } \\
\text { assembly }\end{array}$ & $\begin{array}{c}\text { NTR operations (during } \\
\text { burns) }\end{array}$ & $\begin{array}{c}\text { Coast } \\
\text { (to/from Mars) }\end{array}$ & $\begin{array}{l}\text { In-orbit } \\
\text { shadow }\end{array}$ & $\begin{array}{c}\text { In-orbit } \\
\text { science ops }\end{array}$ \\
\hline $\mathrm{AD} \& \mathrm{C}$ & $\begin{array}{l}\text { The control moment } \\
\text { gyros (CMGs) control } \\
\text { the CTCV attitude in } \\
\text { orbit }\end{array}$ & $\begin{array}{l}\text { Auxiliary Thrusters for } \\
\text { Control }\end{array}$ & $\begin{array}{l}\text { Auxiliary Thrusters for } \\
\text { Control }\end{array}$ & $\begin{array}{l}\text { The CMGs control the } \\
\text { CTCV attitude in orbit }\end{array}$ & $\begin{array}{l}\text { The CMGs control the } \\
\text { CTCV attitude in orbit } \\
\text { Aux thruster control }\end{array}$ \\
\hline \multicolumn{6}{|l|}{ C\&DH } \\
\hline Communications & $\begin{array}{l}\text { S-band communication } \\
\text { to the Earth }\end{array}$ & None & $\begin{array}{l}\text { Health monitoring } \\
\text { comm. with Earth }\end{array}$ & None & $\begin{array}{l}\text { Comm to Mars surface, } \\
\text { and data transfer back } \\
\text { to Earth }\end{array}$ \\
\hline $\begin{array}{l}\text { Power } \\
\text { Environmental } \\
\text { Control }\end{array}$ & Solar arrays for power & Solar arrays for power & Solar arrays for power & Battery power & Solar arrays for power \\
\hline Propulsion & Aux thruster control & $\begin{array}{l}\text { Main NTR thruster } \\
\text { operations, Aux } \\
\text { thruster control }\end{array}$ & Aux thruster control & Aux thruster control & Aux thruster control \\
\hline Structures & Docking & None & Jettison of equipment & None & None \\
\hline ECLSS & TransHab systems & TransHab systems & TransHab systems & TransHab systems & TransHab systems \\
\hline Science & None & None & None & None & $\begin{array}{l}\text { Orbit to surface control } \\
\text { and science }\end{array}$ \\
\hline
\end{tabular}


The following definitions of power mode operations in Table 6 were used to determine the total power requirements on subsystem-by-subsystem bottoms up bases. These modes helped to determine the worst-case loads on the power system and used to size the power subsystem batteries.

Table 6. Power Mode Definitions

\begin{tabular}{|c|c|c|}
\hline $\begin{array}{c}\text { Mode } \\
\text { number }\end{array}$ & Name & Definition \\
\hline CMGs & LEO assembly & $\begin{array}{l}\text { Assembly in LEO (altitude of } 500 \mathrm{~km} \text { circular orbit). Might be going to } 407 \mathrm{~km} \text { circular. Pieces launched } \\
\text { by Ares V to LEO. Dock and assemble in LEO. TransHab stage launched and assembled first. Astronauts } \\
\text { launched on LEO launcher on CEV and dock with the assembled vehicle Aux thrusters, CMGs to provide } \\
\text { additional attitude control. }\end{array}$ \\
\hline CMGs & $\begin{array}{l}\text { NTR operations } \\
\text { (during burns) }\end{array}$ & $\begin{array}{l}\text { Any of the major burns where the NTR engines are in action. TMI. MOI. Mid course correction. TEI. Aux } \\
\text { thrusters, CMGs to provide additional attitude control. }\end{array}$ \\
\hline CMGs & $\begin{array}{l}\text { Coast } \\
\text { (to/from Mars) }\end{array}$ & $\begin{array}{l}\text { In-Space portion of the mission in between burns when the NTR engines are not thrusting. Could be on the } \\
\text { way to Mars, or on the way home to Earth. Aux thrusters, CMGs to provide additional attitude control. }\end{array}$ \\
\hline CMGs & $\begin{array}{l}\text { In-orbit } \\
\text { shadow }\end{array}$ & $\begin{array}{l}\text { In orbit about Mars. Behind Mars and in the shadow. No communications to Earth. No science operations. } \\
\text { Battery power to sustain the CTCV while in shadow. Max of } 30 \text { min. per average orbit. Aux thrusters, } \\
\text { CMGs to provide additional attitude control. }\end{array}$ \\
\hline CMGs & $\begin{array}{l}\text { In-orbit Science } \\
\text { ops }\end{array}$ & $\begin{array}{l}\text { In orbit about Mars. Communicating with the surface elements on Mars: Rockhounds, Truck. } \\
\text { Communications to Earth. Solar arrays pointing to the Sun to provide power. No NTR thruster operating. } \\
\text { Aux RCS thruster control. Aux thrusters, CMGs to provide additional attitude control. }\end{array}$ \\
\hline
\end{tabular}

The power requirements for the subsystems are gathered on an element-by-element basis. Each element has requirements based on the mission phase (assembly, NTR operations, coast, science in orbit). Each element has its own items such as avionics, RCS thrusters, Communications arrays, environmental control, etc. Once the entire vehicle is assembled, the current architecture is that the Orion crew vehicle is launched on an Ares I and docks with the orbiting CTCV.

Table 7. Bottoms-Up PEL

\begin{tabular}{|c|c|c|c|c|c|}
\hline \multirow[b]{2}{*}{ Modes of operation } & \multirow{2}{*}{\begin{tabular}{|l} 
Power Mode 1 \\
LEO assembly
\end{tabular}} & \multirow{2}{*}{\begin{tabular}{|c|}
$\begin{array}{c}\text { Power Mode } \\
2\end{array}$ \\
NTR \\
operations \\
(during \\
burns)
\end{tabular}} & \multirow{2}{*}{\begin{tabular}{|c|}
$\begin{array}{c}\text { Power Mode } \\
3\end{array}$ \\
$\begin{array}{c}\text { Coast } \\
\text { (to/from } \\
\text { Mars) }\end{array}$ \\
\end{tabular}} & \multirow{2}{*}{$\begin{array}{c}\text { Power Mode } 4 \\
\begin{array}{l}\text { In-orbit } \\
\text { shadow }\end{array}\end{array}$} & \multirow{2}{*}{\begin{tabular}{|c|}
$\begin{array}{c}\text { Power Mode } \\
5\end{array}$ \\
$\begin{array}{c}\text { In-orbit } \\
\text { Science ops }\end{array}$ \\
\end{tabular}} \\
\hline & & & & & \\
\hline Crew Telerobotic Control Vehicle (CTCV) & $22964 \mathrm{~W}$ & $23246 \mathrm{~W}$ & $23888 \mathrm{~W}$ & $25099 \mathrm{~W}$ & $25373 \mathrm{~W}$ \\
\hline Core Stage & $1198 \mathrm{~W}$ & $498 \mathrm{~W}$ & $1316 \mathrm{~W}$ & $1334 \mathrm{~W}$ & $1432 \mathrm{~W}$ \\
\hline Attitude Determination and Control & $40 \mathrm{~W}$ & $40 \mathrm{~W}$ & $40 \mathrm{~W}$ & ow & $40 \mathrm{~W}$ \\
\hline Command and Data Handling & $324 \mathrm{w}$ & $369 \mathrm{~W}$ & $324 \mathrm{w}$ & $324 \mathrm{w}$ & $324 \mathrm{~W}$ \\
\hline Communications and Tracking & $0 \mathrm{w}$ & $60 \mathrm{~W}$ & $118 \mathrm{~W}$ & $176 \mathrm{~W}$ & $234 \mathrm{~W}$ \\
\hline Electrical Power Subsystem & $0 \mathrm{w}$ & ow & ow & $\mathrm{ow}$ & ow \\
\hline Environmental Control (Non-Propellant) & $29 \mathrm{~W}$ & $29 \mathrm{~W}$ & $29 \mathrm{~W}$ & $29 \mathrm{~W}$ & $29 \mathrm{~W}$ \\
\hline Propulsion Hardware & $804 \mathrm{~W}$ & $\mathrm{ow}$ & $804 \mathrm{~W}$ & $804 \mathrm{~W}$ & $804 \mathrm{~W}$ \\
\hline Propellant & $\mathrm{ow}$ & ow & ow & $\mathrm{ow}$ & $\mathrm{ow}$ \\
\hline Structures and Mechanisms & ow & $\mathrm{ow}$ & ow & $0 \mathrm{~W}$ & $0 \mathrm{~W}$ \\
\hline In Line Tank & $765 \mathrm{~W}$ & $114 \mathrm{~W}$ & $883 \mathrm{~W}$ & $941 \mathrm{~W}$ & $999 \mathrm{~W}$ \\
\hline Attitude Determination and Control & $0 \mathrm{w}$ & ow & $0 \mathrm{w}$ & $0 \mathrm{~W}$ & $0 \mathrm{w}$ \\
\hline Command and Data Handling & $23 \mathrm{~W}$ & $25 \mathrm{~W}$ & $23 \mathrm{w}$ & $23 \mathrm{~W}$ & $23 \mathrm{w}$ \\
\hline Communications and Tracking & $\mathrm{ow}$ & $60 \mathrm{~W}$ & $118 \mathrm{~W}$ & $176 \mathrm{~W}$ & $234 \mathrm{~W}$ \\
\hline Electrical Power Subsystem & $\mathrm{ow}$ & $\mathrm{ow}$ & ow & ow & $0 \mathrm{~W}$ \\
\hline Environmental Control (Non-Propellant) & $29 \mathrm{~W}$ & $29 \mathrm{~W}$ & $29 \mathrm{~W}$ & $29 \mathrm{~W}$ & $29 \mathrm{~W}$ \\
\hline Propulsion Hardware & $713 \mathrm{~W}$ & ow & $713 \mathrm{~W}$ & $713 \mathrm{w}$ & $713 \mathrm{w}$ \\
\hline Propellant & ow & ow & ow & ow & $0 \mathrm{~W}$ \\
\hline Structures and Mechanisms & ow & ow & ow & ow & $0 \mathrm{w}$ \\
\hline Saddle Truss and dropped Tank & $732 \mathrm{~W}$ & $64 \mathrm{~W}$ & $180 \mathrm{~W}$ & $240 \mathrm{~W}$ & $298 \mathrm{~W}$ \\
\hline Attitude Determination and Control & ow & ow & ow & ow & ow \\
\hline Command and Data Handling & $23 \mathrm{~W}$ & $25 \mathrm{~W}$ & $25 \mathrm{~W}$ & $25 \mathrm{~W}$ & $25 \mathrm{~W}$ \\
\hline Communications and Tracking & $0 \mathrm{~W}$ & ow & $116 \mathrm{~W}$ & $176 \mathrm{~W}$ & $234 \mathrm{~W}$ \\
\hline Electrical Power Subsystem & $0 \mathrm{~W}$ & ow & ow & ow & $\mathrm{ow}$ \\
\hline Environmental Control (Non-Propellant) & $39 \mathrm{w}$ & $39 \mathrm{w}$ & $39 \mathrm{w}$ & $39 \mathrm{w}$ & $39 \mathrm{~W}$ \\
\hline Propulsion Hardware & $670 \mathrm{~W}$ & $0 \mathrm{~W}$ & $\mathrm{ow}$ & $0 \mathrm{w}$ & $0 \mathrm{w}$ \\
\hline Propellant & $0 \mathrm{~W}$ & $\mathrm{ow}$ & $\mathrm{ow}$ & $0 \mathrm{w}$ & $0 \mathrm{w}$ \\
\hline Structures and Mechanisms & ow & ow & ow & ow & $0 \mathrm{w}$ \\
\hline TransHAB and Payload & $20270 \mathrm{~W}$ & $22569 \mathrm{~W}$ & $21509 \mathrm{~W}$ & $22584 \mathrm{~W}$ & 22644 W \\
\hline Attitude Determination and Control & $269 \mathrm{w}$ & $269 \mathrm{w}$ & $269 \mathrm{~W}$ & $269 \mathrm{w}$ & $269 \mathrm{~W}$ \\
\hline Comm and and Data Handling & $922 \mathrm{~W}$ & $922 \mathrm{~W}$ & $787 \mathrm{~W}$ & $787 \mathrm{~W}$ & $787 \mathrm{~W}$ \\
\hline Communications and Tracking & $79 \mathrm{w}$ & $2378 \mathrm{~W}$ & $1453 \mathrm{~W}$ & $2528 \mathrm{~W}$ & $2588 \mathrm{~W}$ \\
\hline Electrical Power Subsystem & $\mathrm{ow}$ & ow & ow & ow & ow \\
\hline Environmental Control (Non-Propellant) & $\mathrm{ow}$ & ow & $\mathrm{ow}$ & ow & $\mathrm{ow}$ \\
\hline Propulsion Hardware & $0 \mathrm{~W}$ & $0 \mathrm{~W}$ & $\mathrm{ow}$ & ow & $0 \mathrm{w}$ \\
\hline Propellant & $\mathrm{ow}$ & ow & ow & $0 \mathrm{w}$ & $0 \mathrm{~W}$ \\
\hline Structures and Mechanisms & $0 \mathrm{~W}$ & ow & ow & ow & $0 \mathrm{~W}$ \\
\hline ECLSS & $19000 \mathrm{~W}$ & $19000 \mathrm{~W}$ & $19000 \mathrm{~W}$ & $19000 \mathrm{~W}$ & $19000 \mathrm{~W}$ \\
\hline
\end{tabular}

The power system is sized using the five power modes and sizing for the worst-case mode. As seen in Table 7, the worst-case power load was $25 \mathrm{kWe}$ for Power Mode 5. Adding on an additional 30\% margin to the Basic of 
CBE power brought the total power load required to $33 \mathrm{kWe}$. In order to size the cabling accordingly, the power was broken out as worst case per element. Each of the element power loads also carried an additional $30 \%$ of the bottoms up estimated power to calculation the total power load margin. Table 8 shows the calculations for worst-case power loads that were used to size the solar arrays and batteries located on the CTCV.

Thermal system waste heat is derived from the power requirements tabulated in the bottoms up PEL in Table 7. The thermal waste heat calculations based on power mode using the bottoms up PEL in Table 7. The maximum thermal waste heat generated is $\sim 30,000$ Wth with margin.

Table 8. Power System Sizing Requirements

\begin{tabular}{|c|}
\hline 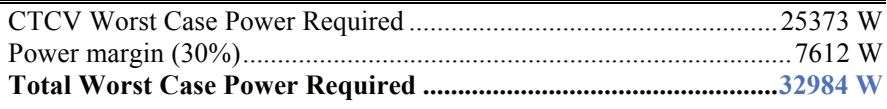 \\
\hline Core Element \\
\hline 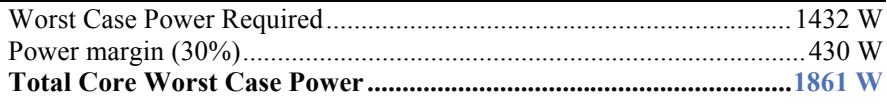 \\
\hline In-Line Tank Element \\
\hline 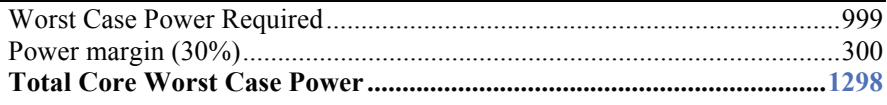 \\
\hline Saddle Tank Element \\
\hline 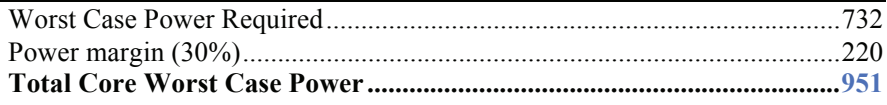 \\
\hline TransHab Element \\
\hline 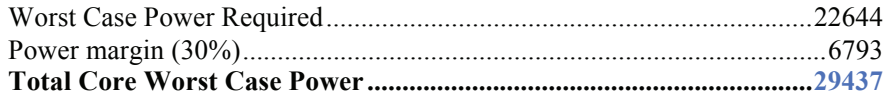 \\
\hline
\end{tabular}

\section{B. System Level Summary}

Where the MEL (Table 4) captures the bottoms-up estimation of CBE and growth percentage line item by item from the subsystem designer. Table 7 wraps up those total wet masses of each of the four elements as well as the total mass in low Earth orbit (IMLEO) of the assembled vehicle. Table 9 through Table 12 all list the subsystem $\mathrm{CBE}$ and total mass after applied growth percentage for each of the launched elements. In order to meet the total of $30 \%$ at the system level, an allocation is necessary for system level growth. This additional system level mass is assumed as part of the inert mass that is flown along the required trajectory. Therefore, the additional system level growth mass impacts the total propellant loading for the mission design. Additional mass is carried at the system level in order to carry $30 \%$ growth on dry masses. This does not include crew, crew consumables, and propellant.

The Ares V performance to LEO is assumed to be $140,000 \mathrm{~kg}$. Each launch fits inside of this performance, leaving a margin of $89,000 \mathrm{~kg}$ for the four launches combined. While the launched elements are labeled 1 through 4 , with Core being the first, this is just the nomenclature of the design and does not necessarily represent the order of launch. The order of launch can be changed as needed in the architecture. The Orion is delivered as a separate launch and not launched with the TransHab in the original designs. Because there is margin left on the TransHab launch, the 10,000 kg Orion could fit both in volume and mass into the Ares V launch of Element 4.

The TransHab element contains the TransHab, and additional sizing of a power system, thermal elements, RCS and propellant, C\&DH, and Communications. Most of the TransHab masses were taken from the DRA 5.0 sizing results. Additional mass is carried at the system level in order to carry $30 \%$ growth on dry masses. This does not include Crew, Crew Consumables, and propellant.

Table 9. System Summary-CTCV

\begin{tabular}{l|c|c|l|c}
\cline { 2 - 4 } & $\begin{array}{c}\text { Total wet } \\
\text { mass }\end{array}$ & $\begin{array}{c}\text { Launch margin, } \\
\text { kg }\end{array}$ & \multicolumn{1}{c}{$\begin{array}{c}\text { Element } \\
\text { Name }\end{array}$} & $\begin{array}{c}\text { Tank length, } \\
\text { m }\end{array}$ \\
\hline Launch Element 1 & 139863 & 137 & Core Element & 17.6 \\
Launch Element 2 & 139815 & 185 & In-Line Tank Element & 23.1 \\
Launch Element 3 & 138845 & 1155 & Saddle Tank Element & 21.6 \\
Launch Element 4 & 51796 & 88204 & TransHab Element & \\
Total IMLEO & 470319 & 89681 & & \\
\hline \hline
\end{tabular}


Table 10. System Summary-CTCV—Core Element

\begin{tabular}{|c|c|c|c|c|c|}
\hline \multicolumn{4}{|c|}{ Launch 1; Element Master Equipment List Rack-up (Mass) - CTCV } & \multirow{2}{*}{$\begin{array}{c}\text { COMPASS S/C } \\
\text { Design } \\
\begin{array}{c}\text { Total Mass } \\
(\mathbf{k g})\end{array} \\
\end{array}$} & \multirow[b]{2}{*}{$\begin{array}{c}\text { Aggregate } \\
\text { Growth (\%) }\end{array}$} \\
\hline WBS & Main Subsystems & $\begin{array}{c}\text { Basic Mass } \\
(\mathbf{l k g})\end{array}$ & Growth (kg) & & \\
\hline 06.1 & Core Element & 126473.0 & 5520.9 & 131993.6 & \\
\hline 06.1 .1 & \begin{tabular}{|c|} 
Attitude Determination and Control \\
\end{tabular} & 8 & 1 & 9 & $15 \%$ \\
\hline 06.1 .2 & Command and Data Handling & 333 & 64 & 398 & $19 \%$ \\
\hline 06.1 .3 & Communications and Tracking & 20 & 2 & 22 & $10 \%$ \\
\hline 06.1 .4 & Electrical Power Subsystem & 221 & 77 & 298 & $35 \%$ \\
\hline 06.1 .5 & Environmental Control (Non-Propellant) & 1735 & 260 & 1995 & $15 \%$ \\
\hline 06.1 .6 & Propulsion Hardware & 20263 & 843 & 21106 & $4 \%$ \\
\hline 06.1 .7 & Propellant & 81839 & N/A & 81839 & \\
\hline \multirow[t]{2}{*}{06.1 .8} & Structures and Mechanisms & 22053 & 4273 & 26326 & $19 \%$ \\
\hline & Estimated CTCV Core Element Dry Mass & 44634 & 5521 & 50154 & $12 \%$ \\
\hline \multicolumn{2}{|c|}{ System LeveL Growth Calculations } & & & & Total Growth \\
\hline & Dry Mass Desired System Level Grow th & 44634 & 13390 & 58023.6 & \begin{tabular}{|l|}
$30 \%$ \\
\end{tabular} \\
\hline & Additional Grow th (carried at system level) & & 7869 & & $18 \%$ \\
\hline Launch 1 & Total dry Mass with Growt th & 44634 & 13390 & 58023.6 & $30 \%$ \\
\hline Launch 1 & Total Wet Mass w ith Grow th & & & 139863.0 & \\
\hline
\end{tabular}

Table 11. System Summary-CTCV—In-Line Tank Element

\begin{tabular}{|c|c|c|c|c|c|}
\hline \multicolumn{4}{|c|}{ Launch 2: Element Master Equipment List Rack-up (Mass) - CTCV } & \multirow{2}{*}{\begin{tabular}{|c|}
$\begin{array}{c}\text { COMPASS S/C } \\
\text { Design }\end{array}$ \\
$\begin{array}{c}\text { Total Mass } \\
(\mathbf{k g})\end{array}$ \\
\end{tabular}} & \multirow[b]{2}{*}{$\begin{array}{c}\text { Aggregate } \\
\text { Growth (\%) }\end{array}$} \\
\hline WBS & Main Subsystems & \begin{tabular}{|c|} 
Basic Mass \\
$(\mathbf{k g})$
\end{tabular} & Growth (kg) & & \\
\hline 06.2 & In Line Tank & 131885 & 4156 & 136041 & \\
\hline 06.2 .1 & \begin{tabular}{|c|} 
Attitude Determination and Control \\
\end{tabular} & 0 & 0 & o & TBD \\
\hline 06.2 .2 & Command and Data Handling & 91 & 16 & 107 & $17 \%$ \\
\hline 06.2 .3 & Communications and Tracking & 0 & 0 & $\mathbf{0}$ & TBD \\
\hline 06.2 .4 & Electrical Power Subsystem & 102 & 45 & 147 & $44 \%$ \\
\hline 06.2 .5 & Environmental Control (Non-Propellant) & 1735 & 260 & 1995 & $15 \%$ \\
\hline 06.2 .6 & Propulsion Hardware & 3192 & 638 & 3831 & $20 \%$ \\
\hline 06.2 .7 & Propellant & 105451 & $\mathrm{~N} / \mathrm{A}$ & 105451 & \\
\hline \multirow[t]{2}{*}{06.2 .8} & Structures and Mechanisms & 21313 & 3197 & 24510 & $15 \%$ \\
\hline & Estimated CTCV In Line Tank Element Dry Mass & 26434 & 4156 & 30590 & $16 \%$ \\
\hline \multicolumn{2}{|c|}{ System LeveL Growth Calculations } & & & & Total Growth \\
\hline & Dry Mass Desired System Level Grow th & 26434 & 7930 & 34364 & $30 \%$ \\
\hline & Additional Growth (carried at system level) & & 3774 & & $14 \%$ \\
\hline Launch 2 & Total Dry Mass wi ith Growth & 26434 & 7930 & $\mathbf{3 4 3 6 4}$ & \\
\hline Launch 2 & Total Wet Mass with Growth & & & 139815 & \\
\hline
\end{tabular}

Table 12. System Summary—CTCV—Saddle Dropped Tank Element

\begin{tabular}{|c|c|c|c|c|c|}
\hline \multicolumn{4}{|c|}{ Launch 3: Element Master Equipment List Rack-up (Mass) - CTCV } & \multirow{2}{*}{\begin{tabular}{|c|}
$\begin{array}{c}\text { COMPASS S/C } \\
\text { Design }\end{array}$ \\
$\begin{array}{c}\text { Total Mass } \\
(\mathbf{k g})\end{array}$ \\
\end{tabular}} & \multirow[b]{2}{*}{$\begin{array}{l}\text { Aggregate } \\
\text { Growth (\%) }\end{array}$} \\
\hline WBS & Main Subsystems & \begin{tabular}{|c|} 
Basic Mass \\
(lkg)
\end{tabular} & Growth (kg) & & \\
\hline 06.3 & Saddle Truss and dropped Tank & 129547 & 6225 & 135772 & \\
\hline 06.3 .1 & Attitude Determination and Control & 0 & 0 & o & TBD \\
\hline 06.3 .2 & Command and Data Handling & 91 & 16 & 107 & $17 \%$ \\
\hline 06.3 .3 & Communications and Tracking & 0 & 0 & $\mathbf{0}$ & TBD \\
\hline 06.3 .4 & Electrical Power Subsystem & 103 & 47 & 150 & $45 \%$ \\
\hline 06.3 .5 & Environmental Control (Non-Propellant) & 2322 & 348 & 2670 & $15 \%$ \\
\hline 06.3 .6 & Propulsion Hardware & 3053 & 611 & 3663 & $20 \%$ \\
\hline 06.3 .7 & Propellant & 98554 & $\mathrm{~N} / \mathrm{A}$ & 98554 & \\
\hline 06.3 .8 & \begin{tabular}{|l|} 
Structures and Mechanisms \\
\end{tabular} & 25425 & 5204 & 30629 & $20 \%$ \\
\hline Launch 3 & $\begin{array}{l}\text { Estimated CTCV Saddle Truss/ Drop Tank Element Dry } \\
\text { Mass }\end{array}$ & 30993 & 6225 & 37219 & $20 \%$ \\
\hline \multicolumn{2}{|c|}{ System LeveL Growth Calculations } & & & & Total Growth \\
\hline & Dry Mass Desired System Level Growith & 30993 & 9298 & 40291 & \begin{tabular}{|l|}
$30 \%$ \\
\end{tabular} \\
\hline & Additional Grow th (carried at system level) & & 3073 & & $10 \%$ \\
\hline Launch 3 & Total Dry Mass with Growth & 30993 & 9298 & 40291 & \\
\hline Launch 3 & Total Wet Mass w ith Grow th & & & 138845 & \\
\hline
\end{tabular}

American Institute of Aeronautics and Astronautics 
Table 13. System Summary—CTCV—TransHab Element

\begin{tabular}{|c|c|c|c|c|c|}
\hline \multicolumn{4}{|c|}{ Launch 4: Element Master Equipment List Rack-up (Mass) - CTCV } & \multirow{2}{*}{\begin{tabular}{|c|}
$\begin{array}{c}\text { COMPASS S/C } \\
\text { Design }\end{array}$ \\
$\begin{array}{c}\text { Total Mass } \\
(\mathbf{k g})\end{array}$ \\
\end{tabular}} & \multirow[b]{2}{*}{$\begin{array}{l}\text { Aggregate } \\
\text { Growth (\%) }\end{array}$} \\
\hline WBS & \begin{tabular}{|c|} 
Main Subsystems \\
\end{tabular} & $\begin{array}{c}\text { Basic Mass } \\
(\mathbf{l k g})\end{array}$ & Growth (kg) & & \\
\hline 06.4 & TransHAB and Payload & 47425 & 4128 & 51552 & \\
\hline 06.4 .1 & \begin{tabular}{|c|c|} 
Attitude Determination and Control \\
\end{tabular} & 1088 & 163 & 1251 & $15 \%$ \\
\hline 06.4 .2 & Command and Data Handling & 1112 & 194 & 1307 & $17 \%$ \\
\hline 06.4 .3 & Communications and Tracking & 1039 & 271 & 1310 & $26 \%$ \\
\hline 06.4 .4 & Electrical Power Subsystem & 1413 & 452 & 1865 & $32 \%$ \\
\hline 06.4 .5 & Environmental Control (Non-Propellant) & 15500 & 186 & 15685 & $1 \%$ \\
\hline 06.4 .6 & Propulsion Hardware & 194 & 29 & 223 & $15 \%$ \\
\hline 06.4 .7 & Propellant & 3788 & $\mathrm{~N} / \mathrm{A}$ & 3788 & \\
\hline 06.4 .8 & Structures and Mechanisms & 8092 & 1678 & 9770 & $21 \%$ \\
\hline 06.4 .9 & ECLSS & 15200 & 1154 & 16353 & $8 \%$ \\
\hline Launch 4 & $\begin{array}{l}\text { Estimated CTCV TransHAB and Payload Element Dry } \\
\text { Mass }\end{array}$ & 43637 & 4128 & 47765 & $9 \%$ \\
\hline \multicolumn{2}{|c|}{ System LeveL Growth Calculations } & & & & Total Growth \\
\hline & Crew, Consumables and GCR Water (no addt'l growth) & 16438 & 0 & 16438 & $0 \%$ \\
\hline & Total Dry Mass & 27199 & 4128 & 31327 & $15 \%$ \\
\hline & Dry Mass Desired System Level Growt th & 27199 & 8160 & 35358 & $30 \%$ \\
\hline & Additional Growth (carried at system level) & & 4031 & & $15 \%$ \\
\hline Launch 4 & Total Dry Mass wi ith Growth & 27199 & 8160 & 35358 & $30 \%$ \\
\hline Launch 4 & Total Wet Mass with Growth & 43637 & 8160 & 51796 & \\
\hline
\end{tabular}

\section{Design Concept Drawing and Description}

The CTCV is comprised of four sections, each requiring their own launch, and assembled in LEO as described earlier. The four sections include the TransHab section, drop tank section, in-line tank section, and the core section. Figure 30 shows the vehicle fully assembled prior to departure with dimensions for the overall vehicle, sections, and tanks. Two isometric views of the CTCV are shown in Figure 31.

1. Core Element

The primary components contained on the core element include the NTR thrusters, radiation shielding, thrust structure, $\mathrm{LH}_{2}$ tank, RCS system, cryo-coolers, radiators for the cryo-coolers, cylindrical structure for transferring loads to and from the $\mathrm{LH}_{2}$ tank, conduit for running lines around the $\mathrm{LH}_{2}$ tank, and the interface to the in-line tank section. No deployable components are required on the core element. The core element is shown in Figure 32.

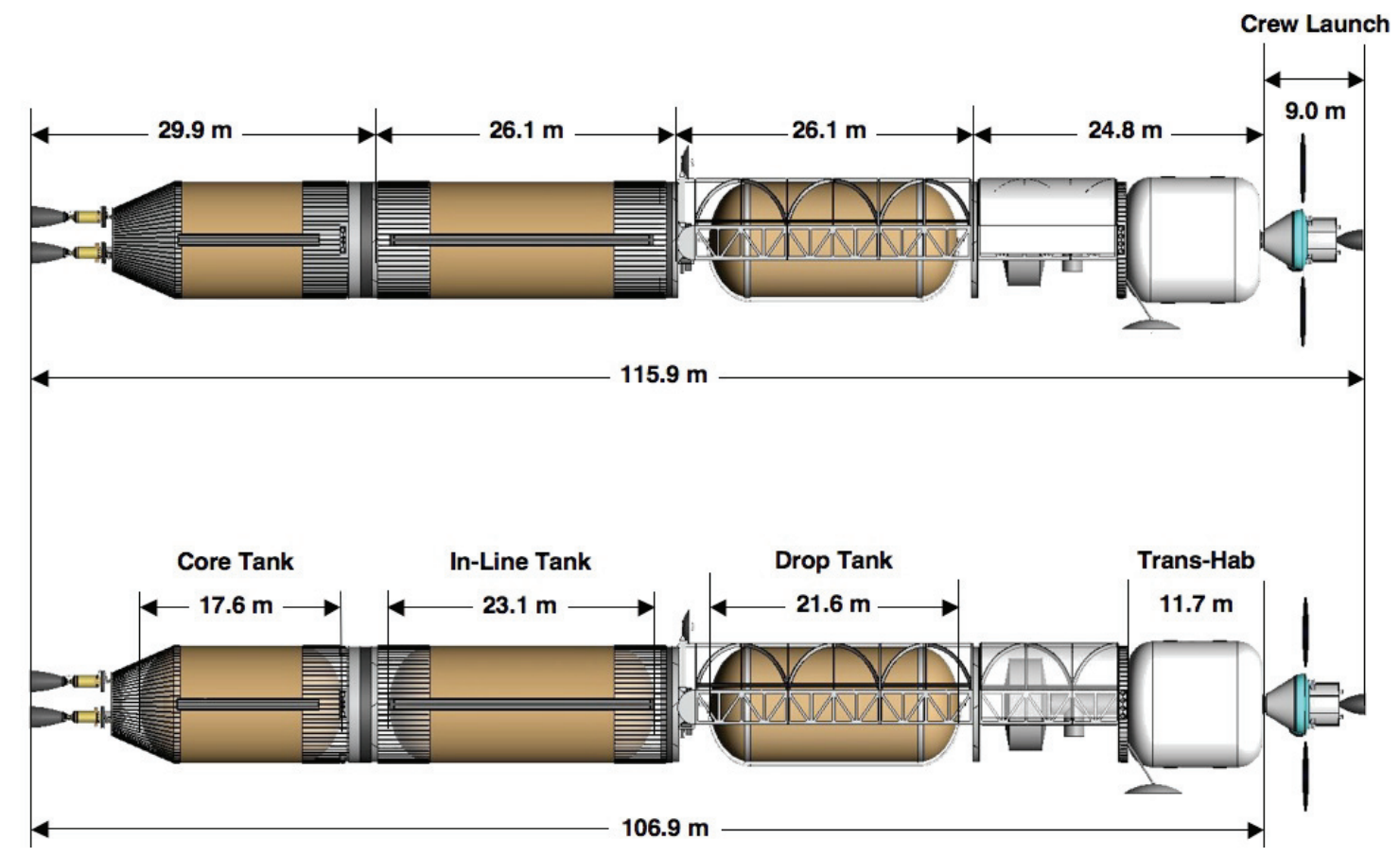

Figure 30. CTCV with dimensions. 

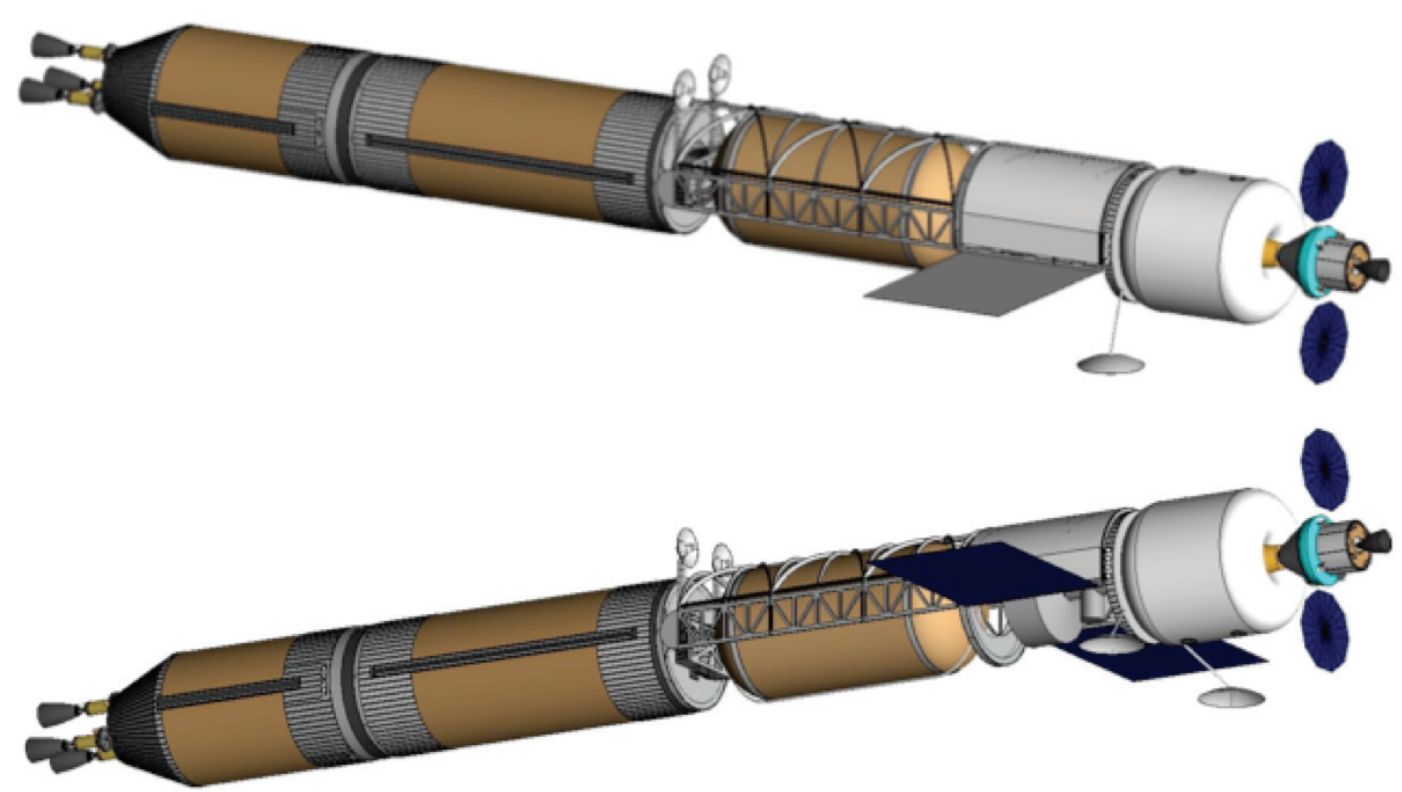

Figure 31. Isometric views of the CTCV.

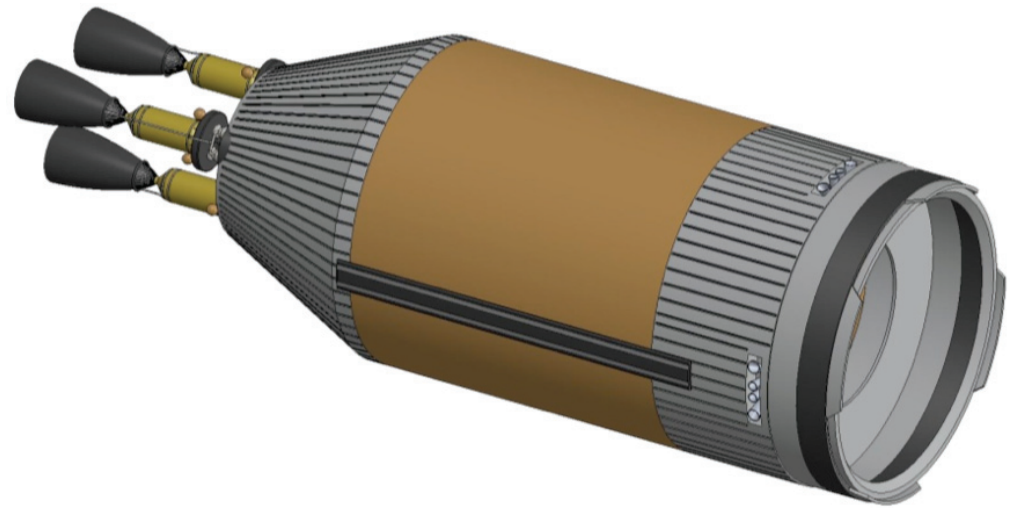

Figure 32. Core tank element.

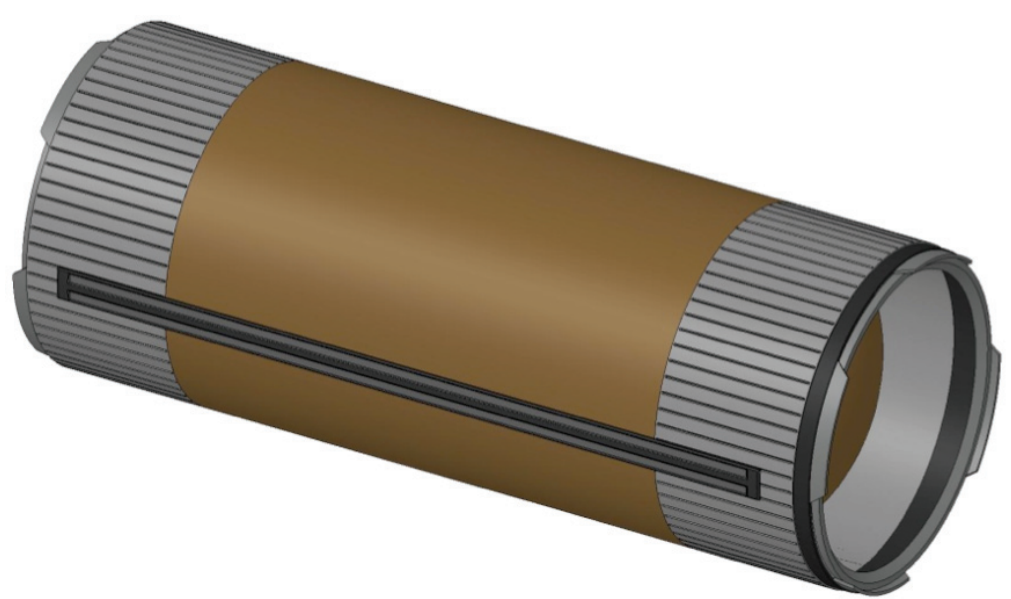

Figure 33. In-line tank element. 


\section{In-Line Tank Element}

The primary components contained on the in-line tank element include the $\mathrm{LH}_{2}$ tank, cryo-coolers, radiators for the cryo-coolers, cylindrical structure for transferring loads to and from the $\mathrm{LH}_{2}$ tank, conduit for running lines around the $\mathrm{LH}_{2}$ tank, and the interfaces to both the core element and the drop tank element. No deployable components are required on the in-line tank element. Figure 33 shows the in-line tank element.

3. Saddle Truss Dropped Tank Element

The saddle truss, or drop tank element of the CTCV consists of an $\mathrm{LH}_{2}$ tank, saddle truss section that hold the $\mathrm{LH}_{2}$ tank and allows it to be jettisoned, the Mars surface communications system including two dish antennas, conduit for running lines along the saddle truss section, and the interfaces to both the in-line tank and TransHab elements. Deployable components on the saddle truss section include the two Mars antennas. Figure 34 shows the saddle truss element prior to antenna deployment.

\section{TransHab Element}

The main components contained on the TransHab element include the TransHab, the Earth pointing dish antennas, RCS system, saddle truss section, conduit for lines running along the TransHab element, solar arrays, TransHab radiator, cargo canister, docking tunnel, and the interface to the drop tank element. Deployable components include the solar arrays, Earth pointing antennas, and the TransHab (inflatable). Deployment of the Earth pointing antennas must be done prior to inflating the TransHab due to the location of the antennas while stowed for launch. The TransHab element is shown in Figure 35.

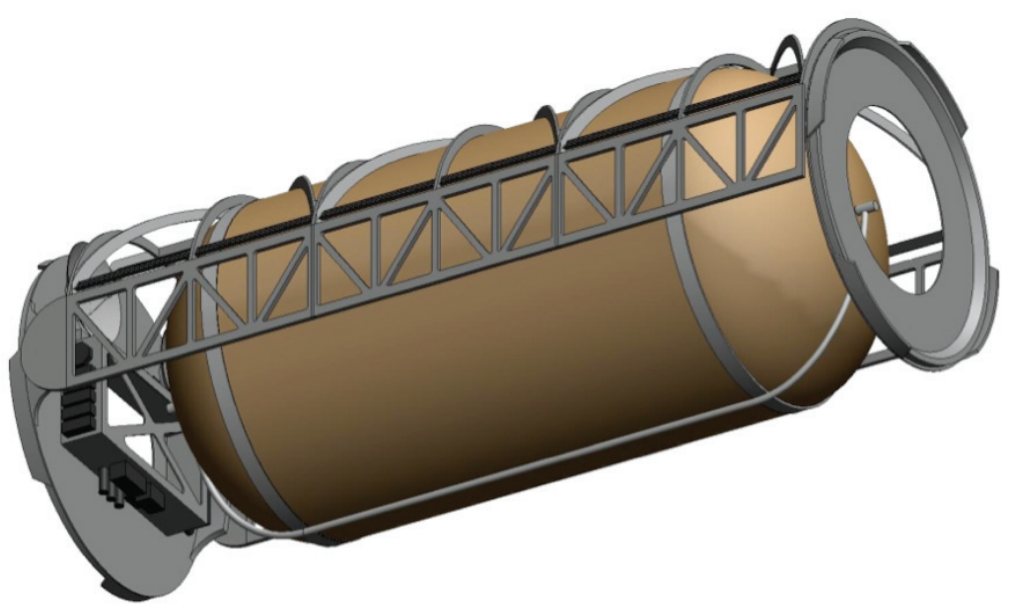

Figure 34. Saddle/dropped tank element.

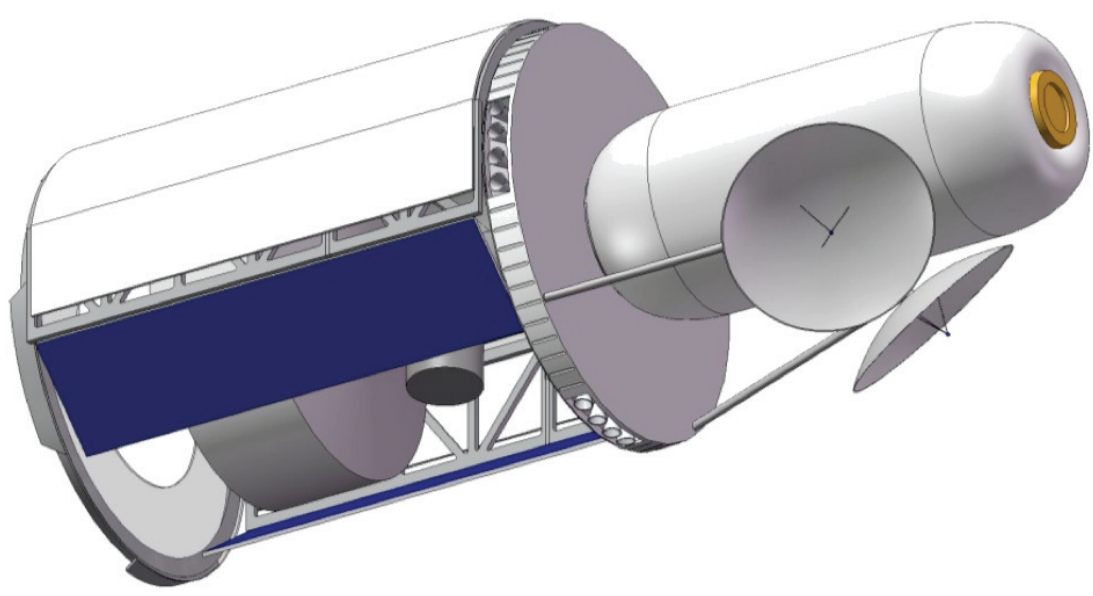

Figure 35. Stowed TransHab element. 


\section{Subsystem Breakdown}

\section{A. Attitude Determination and Control (AD\&C)}

\section{AD\&C Requirements}

Provide control of the attitude and orientation of the CTCV as it is assembled in LEO as well as throughout the mission. Spin the CTCV at Mars in order to provide Mars equivalent gravity for the crew during mission operations.

2. AD\&C Assumptions

The TransHab element, deployed first, will provide power and control of the entire CTCV vehicle as it is assembled in LEO. Therefore, the only attitude control hardware will be located in this element. Thrusters, both the main NTR and the additional RCS, provide attitude control during the mission.

Much of the control of the CTCV during LEO assembly will be done by the CMGs and the RCS auxiliary thruster system. Unloading of the momentum wheels is done twice during the mission, once during the Earth to Mars outbound coast and once during the Mars to Earth inbound coast. It is assumed that the CMGs are unloaded by simultaneously firing the RCS thrusters at each end of the CTCV vehicle. Steering during NTR thrusting will be done with gimbals on those engines.

3. AD\&C Design and MEL

Aside from some star trackers on the Core element, since it is launched last for the LEO assembly, most of the $\mathrm{AD} \& \mathrm{C}$ hardware is located in the TransHab and payload element. Four of CMGs are used to maintain the attitude of the CTCV. The mass and power level assumptions are taken directly from the current known ISS CMG data.

\section{Spin Up/Down Delta $V$}

The below equations were used to estimate the amount of RCS firing time, $\Delta t$, to despin the momentum wheels from the momentum wheel angular momentum, $H_{m w}$, as well as the torque, $\mathrm{T}$, generated by firing the RCS thrusters. The mass of the RCS propellant, $m_{p}$, required was then calculated from the total firing time of the RCS thrusters. Due to the size of the CTCV vehicle, only a small amount of RCS propellant $\left(\mathrm{m}_{\mathrm{p}}\right)$ is necessary to unload the momentum wheels, $0.06 \mathrm{~kg}$ per wheel.

$$
\begin{gathered}
\Delta t=\frac{H_{m w}}{T} \\
m_{p}=\frac{F(\Delta t)}{g I s p}
\end{gathered}
$$

Following the MOI burn, the CTCV is spun up to an angular rate of $2.7 \mathrm{rpm}$ to simulate gravity for the crew during the Mars orbit loiter period. The spin axis is aligned initially in a Sun-pointing orientation. Since the science orbit of the CTCV is not Sun-synchronous it is necessary for the spin axis to be precessed during the $500 \mathrm{~d}$ loiter period to maintain alignment with the Sun. Following the loiter period and prior to the TEI burn, the CTCV is despun to remove all angular momentum from the vehicle for the Mars to Earth coast.

CTCV spin-up and despin as well as spin axis precession is performed using the RCS engines. The required RCS propellant mass for each of these maneuvers was calculated using an estimated instantaneous moment of inertia of the CTCV, $I_{s c}$.

For CTCV spin-up and despin, the total time the RCS engines need to be fired was calculated using the below equation. The RCS propellant required to spin-up the CTCV at the beginning of the Mars loiter phase of the mission is $326 \mathrm{~kg}$ and to despin at the end of Mars loiter is $324 \mathrm{~kg}$. In the following equation, $\omega_{\mathrm{sc}}$ is the spacecraft rate of rotation, the $\mathrm{I}_{\mathrm{sc}}$ is moment of inertia of the spacecraft, and $\mathrm{T}$ is the torque created by the thruster firing.

$$
\Delta t=\frac{I_{s c} \omega_{s c}}{T}
$$

Throughout the 500 day loiter period the spin axis of the vehicle will be required to precess a total of $140^{\circ}(\Delta \Psi)$ to maintain a Sun-pointing orientation. The total time the RCS engines will be firing during the entire 500 day loiter is calculated from the above equation, assuming the RCS engines will be pulsed once during each revolution of the CTCV to process the spin axis. This results in the required RCS propellant load for procession of $795 \mathrm{~kg}$.

\section{B. Command and Data Handling (C\&DH)}

The C\&DH subsystem MEL is divided up by vehicle stage. The habitation module stage avionics subsystem provides control and support to the living and work quarters and provides enhanced support when in 
communications with the attached Orion crew module. However, the avionics subsystem must be able to operate in some limited modes whenever the Orion crew module is undocked (for example when performing local translation and docking maneuvers).

The C\&DH subsystem generally provides all telemetry acquisition and processing, and forwards telemetry to the C\&T subsystem for transmission to Earth. In addition, C\&DH Avionics performs the GN\&C calculations necessary to perform in-transit and rendezvous operations in concert with Ground commanding. Telemetry and image data is stored on the on-board Mass Memory until downlinking has been confirmed as successful. However, for the middle stages of the assembled stack, $\mathrm{C} \& \mathrm{DH}$ is pared down to merely interfacing to sensors and effectors.

\section{C\&DH Requirements}

The design requirements for the $\mathrm{C} \& \mathrm{DH}$ system are, as follows:

- Avionics components and parts classification shall be Class S (see Ref. 4), MIL-STD-883B screened, commercial screened

- All avionics shall be $65 \mathrm{Krad}$ or higher

- Components shall be at TRL 6 at technology cutoff (2028)

- Data storage units shall be capable of handling at least 1 Terabyte (2028)

- Radiation hard to mission requirements (Mars surface)

- Power PC cores

- Peripheral Component Interconnect (cPCI) bus

- Serial communications and MIL-STD-1553 for instruments, sensors, actuators, controllers

- Custom controllers and signal conditioning for actuators and sensors

- Sensors - tilt, IMU, motor currents, position, strain, temperature, pressure

- Human-rated, requiring at least 2 fault tolerant (FT)

\section{C\&DH Assumptions}

The following design assumptions are based on the mission requirements:

- Assume all science and ACS instruments have radiation-tolerant microcontrollers/Flight Programmable Gate Arrays (FPGAs) and data storage

- Avionics spares are cold spares to minimize power consumption

- Hardware design heritage will be based on previous S/C such as the New Horizon (NH), Dawn, and perhaps on the newly designed MSL for design and implementation of software for precision landing and for SCS750 processor or equivalent.

- Data storage technology will continue to follow Moore's Law and by mid-decade (2030s) will store dramatically larger volumes of data

- By mid-decade (2030s) advances in semi-automatic code generation will help guarantee very capable, secure, and reliable operating system execution

- Look for some breakthroughs in semi-autonomous semi-intelligent software code.

\section{3. $C \& D H$ Design}

\section{CTCV TransHab Element}

The avionics (C\&DH) system consists of independent avionics boxes or integrated electronics modules (IEMs) to provide for single fault tolerance. Each IEM includes the SCS750 main processor capable of supporting GN\&C and C\&DH functions, a $>10$ TB solid-state memory card, and communications and payload interface cards. The IEM is capable of autonomous failover to a redundant unit when a fault is detected.

Flight computers will use PowerPC 750 FX family architecture (as upgraded in the late 2020s) with a real-time Operating System similar to 2010s VxWorks or Green Hills Integrity. The number of source lines of code to support all mission phases will be in excess of 800,000 SLOCs (estimate based on taking 2/3 of the current Orion code estimate) to support all phases of long-term human habitation.

An assumption is made here that with a docked Orion module, it will be possible to use the Orion Avionics computers, over the internal high-speed data bus, to provide computational assistance during certain critical portions of the mission.

The following listing is of the main avionics components and their quantities as input to the MEL. The TransHab requirements on redundancy are higher than on the other elements of the CTCV. 
- Flight computers (x3 or TBD)

- SCS750 Central Processing Unit (CPU)

- S710 communications PCI Mezzanine Card (PMC)

- (http://www.rugged.com/s710.htm)

- cPCI enclosure with power supply, rad hard

- Data acquisition units (x3 or TBD)

- Data bus interface -1553 (x3 or TBD)

- Solid State Mass Memory

- Video system

- Instrumentation

- Min. 144+ sensors, 6 oz ea, $50 \mathrm{~mW}$ ea

- Cabling

- Instrumentation TBR (1/2 length of stage) per sensor, 22-24 American Wire Gauge (AWG) Tefzel

- C\&DH min. 144+ sensors and I/O's (for reference: in October $2009 \mathrm{CEV}$ is planning to have over $1000 \mathrm{I} / \mathrm{O}$ 's)

- Custom motor controllers (*one per drive motor)

- Total avionics mass is $1307 \mathrm{~kg}$, which includes a nominal 15\% growth allowance.

- Total avionics electrical power requirements are $922 \mathrm{~W}$ peak power with only a small amount of variations in power load requirements

Flight Computers and Software

- Load, initialization, executive functions and utilities

- FC redundancy management

- Data acquisition and control

- Command and telemetry processing

- Health monitoring and management

- Power management, control and distribution

- GN\&C

- Event sequence management

- Fault detection, diagnostics and recovery

- Motor and gimbal commanding

Data Acquisition System

- Collecting and distributing non-flight-critical sensor data from the instrumentation throughout the mission

- Providing the data to Mass Memory via high speed data buses

Video System

- High resolution cameras for viewing stage separations, docking, and operations and any EVAs

- Camera controller for controlling and managing cameras

$G N \& C$

- GN\&C components are covered in a different Section

Saddle/Dropped Tank Element

All avionics will consist of sensors and effectors plus just enough signal conditioning and isolation to allow instrumentation measurements to reach the data bus and to allow commanding from the data bus to reach effectors. Small avionics enclosures for data transfer can be built with FPGAs.

Umbilical connections between modules are assumed to be pairs of dead-faced connector panels that are automatically jack-screwed together with motor drives and aligned with goof-proof alignment pins.

- Total avionics mass is $107 \mathrm{~kg}$, which includes a nominal $15 \%$ growth allowance.

- Total avionics electrical power requirements are $23 \mathrm{~W}$ peak power with only a small amount of variations in power load requirements

\section{In-Line Tank Element}

All avionics will consist of sensors and effectors plus just enough signal conditioning and isolation to allow instrumentation measurements to reach the data bus and to allow commanding from the data bus to reach effectors. Small avionics enclosures for data transfer can be built with FPGAs. 
Umbilical connections between modules are assumed to be pairs of dead-faced connector panels that are automatically jack-screwed together with motor drives and aligned with goof-proof alignment pins.

- Total avionics mass is $107 \mathrm{~kg}$, which includes a nominal $15 \%$ growth allowance.

- Total avionics electrical power requirements are $23 \mathrm{~W}$ peak power with only a small amount of variations in power load requirements

\section{Core Element}

The avionics (C\&DH) system consists of two independent avionics boxes or IEMs to provide for single fault tolerance. Each IEM includes the SCS750 main processor capable of supporting GN\&C and C\&DH functions, a $>10$ TB solid state memory card, and communications and payload interface cards. The IEM is capable of autonomous failover to a redundant unit when a fault is detected.

Flight computers will use PowerPC 750 FX family architecture (as upgraded in the late 2020s) with a real-time Operating System similar to 2010s VxWorks or Green Hills Integrity. The number of source lines of code to support all mission phases will be in excess of 100,000 SLOCs.

The following listing is of the main avionics components and their quantities as input to the MEL.

- Flight computers (x2 or TBD)

- SCS750 CPU

- $\quad$ S710 communications PMC

- $\quad$ (http://www.rugged.com/s710.htm)

- cPCI enclosure with power supply, rad hard

- Data acquisition units (x2 or TBD)

- Data bus interface -1553 (x2 or TBD)

- Solid State Mass Memory

- Video system

- Instrumentation

- Min. $144+$ sensors, 6 oz ea, $50 \mathrm{~mW}$ ea

- Cabling

- Instrumentation $2.5 \mathrm{~m}$ ( $1 / 2$ length of stage) per sensor, 22-24 AWG Tefzel

C\&DH min. 144+ sensors and I/O's

(for reference: in October 2009 CEV is planning to have over $1000 \mathrm{I} / \mathrm{O}$ 's)

- Custom Motor Controllers (*one per drive motor)

- Total avionics mass is $398 \mathrm{~kg}$ which includes a nominal $15 \%$ growth allowance.

- Total avionics electrical power requirements are $369 \mathrm{~W}$ peak power with only a small amount of variations in power load requirements

Flight Computers and Software

- Load, initialization, executive functions and utilities

- FC redundancy management

- Data acquisition and control

- Command and telemetry processing

- Health monitoring and management

- Power management, control and distribution

- GN\&C

- Event sequence management

- Fault detection, diagnostics and recovery

- Motor and gimbal commanding

Data Acquisition System

- Collecting and distributing non-flight-critical sensor data from the instrumentation throughout the mission

- Providing the data to Mass Memory via high speed data buses

Video System

- High resolution cameras for viewing stage separations, docking, and operations and any EVAs

- Camera controller for controlling and managing cameras 
$G N \& C$

- GN\&C components are covered in a different Section

4. $C \& D H$ Trades

The S/C must have sufficient particle shielding due to the long-term space orbital time and the cumulative effects of the local radioisotope electric power units. Therefore include an evaluation of whether to include additional particle shielding in the avionics enclosures by using Ti. It is recognized here that portions of the vehicle stack were intentionally designed to have water shielding.

By mid-decade (2030s) advances in semi-automatic code generation will help guarantee very capable, secure, and reliable operating system execution. Therefore a choice of which computer operating system applicable to 2009 is not obviously the best choice for the early 2030s.

Also by mid-decade (2030s) advances in semiconductor technology may have permitted manufacturers to evolve the PowerPC $750 \mathrm{FX}$ processor architecture into a new form with faster clocking and/or more tolerance to particle radiation. A choice of which microprocessor to specify for the late 2020s and early 2030s is uncertain: therefore the current $750 \mathrm{FX}$ processor architecture is all that could be called out in 2009.

5. C\&DH Analytical Methods

As a matter of common practice and for good reasons, the design of a new S/C's C\&DH system is often based on one that has been proven on another $\mathrm{S} / \mathrm{C}$ and which requires minor or no modification for the mission under development. The CTCV's combined C\&DH system is partially based on previous S/C such as the New Horizons $(\mathrm{NH})$, Dawn and perhaps on the newly designed Mars Science Laboratory (MSL) which was scheduled to launch in 2009, as well as JPL's existing Spirit and Opportunity.

6. C\&DH Risk Inputs

The S/C must have sufficient EMI/RFI shielding as well as being sufficiently ground-bonded and surgeprotected to resist on-pad lightning damage. The S/C must have sufficient particle shielding due to the long-term space orbital time and the cumulative effects of the local radioisotope electric power units. Long-term availability and reliability of Avionics for the length of this mission is crucial for mission success.

\section{Communications}

1. Communications Requirements

The communications systems designed in this section are those that communicate back to Earth as well as those used to communicate to the Martian surface. The communications for the Truck on the Mars surface for the HERRO mission entails two communication systems. There is the communications between itself and the rovers on the Martian surface. The other is the communication between itself and the HERRO S/C or other orbiting vehicles around Mars. Line-of-site communications is required between Rockhound and Truck. The Rockhound is controlled by telerobotic communications from the orbiting crewed vehicle relayed through Truck. This section describes the portion of the communications systems located on the orbiting CTCV.

CTCV to Truck

- $20 \mathrm{Mbits} / \mathrm{sec}$ up to Crew Vehicle (per Truck)

- $3 \mathrm{~m}$ antenna X-Band, $1^{\circ}$ beamwidth ( $\sim 0 \mathrm{~km}$ spot on mars) $\left(\sim 0.1^{\circ}\right.$ pointing accuracy)

CTCV to Earth

- Full $8 \mathrm{hr}$ of $20 \mathrm{Mbits} / \mathrm{sec}$ telepresence sent back to Earth but over entire Crew vehicle orbit (24 hr) 7 $\mathrm{Mbits} / \mathrm{sec}$ (rest could be stored for other open times - during rover transfers)

- Ka-band (32-GHz)

- $6 \mathrm{~m}$ antenna back to $34 \mathrm{~m}$ at Earth (worst case range 390 million $\mathrm{Km})(220 \mathrm{~kg}$ )

- $300 \mathrm{~W}$ transmit power to Earth, bit error rate $1 / 2$ coding at BER $10^{-8}$, SNT (34 m antenna) $105 \mathrm{~K}$

- Beamwidth $\left(0.1^{\circ}\right), \sim 0.01^{\circ}$ pointing accuracy

- $\quad \mathrm{S}$ and $\mathrm{X}$ band for ranging

- Uplink from Earth (Gbits/d): 90\% availability (weather)

2. Communications Assumptions

Assumptions for communications:

- S-band Assumptions (While Docking, Between Elements)

- Frequency: $2.20 \mathrm{GHz}$ transmit, $2.0 \mathrm{GHz}$ receive

- Format: Standard SN formats with software-defined transceiver

- Transmit power: $8 \mathrm{~W}$ 
- DC power: $60 \mathrm{~W}$

- Mass: $15.6 \mathrm{Kg}$

- Antennas system: Phase array

- $\mathrm{Ka} / \mathrm{X}$ band Assumptions (on TransHab)

- Data rate: $20 \mathrm{Mbps}$ at Ka band and 0.5 Mbps as X-band

- Transmit antenna size: $5 \mathrm{~m}$ diameter, single feed

- $\quad$ Beam width: $0.137^{\circ}$ at Ka-band and $0.52^{\circ}$ at X-band

- Pointing requirement: $0.025^{\circ}$ or better for $\mathrm{Ka}$ band and $0.13^{\circ}$ for $\mathrm{X}$-band

- Receive antenna size: $70 \mathrm{~m}$ diameter, single feed

- Mass $630 \mathrm{~kg}$ with $501 \mathrm{~kg}$ in the antenna and $78 \mathrm{~kg}$ in the gimbals

- Modulation: Quadratic phase shift key (QPSK) or offset quadratic phase shift key (OQPSK)

- Coding: rate $1 / 2$ low density parity check (LDPC) $(204 / 255)$

- Needed Eb/N0: $2.2 \mathrm{db}$

- $\quad$ Receiver system noise temperature: $127 \mathrm{~K}$ assumed for both Ka and X-band

- Transmit power: $400 \mathrm{~W}$ for Ka-band and $70 \mathrm{~W}$ for X-band

- DC power: $1050 \mathrm{~W}$ when Ka-band is turned on.

- $\quad$ X-band (Mars orbit to the surface)

- For the link to the planet surface

- Antenna size $3 \mathrm{~m}$ diameter

- Frequency X-band

- Power: $5 \mathrm{~W}$ transmit and $30 \mathrm{~W}$ DC

- Total power: $45 \mathrm{~W}$

- Mass: $186 \mathrm{~kg}, 151 \mathrm{~kg}$ in 2 antennas

- Beam width: $0.70^{\circ}$

- $\quad$ The X-band is used only to give out control and commands to the robots on the Martian surface.

\section{Communications Design}

The CTCV is made up four major modules, Core Stage, In-Line Tank, Saddle Truss and Dropped Tank, and TransHab Payload that has been explained elsewhere. Each of these vehicles will need its own communication system while in Earth orbit so that it can dock with the other modules and the Orion S/C that delivers the crew to journey to the far reaches of the solar system.

The first three sections that are basically the fuel tank and engines for the journey to Mars just need current Sband and GPS communications for docking. The crew part of the S/C, TransHab Payload, will have S-band, GPS, $\mathrm{X}$-band, and Ka-band. The former two are for use in Earth orbit primarily and the latter two are for use on the journey to and from Mars, and the stay at Mars. The S-band system currently being considered for Orion was applied for all the Elements except as noted later. For TransHab Payload section, the S-band output power was increased so that the crew could communicate up to 10 days after TMI to Mars. The 10 day limit was chosen because 10 days is the estimated number of days out that the crew could abort the mission, turn around and make it back to Earth without going to Mars.

The X-band communication transceiver also includes the circuitry necessary for tracking by using ranging and Doppler shift measurements. It also provides low to medium data rates depending on the distance. The X-band communication equipment forms the primary communication system for command and control functions from Earth.

The Ka-band communication is for the high-speed communication to send video and experimental data from the CTCV to Earth. There are many configurations of antennas to support the high data rate and some of them will be discussed later. But for the base line, a single parabolic dish 5-m diameter with a single horn and single power amplifier was chosen for the baseline calculations. The most challenging aspect of the communication system is for the Ka-band antenna system. Because of the large size of the antenna on the CTCV, the beam width at the Ka-band on the $\mathrm{S} / \mathrm{C}$ is $0.13^{\circ}$. The narrow beam translates into a two-axis angle control of $0.022^{\circ}$ or better. This is an extreme control on the angle for an antenna system on a $\mathrm{S} / \mathrm{C}$ for such a large antenna. Some of the unknowns that may prevent achieving this type of alignment are the amount of precession and nutation of the primary axis of rotation. In this analysis of the communication no analysis on the rate of change of the angles of the antenna system due to precession or nutation of the CTCV was done and was left for the next study.

Core Stage, In-Line Tank and Saddle Truss Docking Communications Systems

These communication systems use S-band during the docking procedures of the elements to each other. 


\section{TransHab Module Communications Systems}

The communication system for the TransHab consists of S-band, X-band, GPS and Ka-band systems for communication with Earth, and X-band communication system for communication between the Martian surface and the TransHab. The TransHab uses an S-band system, the same as used for the other modules, when communicating between elements and to the ground. The TransHab also uses a dual $\mathrm{Ka} / \mathrm{X}$ band communication.

The transmit power was chosen based on the distance to the Earth of 2.5 AU. The DC power was estimated from the transmit power by assuming a total efficiency of $40 \%+50 \mathrm{~W}$ for the transceiver. Future improvements in the Traveling Wave Tube Amplifier (TWTA) and its power conditioner, and a more efficient LPDC may result in a 60 to $70 \%$ improvement in DC power required. The mass is $630 \mathrm{~kg}$ with $501 \mathrm{~kg}$ in the antenna system.

Two antennas were included in the master equipment list for redundancy. The antennas were estimated by assuming $3 \mathrm{~mm}$ thick $\mathrm{Al}$ for each of the antennas with a diameter of $5 \mathrm{~m}$. Twenty percent for structure was added to that value. The mass of these antennas can be reduced in the future by going with a fiber composite with a metal coating, or the use of mesh antennas if mass reduction is desired.

The small beam width, $0.137^{\circ}$, of the antenna does present a challenge to both the antenna pointing system and the $\mathrm{S} / \mathrm{C}$ attitude control system. Further analysis and the interaction between these two systems are warranted in the future.

In addition to the communication equipment the TransHab includes teleoperations in the MEL.

It is assumed that there will be two teleoperator stations for robotic telecommunications controls and four science terminals with two spares. The amount of power these terminals would take is estimated to be the same as today's technology requirement. It is assumed that the speed of the processors will be fully utilized. Also, included here is a miscellaneous item for crew entertainment. That is, two crew entertainment centers, which are linked to the communication systems where the crew can download movies and games.

The properties are

- Mass: $185.88 \mathrm{~kg}$

- Power: $1090 \mathrm{~W}(\max )$

The TransHab also contains Ka band antenna for communications from the CTCV at Mars to Earth.

\section{Electrical Power System}

The CTCV electrical power system is designed to provide the functionality of power generation, energy storage and power distribution/control and regulation to each stage of the vehicle. Each stage of the CTCV must have power and at least two stages (Core and TransHab) require energy storage. Power must be provided from Earth to Mars and back again and during Earth and Mars eclipses.

\section{Power Requirements}

Core stage requires batteries to support $1560 \mathrm{~W}$ for a free-flying phase $(12 \mathrm{hr})$ until docking with the rest of the CTCV assembly. The Mars configuration of CTCV requires $\sim 30 \mathrm{kWhr}$ energy storage for the Mars eclipse phase of $0.5 \mathrm{hr}$ plus $0.2 \mathrm{hr}$ for other orbital operations (e.g., pointing). The PEL provides the most recent tabulated power level requirements for each mission phase and stage. However, some assumed power levels were used for sizing during the iterative COMPASS design process and these are listed in later sections. Two-fault tolerance was required in most power system components except for the solar array wings (i.e., if one wing is unable to deploy or is lost for some reason during the later parts of the mission would mean a mission abort) and stage specific harness (assumed that the loads themselves were redundant so redundant harness not necessary).

\section{Power Assumptions}

The energy storage system is assumed to be composed of Li ion batteries with a $200 \mathrm{~W}-\mathrm{hr} / \mathrm{kg}$ specific energy. Specific Energy is the nominal battery energy per unit mass, sometimes referred to as gravimetric energy. This level is the current Constellation Engineering Development Technology Program "very high specific energy" battery goal, which should be possible to meet by the time of the CTCV mission technology cutoff. The assumption of $80 \%$ depth of discharge was made for batteries used at Mars and $90 \%$ for the batteries used in LEO (rationale: lower number of cycles for LEO). The discharge conversion efficiency of the batteries was assumed to be $90 \%$.

Electrical power distribution was assumed to be at $120 \mathrm{~V}$ dc. The use of such a high voltage (primarily based on the need to reduce harness mass) is a requirement for Constellation (and Orion) and has been approved by the Safety Organization of those programs. By the time of the CTCV mission, the use of $120 \mathrm{~V}$ dc should be well established. The harness to each stage was assumed to be 2 fault tolerant. 
The power management/regulation and control electronics are based on a $200 \mathrm{~W}-\mathrm{hr} / \mathrm{kg}$ specific energy. The electronics require redundant units in order to meet be 2 FT. The solar array was assumed to be a Stretched Lens Array SquareRigger (SLASR) because the technology has the highest specific power $(300 \mathrm{~W} / \mathrm{kg})$ of all solar array technologies that have been demonstrated (at least on the ground/laboratory in terms of deployment). The following image shows an example of this type of solar array (1 "bay") in its fully deployed state.

SLASR is a concentrating-type solar array. The benefit of some level of concentration in a solar array ( $8 \mathrm{X}$ for SLASR which means the pointing error tolerance must be $2^{\circ}$ ) is that the number of solar cells can be reduced (which are a very expensive part of the power system). The solar cells are easier to shield from radiation and micrometeorites (coverglass is a significant mass for a solar array, but with fewer cells both the coverglass area and mass is much lower). The temperature of the solar cells can be lower since the area normally devoted to the solar cells can be replaced with a radiative surface, thus higher illumination and lower temperature can boost the solar cell efficiency. SLASR solar arrays have elegant deployment methods which have been formulated for power levels up to $100 \mathrm{kWe}$. The following figures shows one SLASR module (or "bay") as it's deployed from its compact launch state. First, the module unfolds and then the solar cells/concentrator unfurl.

The solar array so far assumed for Constellation use is the Ultraflex design which (1) has a limit to the deployed area per wing and which (2) is not adaptable/amenable to concentrator type lens.

The solar cells assumed were advanced triple junction cells whose efficiency are enhanced by concentrated illumination and lower temperatures (36\% at beginning of life and $32 \%$ at end of life). It was assumed that the solar cells for the SLASR degrade $10 \%$ due to a variety of factors over the life of the CTCV.

For the CTCV, the SLASR solar array wings are both deployed in Earth orbit. Because the power generation capability is much greater at Earth (1 AU) than at Mars, several methods may be used to limit the excess power from the solar arrays. Deployment would take place with the solar arrays facing away from the Sun and batteries used to power the activity. One or more bays could be fully populated with solar cells without concentrator lens such that with minor off-pointing of the solar array wing $\left(\sim 5^{\circ}\right.$ to $\left.10^{\circ}\right)$ the solar power from the lensed bays would be minimal but would be adequate for the non-lensed bays. The other method would be to use a semi-transparent surface on the back of the SLASR solar cells such that if they point with their back facing the Sun, they would still generate power (a fraction of the concentrated/lensed power). ISS solar arrays generate power from the back of their solar cells too, so in principle this could work. The final alternative would be to develop electronics/switchgear to shunt the various bays depending on the distance from the Sun. Each of these alternatives has its benefits and drawbacks and requires more study to quantify. This was not done for this study.

\section{Power Design}

The power system is composed of the previously described hardware components assumed for this vehicle. There are two solar array "wings" composed of 14 SLASR modules or "bays" per wing. One SLASR module or bay is $2.5-$ by $5-\mathrm{m}$ in size. The exact arrangement of modules is fairly flexible and must be based in part on structural and dynamics analyses. For this study, the wing was assumed to be roughly seven bays wide and two deep (11.5- by 10-m, or about square for the wing). If pointing at the Sun in LEO, the power produced by the solar arrays would be $140 \mathrm{kWe}$. This power level is not supportable by the present CTCV electronics or harness design so the previously described methods (in the previous section) are needed to reduce the power level. At Mars, to support $40 \mathrm{kWe}$ user load, the solar arrays produce $51 \mathrm{kWe}$ (power for recharge of the batteries occurs over the long $12 \mathrm{hr}$ part of the orbit that is illuminated. Each solar array is assumed to have two gimbal axes per wing to assure the $\pm 2^{\circ}$ of pointing tolerance could be met. The gimbal mass estimate was based on $72 \%$ of the mass supported (SLASR solar array and structure outboard of the gimbal).

The exact quantity of batteries is not known because the amp-hr capacity per battery is not currently defined, so the mass and size were based on specific energy and volumetric energy metrics only. Battery housing mass was assumed to be $20 \%$ of the battery mass. It is assumed that all batteries were cycled to $80 \%$ depth of discharge (except for the Core stage ones which were cycled to $90 \%$ ). Battery discharge efficiency is assumed to be $90 \%$. The Core stage batteries were sized to provide $12 \mathrm{hr}$ of energy $(1560 \mathrm{~W})$ to the Core stage until it can dock with the remaining stages. The TransHab batteries were sized to provide $40 \mathrm{kWe}$ for $0.7 \mathrm{hr}$.

Electronics sizing for each stage was based on the power level, whether the stage required power distribution electronics, voltage conversion electronics, battery charge and/or discharge electronics, and solar array control/regulation electronics. Specific power of each component was applied to the power level for each stage. The solar array regulator sizing was based on the Mars power level limit. The inline and saddle/drop tank stages only required power distribution/voltage conversion electronics. The inline stage was assumed to have a power level of $1300 \mathrm{~W}$ and the power distribution unit/voltage conversion electronics has a specific power of $200 \mathrm{~W} / \mathrm{kg}$, however due to a 2 FT requirement, the required mass was increased by a factor of 3 . The saddle stage was assumed to have a design power level of $1000 \mathrm{~W}$ and had a basis of mass estimation similar to the inline stage. The core stage was 
assumed to have a design power level of $1861 \mathrm{~W}$ and the battery charge/discharge electronics/power distribution unit/voltage conversion electronics had a specific power of $200 \mathrm{~W}-\mathrm{kg}$, but with a $2 \mathrm{FT}$ requirement, the required mass was increased by a factor of 3 . The TransHab stage was assumed to have a design power level of $30000 \mathrm{~W}$ and the solar array regulator/battery charge/discharge electronics/power distribution unit/voltage conversion electronics had a specific power of $200 \mathrm{~W} / \mathrm{kg}$, but with a $1 \mathrm{FT}$ requirement, the required mass was increased by a factor of 2 .

The harness masses required a number of assumptions to allow them to be estimated. The TransHab solar array cable masses were based on $120 \mathrm{~V} \mathrm{dc}$ (from the solar array), $15 \mathrm{~m}$ length (from solar array to regulator electronics), 2 FT and $70 \mathrm{kWe}$ maximum total power from the solar arrays. For the stages there are two sets of harness: one set goes to loads in that stage, the other are harness segments that go to provide power to the other stages. The TransHab stage loads were assumed to number 200 in quantity and be on average $500 \mathrm{~W}$ and on average $13 \mathrm{~m}$ distant with $0 \mathrm{FT}$ and $120 \mathrm{~V}$ dc. The saddle stage loads were assumed to number 30 in quantity and be on average $500 \mathrm{~W}$ and on average $26 \mathrm{~m}$ distant with $0 \mathrm{FT}$ and $120 \mathrm{~V}$ dc. The inline stage loads were assumed to number $30 \mathrm{in}$ quantity and be on average $500 \mathrm{~W}$ and on average $26 \mathrm{~m}$ distant with $0 \mathrm{FT}$ and $120 \mathrm{~V}$ dc. The core stage loads were assumed to number 30 in quantity and be on average $500 \mathrm{~W}$ and on average $26 \mathrm{~m}$ distant with $0 \mathrm{FT}$ and $120 \mathrm{~V}$ dc.

The other stage harness segments are based on the power level that must be provided to the stage that the harness is powering and the length of the segment it must pass through. The total mass of the entire length of the harness that goes to the saddle stage from the TransHab stage is based on $951 \mathrm{~W}$ and $13 \mathrm{~m}$ length. The total mass of the entire length of the harness that goes to the inline stage from the TransHab stage is based on $1300 \mathrm{~W}$ and $39 \mathrm{~m}$ length. The total mass of the entire length of the harness that goes to the core stage from the TransHab stage is based on $1860 \mathrm{~W}$ and $65 \mathrm{~m}$ length. Distribution voltage in all harnesses is assumed to be $120 \mathrm{~V}$ dc and that each harness is optimized for mass such that it has $97 \%$ efficiency. The harness segments mass is proportionally distributed to each element based on the length of the stage segment. Assumed is 2-FT in these stage power harnesses and that each harness is a separate harness directly from the TransHab to the relevant stage.

4. Power Trades

The only trade performed was by varying the voltage level beyond $120 \mathrm{~V} \mathrm{dc}$ as well as below $120 \mathrm{~V}$ dc. For the $\mathrm{CTCV}$, the harness mass does decrease significantly for 200 to $500 \mathrm{~V} \mathrm{dc}$. However, since no planned heritage or flight experience (from Constellation) for this voltage range is anticipated, it was felt that the added technology development cost required to utilize such voltages was not feasible. Lower voltages than $120 \mathrm{~V}$ dc are very mass prohibitive.

5. Power Analytical Methods

The harness masses were estimated using a spreadsheet tool developed by Ken Metcalf. The solar array, energy storage and electronics sizing was performed using a spreadsheet tool developed for an Outer Planetary Solar Array.

\section{Power Risk Inputs}

The SLASR solar array is currently not planned for any Constellation elements because it has a lower technology readiness level (TRL 4) than the Ultraflex solar array (TRL 5-6). Funding for the SLASR solar array concept has not continued since 2008 so there is some risk that it may not be developed further. SLASR or even just a SquareRigger solar array has not been demonstrated in space, so there may be risk due to its deployment complexity. Half of the complexity is due to the stretched lens part of the solar array which is collapsed prior to deployment. This needs to be tested in space to confirm it can deploy properly for many SLASR bays (of which no simulation has been performed even via computers or 3D animation). If the method is not practical, then this part of the solar array may be omitted (resulting in more solar cells, thus increased cost), with only the SquareRigger solar array bay concept being used. This concept has not been tested in space either and if there are problems with this, then a new concept using multiple Ultraflex solar arrays may be required for the CTCV.

High voltage distribution $(120 \mathrm{~V} \mathrm{dc})$ is not considered to be a risk due to pre-established hardware and operations in the Constellation program prior to the CTCV deployment.

\section{E. Environmental Control}

The environmental control system was used to maintain thermal control for the $\mathrm{S} / \mathrm{C}$ as well as provide shielding from both micro-meteor impacts and radiation. The environmental control system also included the life support systems required to maintain the crew for the duration of the mission.

The various thermal and environmental control systems were modeled and sized through a spreadsheet based analysis to provide mass and power requirements. Worst-case operating conditions were used to size the individual systems. The systems included:

- Electric Heaters

- MLI 
- Thermal Paint

- Radiator with Louvers

- Thermal Control System (sensors, switches, data acquisition)

- Cold plates with heat pipe connections to the radiator

- MMOD

- Galactic Cosmic Radiation (GCR) Shielding

- Environmental Control \& Life Support (ECLSS)

\section{Environmental Control Requirements}

The environmental control requirements for the mission were to provide a means of cooling and heating of the spacecraft in order to remain within their maximum and minimum temperature requirements during transit and orbit insertion at Mars and for the return trip to Earth. In addition to thermal regulation, vital components had to be protected against micro-meteor damage.

The environmental control systems also had to accommodate the requirements of the crew for sustaining them through the transits to and from Mars as well as for the duration in Mars orbit. These requirements included sufficient food, water and breathable air. Also protection against GCRs to keep the total dose below the allotted safety limit was needed.

The spacecraft can be considered as two segments, the propulsion vehicles, which includes the propellant tanks and support structure and the TransHab section, which includes crew habitat. The propulsion vehicles requirements would include insulation and MMOD shielding to protect the propellant tanks. The TransHab would also have these requirements as well as the ECLSS and GCR shielding. The maximum heat load on the transit stage was 30,000 W. The desired operating temperature for the electronics was 300 and $250 \mathrm{~K}$ for the spacecraft structure. The spacecraft was required to maintain these temperature requirements at the various stages of the mission, Earth orbit, transit to and from Mars and in Mars orbit.

The GCR water shielding was located around the inner sleep and work areas of the TransHab section as shown in Figure 36 and Figure 37. This was done to reduce the required mass of the shielding water. Over the course of the mission the water volume was sized to provide a maximum of $75 \mathrm{rem}$ to the personnel. For the majority of the day the crew would be in the work or sleep area, which is surrounded by the water shield. While outside the shielded area the crew would be exposed to a higher level of GRC coming from the outside, unshielded, wall of the TransHab. However, there would effectively be twice the shielding on the inner wall.

In addition to shielding the sleep and work areas the shielding water was pumped to the engine bulkhead during the periods of time when it was operating. This provided radiation shielding from the nuclear propulsion system. Because the engine operating times were short, the reduced GCR shielding around the crew work and sleep areas is not a significant factor in the total rem dose to the crew.

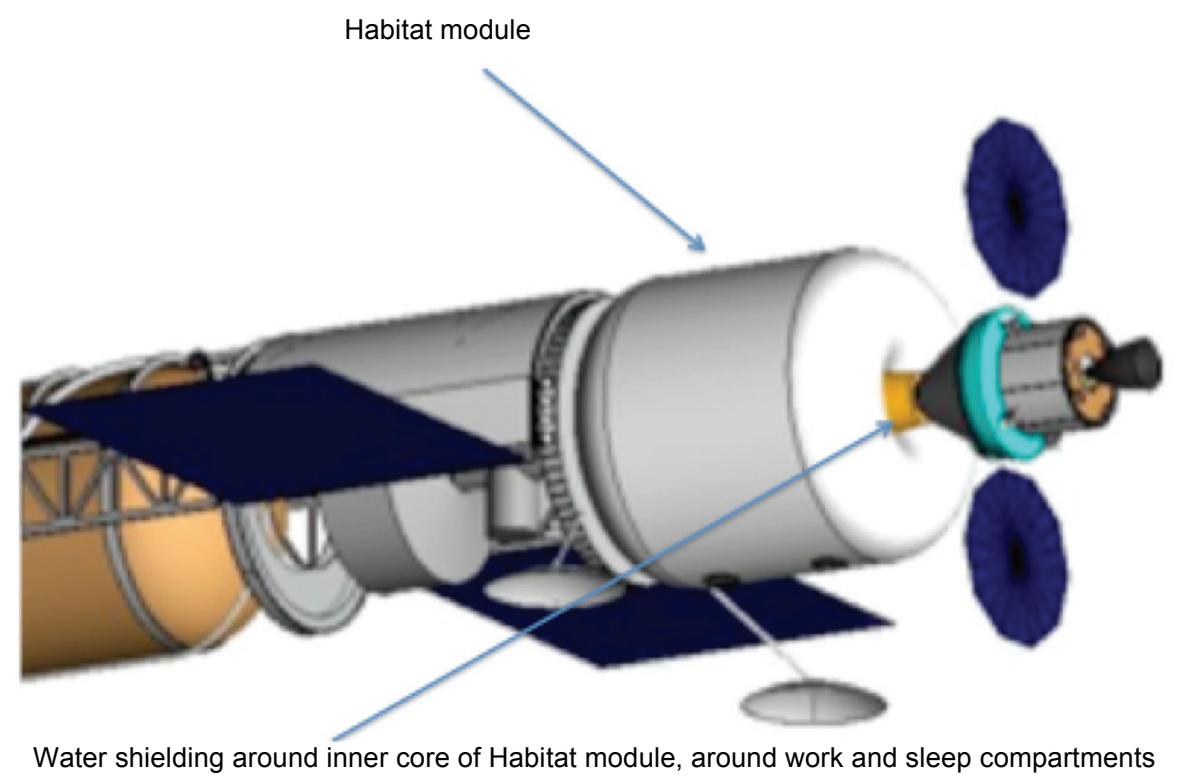

Figure 36. Location and Orientation of the TransHab. 


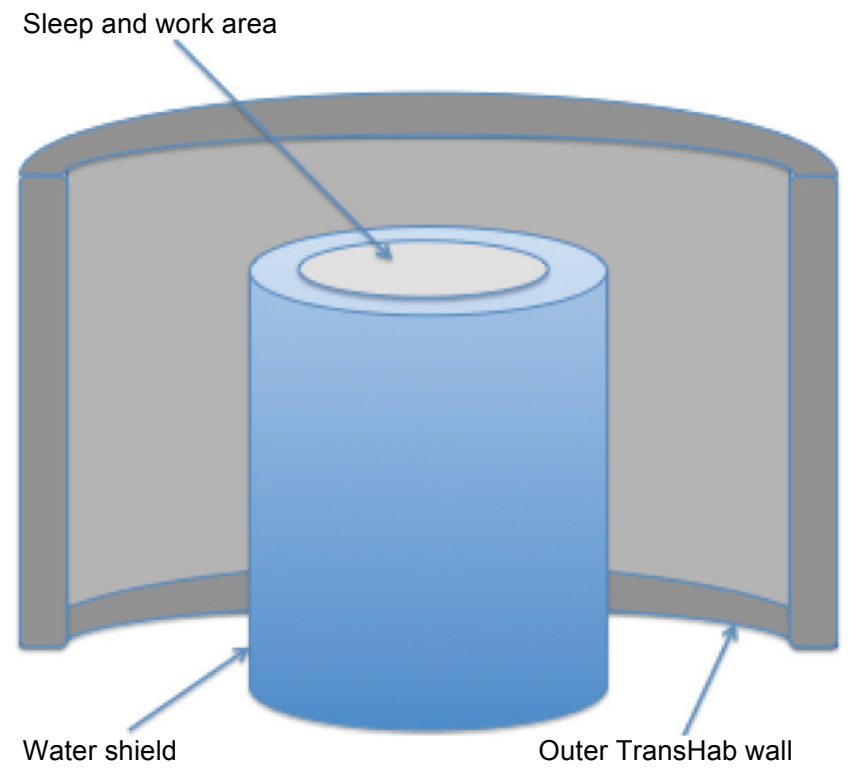

Figure 37. Illustration of the water shield surrounding the sleep and work areas of the TransHab.

To provide additional synergy with the other systems on the spacecraft it was also proposed that the shielding water could be used as a fresh water source for the crew. The used water could be replaced with gray water generated throughout the course of the mission.

2. Environmental Control Assumptions

The assumptions utilized in the analysis and sizing of the thermal system were based on the operational environment, including LEO, transit to and from Mars and Mars orbit. The following assumptions were utilized to size the thermal system.

- LEO provided the worst case operating condition thermally.

- Radiator designed to see deep space with minimal view factors to the Earth or Mars surface.

- The maximum angle of the radiator to the Sun was $20^{\circ}$.

- The radiator temperature was $320 \mathrm{~K}$.

- View factor of the radiator to the $\mathrm{S} / \mathrm{C}$ solar array was 0.1 .

- View factor of the radiator to the Earth was 0.25

- A redundant radiator was used to account for vehicle orientation on the surface and to increase overall reliability.

- MLI was used to insulate the $\mathrm{S} / \mathrm{C}$ to minimize heat transfer to and from the surroundings.

- Electric heaters and the radiator louvers were used to maintain the desired internal temperature of the S/C

\section{Radiation Environment Assumptions}

Estimates are that humans unshielded in interplanetary space would receive roughly between 40 to 90 rem (1 sievert $=100 \mathrm{rem}$ ) annually. On earth the average dose of cosmic rays is $28 \mathrm{mrem} / \mathrm{yr}$. The radiation limits for critical organs (through inhalation, ingestion or absorption) range from 5 to $30 \mathrm{rem} / \mathrm{yr}$. External radiation exposure to the skin is limited to $15 \mathrm{rem} / \mathrm{yr}$. Whole body radiation exposure is limited to $5 \mathrm{rem} / \mathrm{yr}$ for occupational exposure on Earth. Whole body is defined as the location of the majority of the blood producing areas of the body and location of the major organs. It extends from the top of the head to the elbows and knees.

"For a mission to Mars: 6-month trip, 18 months at Mars with some shielding by the atmosphere and planet, followed by a 6-month return. Estimate a radiation dose equivalent of $114 \mathrm{cSv}$ (114 rem) due to GCRs for a Mars mission at solar minimum, including 73 (73 rem) cSv enroute and 41 (41 rem) cSv on the Martian surface." (Ref. 5)

Low-atomic-mass materials such as hydrogen, boron, Li, carbon, are more desirable than high-mass nuclei because, when struck by high-energy primary cosmic particles, they do not fragment in the same fashion as heavy nuclei and don't produce secondary radiations to the same degree. Hydrogen, boron and Li also have a high thermal neutron absorption cross section. This would aid in absorbing low energy neutrons generated by the initial particle 
interaction. Hydrogen rich plastics or composites with boron or Li can be used instead of metal to construction. The $\mathrm{LH}_{2}$ or water carried on the vehicle can be used for shielding.

An alternate approach is to utilize an electromagnetic field generated around the $S / C$ to deflect the incoming particles. This approach would be power intensive and would need a period of technology development to make it a feasible alternative. Sink temperatures for Key mission locations are given in Table 14.

Table 14. Thermal Sink Temperatures for Various Locations Throughout the Mission

\begin{tabular}{l|c}
\hline \multicolumn{1}{c|}{ Location } & Temperature \\
\hline Low Earth Orbit $(220 \mathrm{~nm})$ & $201.6^{\circ} \mathrm{K}\left(-96.7^{\circ} \mathrm{F}\right)$ \\
0.5 A.U. Heliocentric orbit & $222.1^{\circ} \mathrm{K}\left(59.9^{\circ} \mathrm{F}\right)$ \\
Mars orbit $(220 \mathrm{~nm})$ & $163.2^{\circ} \mathrm{K}\left(165.8^{\circ} \mathrm{F}\right)$ \\
1.5 A.U. Heliocentric orbit & $129.0^{\circ} \mathrm{K}\left(227.5^{\circ} \mathrm{F}\right)$ \\
\hline \hline
\end{tabular}

\section{Environmental Control Design}

The thermal system is used to remove excess heat from the electronics and other components of the system as well as provide heating to thermally sensitive components throughout the nighttime and periods of inactivity.

Excess heat is collected from a series of Al cold plates located throughout the interior of the vehicle. These cold plates have heat pipes integrated into them. The heat pipes transfer heat from the cold plates to the radiator, which radiates the excess heat to space. The radiator is only utilized if the localized internal temperature gets too high. Most of the excess heat can be rejected through the vehicle to the surroundings. The equilibrium operating temperature for the vehicle at the average atmospheric temperature of $227 \mathrm{~K}$ is $320 \mathrm{~K}$. The portions of the heat pipes that extend from the $\mathrm{S} / \mathrm{C}$ and are integrated to the radiator are protected with a micrometeor shield. The radiator system utilizes a louver system to regulate the internal temperature and to insulate the radiators during cold periods. When the louvers close they cover the surface of the radiator thereby reducing the convective and radiative heat transfer from the radiator. The louvers reduce the radiator area by $30 \%$.

The radiator panel area along with its mass has been estimated at $88 \mathrm{~m}^{2}$. The modeling was based on first principles analysis of the area needed to reject the identified heat load to the surroundings through convection and radiation.

From the required area a series of scaling equations were used to determine the mass of the radiator. The radiator is broken into the following components: panel, coating, tubing, header, adhesive, stringer, attachment. Worst-case thermal environment of 1.0 AU (Earth orbit) thermal was used to size the radiator.

MLI insulation was used to insulate the S/C and minimize heat loss for deep space operation. MLI is constructed of a number of layers of metalized material with a nonconductive spacer between the layers. The metalized material has a low absorptivity that resists radiative heat transfer between the layers. The insulation can be molded to conform over the exterior of the $\mathrm{S} / \mathrm{C}$ or any individual component.

Shielding against GCRs can be accomplished with a variety of materials that absorb the charged nuclear particles. An alternate approach is to utilize an electromagnetic field generated around the S/C to deflect the incoming particles. This approach would be power intensive and would need a period of technology development to make it a feasible alternative.

4. Environmental Control Trades

Shielding Integration Options

- Water in cells surrounding crew

- Reuse as thermal control radiators, glycol mix

- Allow to freeze to eliminate slosh

- Pump in from tanks once TransHab is deployed

- $\mathrm{LH}_{2}$

- Main propellant tanks around habitat

- Small doughnut tanks around habitat

The shielding can be placed along the outer bulkhead outside of the work and or living area. The total dosage on the occupants due to GCRs would be dependent on the amount and location of the shielding and the phase of the mission. The cosmic ray dose estimates at different phases of the mission are listed in Table 15. 


\section{Environmental Models}

The environmental models used were those that model solar intensity based on $\mathrm{S} / \mathrm{C}$ location. Components were sized for worst case operating conditions, heat rejection: near Earth, minimum temperature: deep space transit. The overall vehicle environment assumptions for thermal modeling were as follows:

- LEO operation (warmest thermal environment)

- Micrometeor shielding based on space station design (Ref. 4). The sizing is based on vehicle orientation.

All exposed areas of each section were covered with shielding.

- Radiator panels (placement, sizing) primarily sees Deep Space

- Maximum angle to the Sun $15^{\circ}$

- View factor of 0.3 to the Earth

- View Factor of 0.05 to the Moon

- Operating temperature $320 \mathrm{~K}$

- Graphite composite radiator with micro-meteor shielding over exposed heat pipe

- MLI around RCS tanks, foam insulation on propellant lines

- $\quad$ MLI around S/C sections (layers of MLI, MLI placement)

- Electrical heaters for RCS tanks and propellant lines

- Thermal control of propellant lines and tanks

- Component heating (electric heaters and/or RHUs)

- Avionics and Power Management and Distribution (PMAD) cooling (number of cold plates, heat pipe length)

- Cold plates and heat pipes used to transfer heat to the radiator panel

Systems Modeled

\section{Radiator}

The radiator system utilized a series of cold plates, heat pipes and a radiator panel to collect and reject the excess heat produced by the S/C to space. The radiator panel area has been modeled along with an estimate of its mass. The model was based on first principles analysis of the area needed to reject the identified heat load to space. From the area, a series of scaling equations were used to determine the mass of the radiator for operation under the worst case conditions. LEO thermal environment was used to size the radiator. From the calculated required radiator area a series of scaling equations were used to determine the mass of the radiator. Table 19 lists the assumptions used in modeling the radiator.

Table 19. Operating and Environmental Variables Used to Size the Radiator

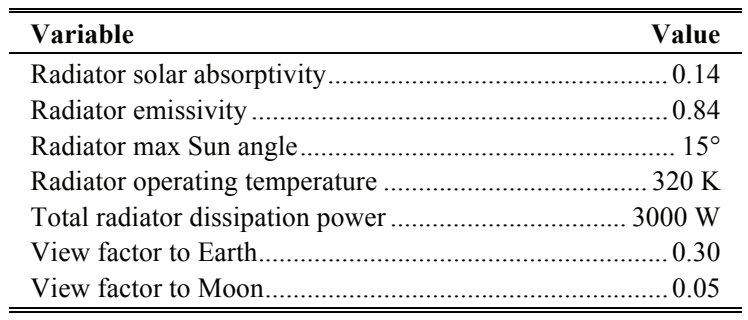

Due to the varying environmental conditions of the mission, louvers were used to control the heat loss from the radiators. Louvers are active or passive devices that regulate the amount of heat rejected by the radiator. Active controlled louvers use temperature sensors and actuators to control the louver position. Passive controlled louvers commonly use a bimetallic spring that opens and closes the louver based on temperature. The louver specific mass is $4.5 \mathrm{~kg} / \mathrm{m}^{2}$.

\section{Electronics, Avionics and Payload Cooling}

Thermal control of the electronics and Active Thermal Control System (ATCS) is accomplished through a series of cold plates and heat pipes to transfer the excess heat to the radiators. The model for sizing these components was based on a first principles analysis of the area needed to reject the identified heat load to space. From the sizing a series of scaling equations were used to determine the mass of the various system components. The specification of the heat collection system is given in Table 20 . 
Table 20. Heat Collection Component Specifications

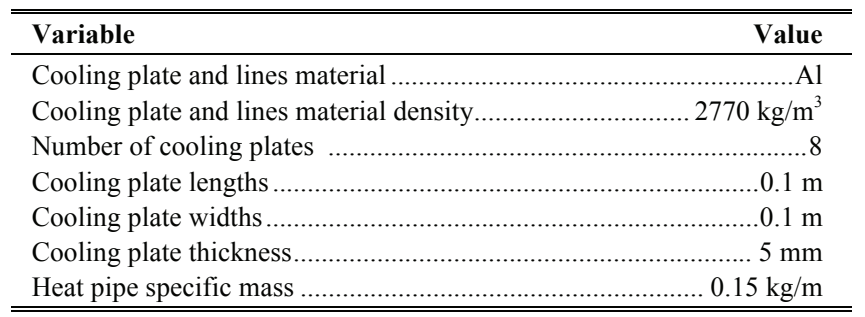

Propellant System Thermal Control

Power requirements and mass have been modeled for thermal control of the propellant system. This modeling included propellant tank MLI and heaters and propellant line insulation and heaters. The model was based on a first principles analysis of the radiative heat transfer from the tanks and propellant lines through the S/C structure to space. The heat loss through the insulation set the power requirement for the tank and line heaters. The deep space thermal environment was used to calculate the heat loss. This diagram is representative of the relationship between the number of layers of insulation utilized and the heat loss and mass of the insulation. This diagram illustrates that the mass of the insulation will increase linearly with an increasing number of layers, however the reduction in heat loss levels off with increasing number of layers. Therefore for a specific area being insulated and a given operating environment, the insulation will provide the biggest benefit in reducing heat loss for a minimal amount of mass.

The propellant tanks and lines required a combination of heaters and insulation to maintain their correct operating temperature. The assumptions for modeling the thermal components used to protect the propellant lines and Tanks were as follows. The model was based on a first principles analysis of the radiative heat transfer from the tanks and propellant lines to space. The heat loss through the insulation set the power requirement for the tank and line heaters. A deep space thermal environment was used to calculate the heat loss.

$S / C M L I$

The S/C MLI insulation was modeled to determine its mass and heat loss. The model was based on a first principles analysis of the heat transfer from the $\mathrm{S} / \mathrm{C}$ through the insulation to space. The near Earth thermal environment was used to size the S/C MLI insulation. The modeling was similar to that used to model insulation on the propellant tanks.

$M M O D$

For reliable operation within the LEO environment a micro-meteor shield will be needed to protect critical components of the vehicle. The MMOD shielding was based on the space station design given in Reference 3. To further component integration, the MLI is positioned within the MMOD shielding.

The MMOD shielding configuration is based on that designed for the International Space Station (ISS), which is shown in Figure 38. The MMOD consisted of $2 \mathrm{~mm}$ layer of $\mathrm{Al}$, six layers or Nextal and six layers of Kevlar. This figure provides a notional diagram of the layers of MMOD protection as used in the ISS design.

\section{Radiation Shielding}

The cosmic ray dose was calculated for the mission duration base on the amount of time in Earth orbit, transit and mars orbit. The dose was determined from the amount of shielding provided by either the water or $\mathrm{LH}_{2}$. The GCR shielding provided by both $\mathrm{LH}_{2}$ and water is shown in Figure 39. This figure shows the ratio of the actual dose, $\mathrm{H}(\mathrm{x})$ to the unshielded dose $\mathrm{H}(\mathrm{o})$ for a given areal density of the shield material, $x$. From this figure, using the density of water $\left(1000 \mathrm{~kg} / \mathrm{m}^{3}\right)$ and $\mathrm{LH}_{2}\left(71 \mathrm{~kg} / \mathrm{m}^{3}\right)$, the required thickness and subsequent shield mass can be determined.

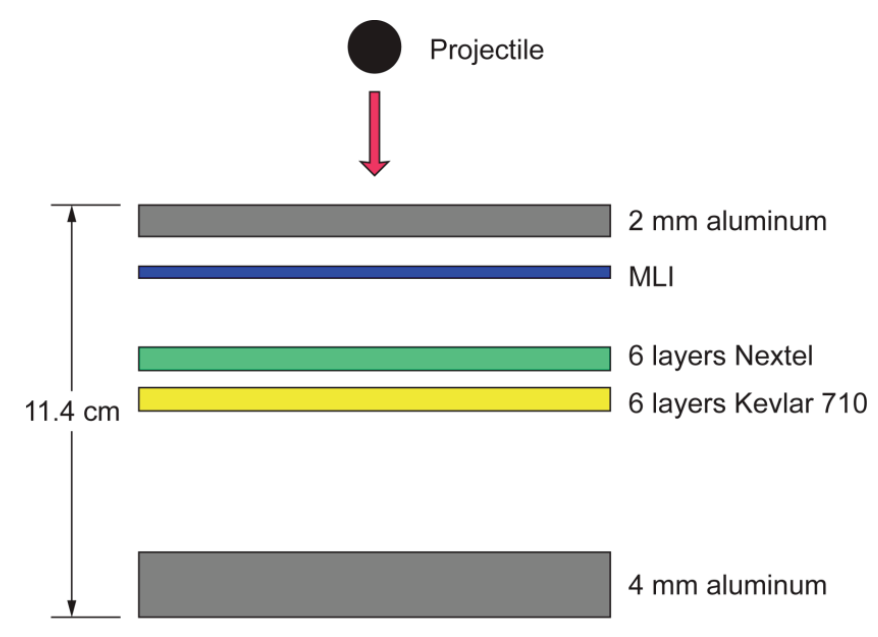

Figure 38. MMOD Space Station shielding configuration (Ref. 1). 


\section{Environmental Control Risk Inputs}

Since the majority of the thermal and environmental system is passive the chance of a failure is fairly low. However, if a component does fail due to thermal cycling or some other means of applied stress then consequences to the vehicle and its system could be significant.

\section{F. Environmental Control \& Life Support Systems (ECLSS)}

The ECLSS consisted of the following items.

- Environmental control and life support (air revitalization system, atmospheric revitalization pressure control system, supply water and waste water system, waste collection system and airlock support system)

- Crew accommodations (food, water clothing, etc.)

- EVA systems (suits, etc.)

- Med Ops

- Crew

- Contingency food and waste

1. ECLSS Requirements

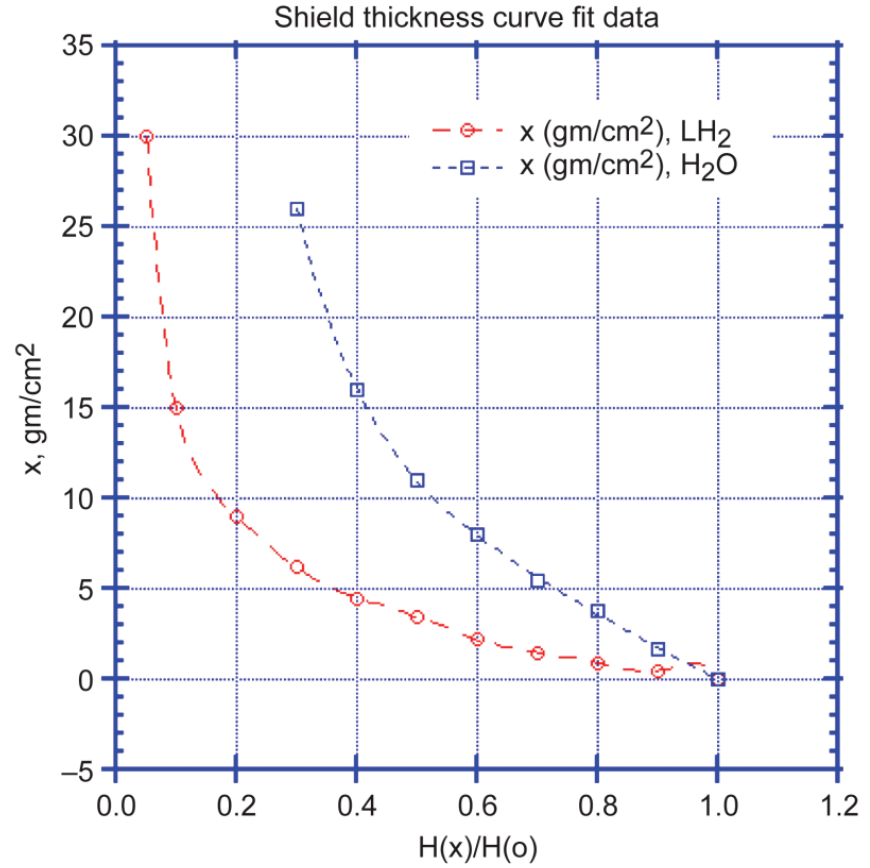

Figure 39. GCR shielding properties of $\mathrm{LH}_{2}$ and $\mathrm{H}_{2} \mathrm{O}$ (Ref. 7.).

The ECLSS requirements are to provide a habitable and life sustaining environment for the crew throughout the mission. This includes maintaining a breathable atmosphere within the S/C. This includes controlling pressure, humidity, oxygen, carbon dioxide and carbon monoxide levels.

Also the ECLSS provides all of the daily and operational needs for the crew, such as food, clothing EVA suits and medical equipment and supplies.

2. ECLSS Assumptions

The ECLSS sizing was taken from the design for the DRA 5.0 and documented in the report, JSC-63743 Preliminary Assessment of Artificial Gravity Impacts to Deep-Space Vehicle Design, Released February 2007.

3. ECLSS Design

The COMPASS team used the DRA 5 habitat in the HERRO design and applied these masses in the ECLSS subsystem MEL shown in Table 21.

Table 21. CTCV Power and Propellant TransHab Element MEL

\begin{tabular}{|c|c|c|c|c|c|c|c|c|c|c|c|c|}
\hline WBS & Description & QTY & $\begin{array}{r}\text { Unit } \\
\text { Mass }\end{array}$ & Basic Mass & Growth & Growth & $\begin{array}{l}\text { Total } \\
\text { Mass }\end{array}$ & $\begin{array}{l}\text { Power } \\
\text { Mode } 1\end{array}$ & $\begin{array}{l}\text { Power } \\
\text { Mode 2 }\end{array}$ & $\begin{array}{l}\text { Power } \\
\text { Mode } 3 \\
\end{array}$ & \begin{tabular}{|c} 
Power Mode \\
$\mathbf{4}$
\end{tabular} & \begin{tabular}{|c} 
Power Mode \\
5
\end{tabular} \\
\hline Number & Crew Telerobotic Control Vehicle (CTCV) & & (kg) & (kg) & $(\%)$ & (kg) & (kg) & (W) & (W) & (W) & (W) & (W) \\
\hline 06 & Crew Telerobotic Control Vehicle & & & 435329 & & 20034 & 455362 & 22964 & 23246 & 23888 & 25099 & 25373 \\
\hline 06.1 & Core Element & & & 126473 & & 5521 & 131994 & 1198 & 498 & 1316 & 1334 & 1432 \\
\hline 06.2 & In Line Tank & & & 131885 & & 4156 & 136041 & 765 & 114 & 883 & 941 & 999 \\
\hline 06.3 & Saddle Truss and dropped Tank & & & 129547 & & 6225 & 135772 & 732 & 64 & 180 & 240 & 298 \\
\hline 06.4 & TransHAB and Payload & & & 47425 & & 4132 & 51555 & 20270 & 22569 & 21509 & 22584 & 22644 \\
\hline 06.4 .1 & Attitude Determination and Control & & & 1088 & $15.0 \%$ & 163 & 1251 & 269 & 269 & 269 & 269 & 269 \\
\hline 06.4 .2 & Command and Data Handling & & & 1112 & $17.5 \%$ & 194 & 1307 & 922 & 922 & 787 & 787 & 787 \\
\hline 06.4 .3 & Communications and Tracking & & & 1039 & $26 \%$ & 271 & 1310 & 79 & 2378 & 1453 & 2528 & 2588 \\
\hline 06.4 .4 & Electrical Power Subsystem & & & 1413 & $32 \%$ & 452 & 1865 & 0 & 0 & 0 & 0 & 0 \\
\hline 06.4 .5 & Environmental Control (Non-Propellant) & & & 15500 & $1 \%$ & 186 & 15685 & 0 & 0 & 0 & 0 & 0 \\
\hline $06.4,6$ & Propulsion Hardware & & & 194 & $15 \%$ & 29 & 223 & 0 & 0 & 0 & 0 & 0 \\
\hline 06.4 .7 & Propellant & & & 3788 & $0 \%$ & 3 & 3791 & 0 & 0 & 0 & 0 & 0 \\
\hline $06,4,8$ & Structures and Mechanisms & & & 8092 & $21 \%$ & 1678 & 9770 & 0 & $\mathbf{0}$ & $\mathbf{0}$ & 0 & 0 \\
\hline 06.4 .9 & ECLSS & & & 15200 & $8 \%$ & 1154 & 16353 & 19000 & 19000 & 19000 & 19000 & 19000 \\
\hline 06.4.9.a & Environmental conrol and life support & 1.00 & 5030.00 & 5030.00 & $15.0 \%$ & 754.50 & 5784.50 & 7000 & 7000 & 7000 & 7000 & 7000 \\
\hline $06.4 .9 . b$ & Crew accomodations (food, water, clothing, etc) & 6.00 & 280.40 & 1682.40 & $0.0 \%$ & 0.00 & 1682.40 & 0 & 0 & 0 & 0 & 0 \\
\hline $06.4 .9 . c$ & EVA systems (suits, etc) & 1.00 & 1613.00 & 1613.00 & $15.0 \%$ & 241.95 & 1854.95 & 9000 & 9000 & 9000 & 9000 & 9000 \\
\hline $06.4 .9 . d$ & Med Ops & 1,00 & 1048.00 & 1048.00 & $15.0 \%$ & 157.20 & 1205.20 & 3000 & 3000 & 3000 & 3000 & 3000 \\
\hline $06.4 .9, \mathrm{e}$ & Crew & 6.00 & 81.82 & 490.91 & $0.0 \%$ & 0.00 & 490.91 & 0 & 0 & 0 & 0 & 0 \\
\hline $06.4 .9 . f$ & Contingency food + waste & 6.00 & 889.20 & 5335.20 & $0.0 \%$ & 0.00 & 5335.20 & 0 & 0 & 0 & 0 & 0 \\
\hline
\end{tabular}




\section{G. Propulsion and Propellant}

The need for exceptional propulsion system performance for missions to Mars has been documented in numerous studies and was the focus of the Rover/Nuclear Engine for Rocket Vehicle Application (NERVA) program lasting from 1955 to 1973 . During the programs existence, engineers built and tested 20 reactors and nearly produced a flight-qualified propulsion system.

Current design studies are leveraging the analysis results from the last engine designed during the NERVA program, the Small Nuclear Rocket Engine (SNRE). The SNRE is a monopropellant (hydrogen) expander cycle engine that utilizes heat from a fission reactor instead of chemical combustion to drive the cycle and heat the propellant. This allows the SNRE to develop $875 \mathrm{sec}$ of Isp, with the potential reach well over $900 \mathrm{sec}$ with upgrades in materials, fissile loading techniques, or by varying the length or radius of the engine design.

1. Propulsion and Propellant Requirements

In order to meet mission requirements and keep the amount of propellant launched into LEO manageable, the main propulsion system is required to deliver both a large amount of thrust and as high an Isp as possible. In order to meet mission requirements, three $111.2 \mathrm{kN}$ ( $25 \mathrm{klbf})$ NTR engines are required. An axial growth variant of the SNRE design is used for this study. All three engines are gimbaled to provide thrust vector control.

Due to the mass of the vehicle, a relatively large RCS motor is required to provide adequate control of vehicle orientation. It is also required that the loss of a single thruster does not cause loss of mission, thus some redundancy in the RCS is provided.

Propellant for both the main propulsion system and the RCS is to be stored and provided at the conditions and flow rates required by the main propulsion system and the RCS. The length of the mission will require a propellant refrigeration system in order minimize propellant boil-off of the cryogenic propellants.

2. Propulsion and Propellant Assumptions

It is assumed that as many COTS components as possible be used in order to reduce cost and increase reliability. Propellant boil-off is assumed to be controlled with an active cooling system and insulation. The three main tanks are assumed to have an identical diameter, with their length adjusted for fuel load as determined by both launch vehicle constraints and mission design. Due to the size of the main propellant tanks, an autogeneous propellant pressurization system is assumed.

RCS propulsion is assumed to be provided by appropriately sized thrusters, with the hydrazine and NTO (MON3) propellants stored in COTS tanks. Gaseous nitrogen will provide RCS pressurization.

\section{Propulsion and Propellant Design}

The various subcomponents in the design of the propulsion system for the CTCV are captured in the subsections below.

\section{Main Propulsion}

For this analysis, an axial growth variant of (SNRE) with a $132 \mathrm{~cm}$ (52 in.) fuel element length, higher propellant through put, and 300:1 area ratio nozzle delivering $900 \mathrm{sec}$ of Isp is used to provide primary vehicle propulsion. A typical NERVA derived NTR engine is shown in Figure 40.

These engines have both an internal and external radiation shield to provide adequate crew protection during engine operation. All three engines are gimbaled, and utilize a dual turbo-pump design for additional operational reliability.

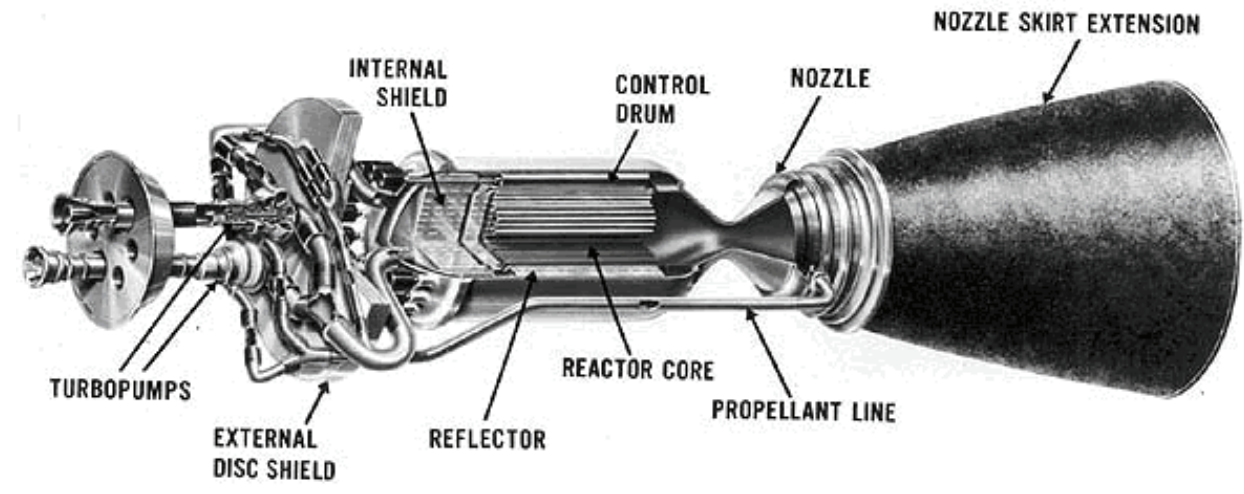

Figure 40. NERVA derived NTR engine.

The hydrogen monopropellant for the main propulsion system is stored in three tanks; the saddle, in-line and core. The saddle tank is designed to perform the entire TMI burn, and then be jettisoned. The in-line and core tanks 
remain with the vehicle for the duration of the voyage. A boil-off reduction system is utilized in conjunction with MLI and foam to keep the hydrogen cold during the entire voyage and vehicle assembly in LEO. Additional tank features include an additional 3\% volume for ullage, $0.3 \%$ margin on volume for manufacturing tolerance, slosh baffles, structural skin, foam insulation, MLI, and MMOD protection.

The main valves between the tanks and the primary fuel valve are pneumatically operated from gaseous nitrogen filled spherical Ti alloy COTS tanks located at the base of the corresponding fuel tank. The valve and nitrogen gas tank assembly at the base of the saddle tank are jettisoned with the saddle tank post TMI. The pressurant tanks selected and their locations on the vehicle are shown in Table 22.

Table 22. Pneumatic Storage Tanks

\begin{tabular}{|c|c|c|c|}
\hline Tank Model & Location & Volume & Dimensions \\
\hline ATK 80326-1 & Saddle Tank & $3.851\left(235\right.$ in. $\left.^{3}\right)$ & $19.5 \mathrm{~cm}$ (7.66 in.) diameter \\
\hline ATK $80202-1$ & In-Line Tank & $14.51\left(886\right.$ in. $\left.^{3}\right)$ & $31.7 \mathrm{~cm}$ (12.5 in.) diameter \\
\hline ATK 80383-1 & Saddle Tank & $36.01\left(2,200\right.$ in. $\left.^{3}\right)$ & $41.6 \mathrm{~cm}$ (16.4 in.) diameter \\
\hline
\end{tabular}

All three propellant tanks are autogenously pressurized during engine operation. During engine chill-down and startup, a set of tanks containing high pressure hydrogen gas provides propellant pressurization. These COTS tanks (ATK 80458-101) are sized to provide $5 \mathrm{sec}$ of full propellant to all three engines and are subsequently refilled with hydrogen from the autogeneous pressurization system during engine operation, thus negating the need for copious quantities of helium and the mass of the related storage tanks. The typical start-up sequence for a NTR engine in this class is approximately $30 \mathrm{sec}$, with the reactor core temperature increasing at a nominal $80 \mathrm{~K} / \mathrm{s}$ and propellant flow rate increasing accordingly. As the engines start up, the autogeneous pressurization system will take over from the tanks at about $10 \%$ of full engine power, thus giving the system ample margin during start up. A schematic this system is shown Figure 41.

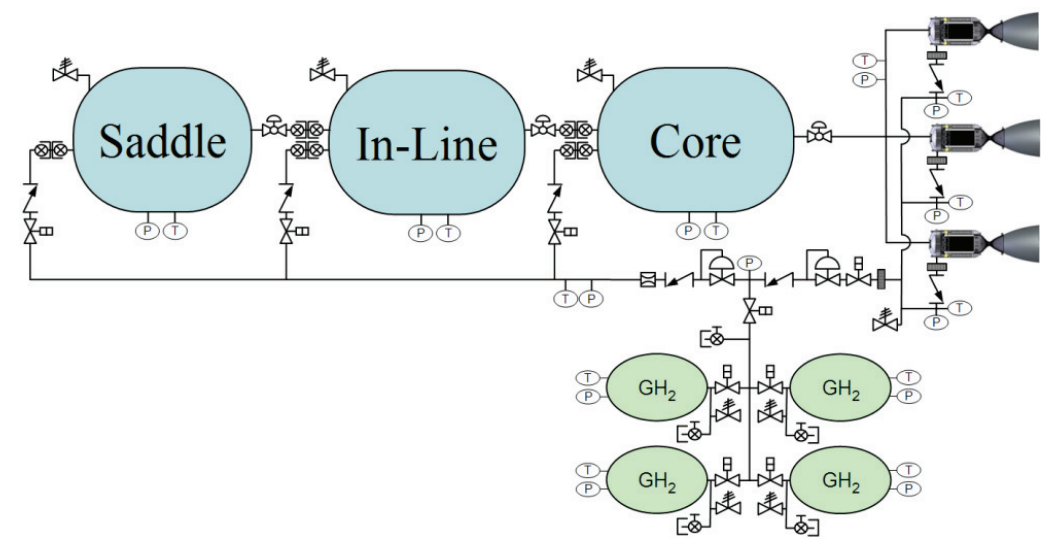

Figure 41. Propellant system schematic.

During operation, the propellant is fed through the tanks is a serial fashion, so that the core tank always feeds the main engines while being replenished by the in-line tank. The in-line tank, however, only receives propellant from the saddle tank during TMI, after which the saddle tank is jettisoned. A depiction of this sequence is shown in Figure 42.

\section{Cryogenic Management}

The Cryogenics subsystem preserves and delivers the cryogenic liquid hydrogen required for main engine propulsion. It is comprised of: Tank Insulation, Tank Pressure Control, and Propellant Acquisition Strategies. Cryogenic feed lines and Tank Pressurization are also important issues for cryogenics although they have been discussed in the propulsion and propellant management section.

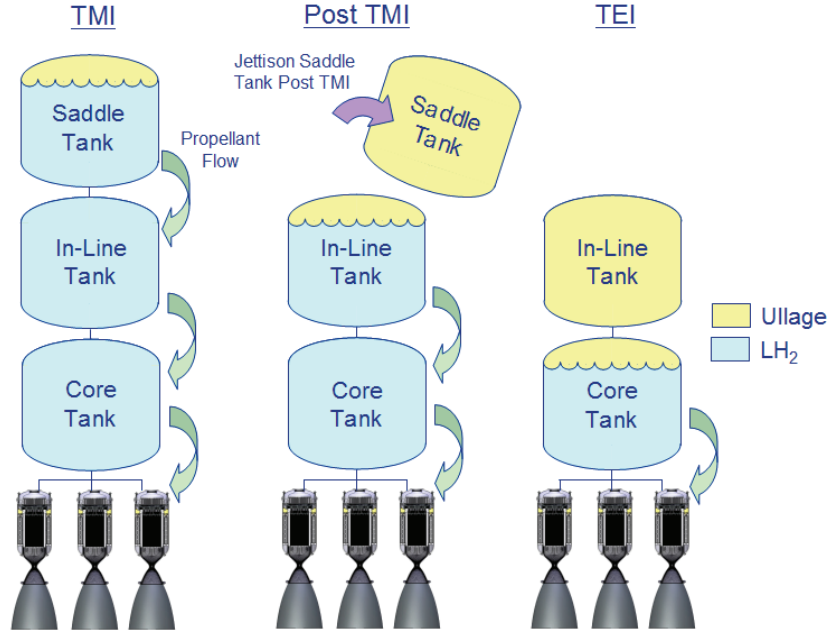

Figure 42. Propellant flow sequence. 
Ground Hold insulation is provided by foam. Foam insulation prevents the formation of liquid air and freezing of water vapor on the tanks prior to lift-off. Spray-On Foam Insulation (SOFI) like that used on the Space Shuttle external tank is used for this study as it has been extensively characterized and its thermal properties are well known. $0.5 \mathrm{in}$. of foam is applied to the tanks.

The tanks are filled and vented continuously on ground T-0 umbilical. Foam does not provide sufficient insulation to prevent significant boil-off while waiting for lift-off. Therefore cryogenic tanks must be continuously replenished until lift-off. This is done routinely for all current cryogenic launch vehicles.

The hydrogen tank is pressurized autogenously by gaseous hydrogen from the engine cooling channels. Prior to engine start the hydrogen tank will be pressurized with helium using external helium stores.

Intermittent propellant settling will be used instead of the continuous settling approach used by Saturn IV. Continuous settling more than a few hours will require large quantities of RCS propellant. Intermittent propellant settling is used on all modern upper stages for low-gravity coast.

MLI was selected for On-Orbit thermal protection of the tanks. Previous studies have shown that this is the only viable insulation for missions over a few hours.

NASA Glenn's Cryogenic Analysis Tool (CAT) was used to evaluate the performance of the cryogenic propellant storage system design. Documentation of CAT models as well as previous usage is found Guernsey 2005, and Plachta 2002. Table 23 shows cryogenic system masses and power consumption estimated by the CAT.

Table 23. Cryogenic System Properties

\begin{tabular}{|c|c|c|c|c|c|}
\hline Units & $\begin{array}{c}\text { Insulation } \\
\text { (kg) }\end{array}$ & $\begin{array}{c}\text { Cryocoolers } \\
(\mathrm{kg})\end{array}$ & $\begin{array}{c}\text { Boil-Off } \\
(\mathrm{kg})\end{array}$ & $\begin{array}{c}\text { Total } \\
\text { (kg) }\end{array}$ & $\begin{array}{c}\text { Power } \\
(W)\end{array}$ \\
\hline \multicolumn{6}{|c|}{ Two Stage Cooler } \\
\hline Core & 1355 & 1638 & 0 & 2994 & 17013 \\
\hline In-Line & 1173 & 3008 & 0 & 4181 & 18484 \\
\hline Saddle & 1098 & 3078 & 0 & 4176 & 18690 \\
\hline \multicolumn{6}{|c|}{ Single Stage Cooler/Shield } \\
\hline Core & 1355 & 519 & 3045 & 4919 & 804 \\
\hline In-Line & 1173 & 452 & 891 & 2516 & 713 \\
\hline Saddle & 1098 & 490 & 313 & 1901 & 670 \\
\hline
\end{tabular}

To achieve the hydrogen storage times required by the HERRO mission additional measures are required beyond just insulating with MLI. To achieve the storage times required an actively powered cryocooler system was added to refrigerate the storage tanks. A system with no boil-off loss would require a cryocooler capable of reaching the $20 \mathrm{~K}$ temperature of liquid hydrogen. Thermodynamic efficiency considerations nearly always force this to be done in two stages one stage operating from space ambient temperature to $90 \mathrm{~K}$ and one stage operating between 90 and $20 \mathrm{~K}$. Although this zero boil-off system has been proposed for previous Mars missions (Borowski, 2009) preliminary CAT tool sizing estimated substantial system dry mass and electrical power consumption. To reduce weight an alternate system was proposed (Plachta, 2008). This design uses a single stage cryocooler working between ambient and $90 \mathrm{~K}$ to cool a lightweight shield, which encloses the hydrogen tanks. CAT tool analysis of this system resulted in an order of magnitude reduction in dry mass and power. Although the cooled shield system does result in a significant of hydrogen lost to boil-off (roughly $0.5 \%$ per month), this is still a lighter system for the saddle and inline tanks. Even though for the core tank with longest storage duration the single stage mass is heavier by $1975 \mathrm{~kg}$, it believed that is weight will be more than offset by weight reductions in power system going from 17013 to $804 \mathrm{~W}$ (more than a twentyfold reduction in power).

It is believed that the cryogenic management system estimate represents a reasonable estimate of the weight, power and cooling requirements of the proposed mission. Areas likely to require technology work include Multilayer insulation and the single stage cooler/shield thermal protection system. A more detailed design trade between the zero-boil off and cooled shield system may be warranted, especially for the core stage.

RCS

The RCS system consists of four pods each containing four Advanced Material Bipropellant Rocket (AMBR) engines (an R-4D derivative). Due to the length of the vehicle, it seems impractical to centrally locate the RCS propellant tanks and then run propellant lines to the engine pods. Therefore, the total RCS propellant and pressurant load is evenly divided between two sets of tank located at each end of the vehicle. This creates two identical halves which comprise the entire RCS, with each half located at opposite ends of the vehicle. Each half is consists of three 
hydrazine tanks, three NTO (MON3) tanks, a single nitrogen pressurant tank, eight AMBR engines, tank and line heaters, MLI, and a nominal feed-system, as shown in Figure 43.

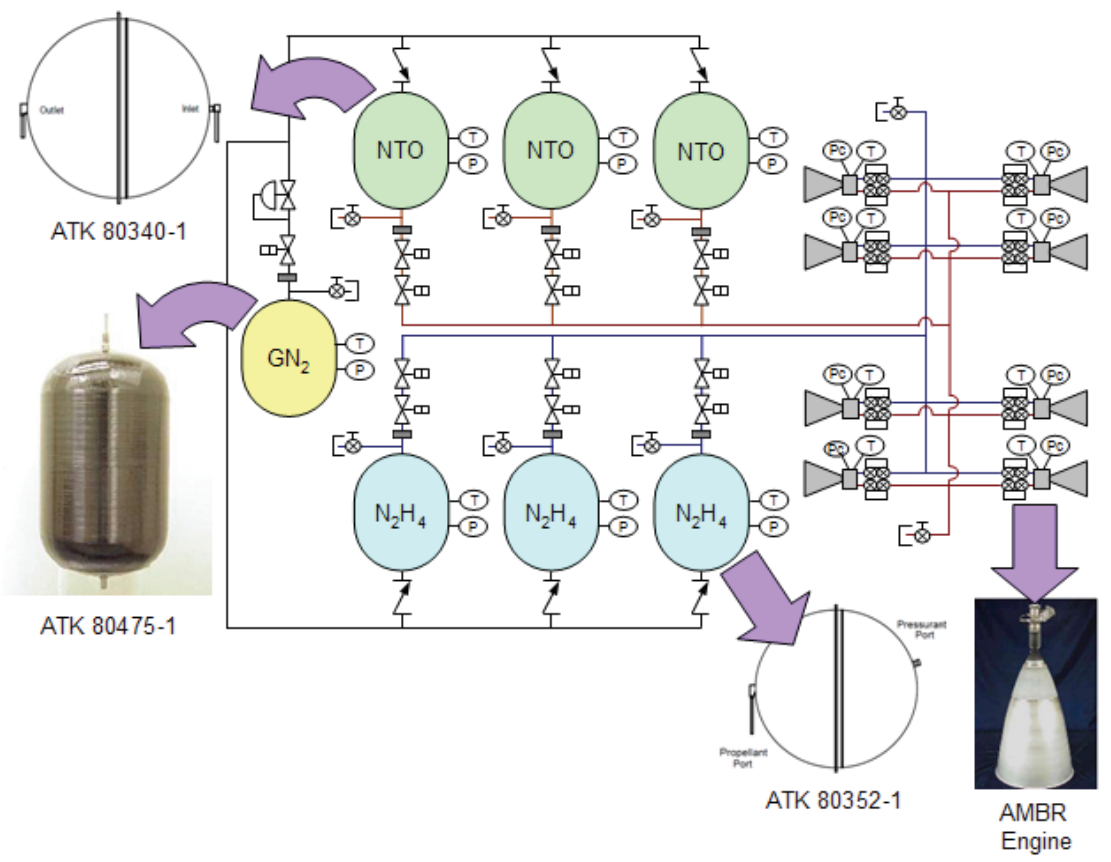

Figure 43. RCS schematic.

Both the propellant and pressurant tank are COTS, and their specifics are listed in Table 24. The propellant tanks contain internal propellant management devices.

Table 24. RCS Tank Data

\begin{tabular}{|c|c|c|c|}
\hline Tank & Type & Volume & Dimensions \\
\hline ATK 80340-1 & 6Al-4V Ti Sphere & $5001\left(30,728\right.$ in. $\left.^{3}\right)$ & $99 \mathrm{~cm}$ (38.97 in.) diameter \\
\hline ATK 80352-1 & 6Al-4V Ti Sphere & $6461\left(30,440\right.$ in. $\left.^{3}\right)$ & $106.7 \mathrm{~cm}$ (42 in.) diameter \\
\hline ATK 80475-1 & COPV w/ Ti Liner & $871\left(5309\right.$ in. $\left.^{3}\right)$ & 42.4 by $86.3 \mathrm{~cm}$ ( 16.7 by 34 in.) \\
\hline
\end{tabular}

\section{Propulsion and Propellant Trades}

There were no propulsion or propellant management trades conducted for this analysis.

5. Propulsion and Propellant Analytical Methods

The propulsion system component masses are calculated using available masses from existing hardware, estimated line lengths, and nominal system layouts. If the required hardware (or its data) is non-existent, then a physics based mass model is developed as needed. System layouts are based on historical systems where applicable with modifications as required. Propulsion system components are selected using requirements determined by mission, configuration, thermal, and CONOPS. These requirements typically include propellant load, thrust level, mass, Isp, and volumetric constraints.

6. Propulsion and Propellant Risk Inputs

There were three risk issues identified for detailed risk analysis:

- MMOD damage sustained during time in LEO.

- Freezing of chemical propellant in-lines or tanks.

- Ability to accommodate an incorrectly functioning NTR engine.

- Effect of radiation environment on composite overwrap tanks.

\section{Propulsion and Propellant Recommendation}

Recommended future trades on the propulsion system are:

- A LOX/hydrogen main propulsion system. 
- Usage of hydroxyl-ammonium nitrate (HAN) based monopropellants for RCS. HANs have increased cold temperature tolerance and density relative to hydrazine with similar performance.

\section{H. Structures and Mechanisms}

The NTR Crew Transfer Vehicle is comprised of four basic launch elements. From stem to stern these are the core stage, the inline tank system, the drop tank and saddle truss, and finally the TransHab element. A sideview of the assembled vehicle is illustrated in Figure 44. Pertinent dimension are also given in Figure 44. As shown all the launch element fall within the $30 \mathrm{~m}$ heavy lift vehicle shroud limit.

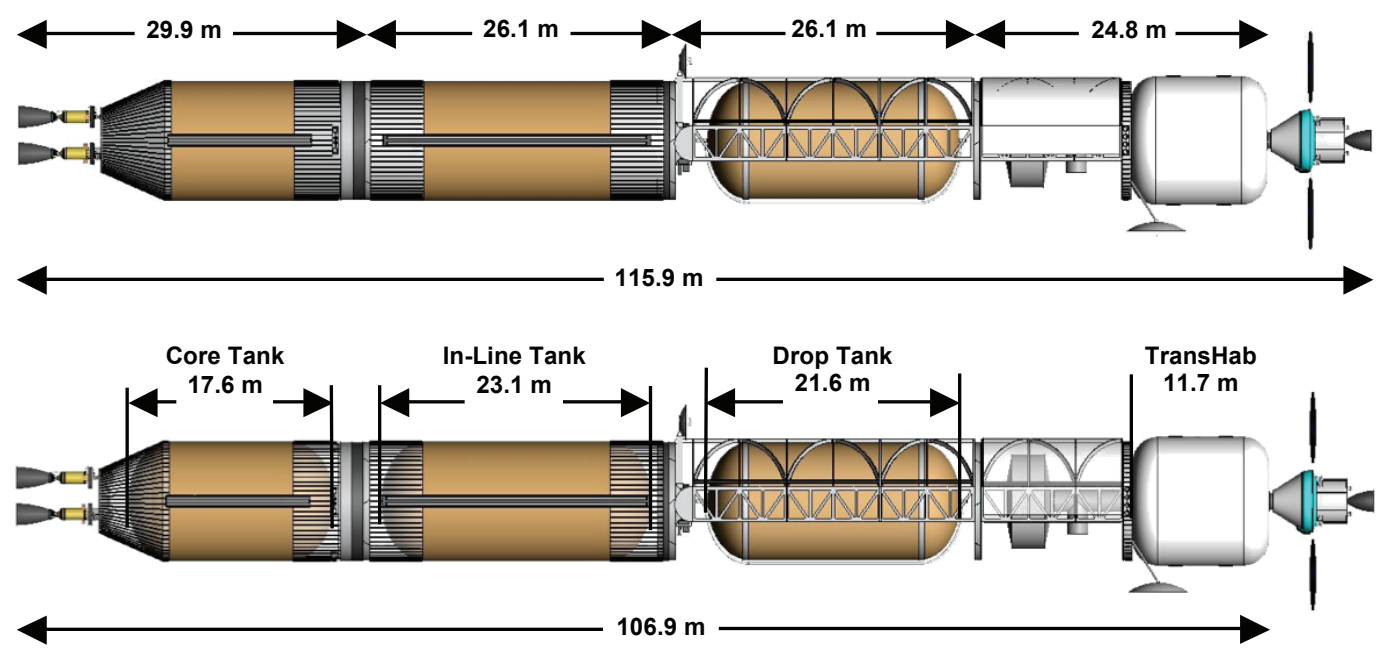

Figure 44. Sideview of the crew transfer vehicle.

\section{Structures and Mechanisms Requirements}

2. Structures and Mechanisms Assumptions

The vehicle elements were sized through either finite element methods or standard hand analysis techniques. Liftoff loads were assumed to be $5 \mathrm{~g}$ ' axial and $2.5 \mathrm{~g}$ 's lateral. The heavy lift vehicle shroud was assumed to accommodate $10 \mathrm{~m}$ diameters by $30 \mathrm{~m}$ long with additional length in the nose cone but at a small diameter. The mass limit for the heavy lift was assumed to be $140 \mathrm{mt}$ not including payload-attaching elements.

Current state of the art $\mathrm{Al} \mathrm{Li}$ fuel tanks were assumed. Additional mass savings are noted to be possible using futuristic composite tanks, which were not used for this study. Composite truss elements were assumed to be current state of the art for the saddle truss and aft thrust structure.

\section{Structures and Mechanisms Design}

\section{CORE Element}

The core stage purpose is to provide the thrust through all phases of the mission. This is done by using three $25 \mathrm{k} \mathrm{lb}$ thrust NTR's arranged in a triangular pattern. The engines are attached to the aft ring of the core tank by a conical thrust structure. The main structural junction for the core stage is the aft ring which is located between the aft end of the cylindrical section and the end of the dome segment. This is the location where the thrust cone mates with the tank and also provides an attachment for the launch adapter. This is illustrated in Figure 45.

The core tank could be launched in one of two orientations. First, the engines could be pointed aft, such that the thrust structure is in tension during launch. This gives the lightest weight structure possible for this system. The other way is to invert the

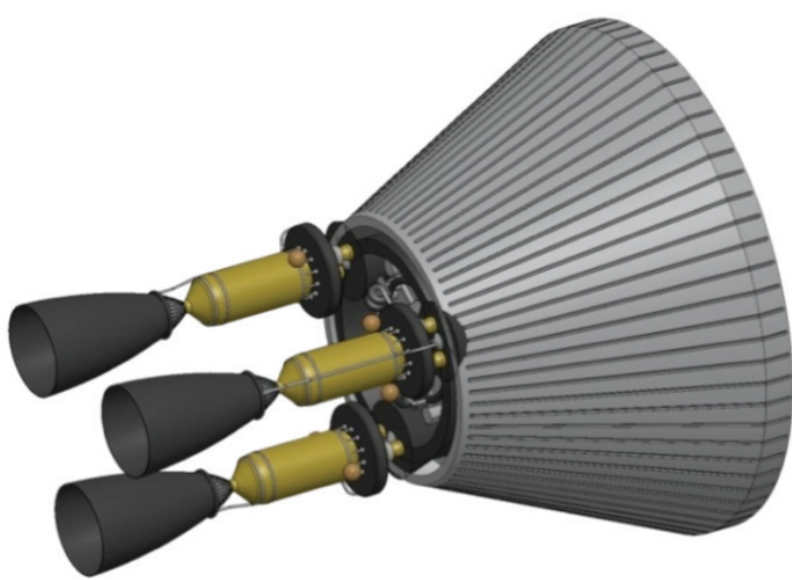

Figure 45. Thrust cone with mated engines. 
tank and launch the engines facing forward as in Figure 46. This means the tank would have to be sized to carry the weight of the three engines and structure. The advantage to the inverted orientation is that longer length tanks can be accommodated because some of the engine nozzle length can be tucked into the nosecone of the shroud. Although the inverted orientation was used for the HERRO mission, the structural masses of the core stage elements were based on the nominal liftoff orientation. In future studies, the structural weights would have to be checked in more detail.

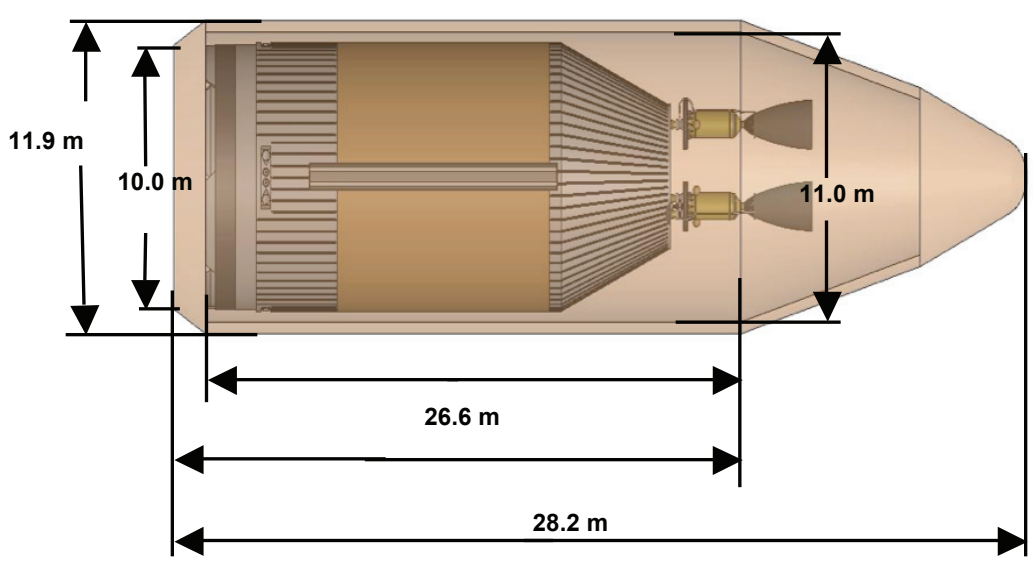

Figure 46. Core element shown in inverted launch position.

The thrust structure basic design is a W-truss shaped as a conic. The truss structure was sized for launch loads with the assumption that liftoff was 5 g's. The FEM was modeled with the vehicle in the standard configuration with engines facing aft. This gave the lightest weight since the truss was mostly in tension during liftoff. Additional sizing may be required if the core were to be flown inverted, because in this orientation the truss would generally be in compression. The general failure mode in compression is usually buckling which tends to require heavier structures to maintain positive margins of safety. This would have to be checked through FEA.

The final main piece of the structure for the core stage is the fuel tank. This tank is assumed to be $9.8 \mathrm{~m}$ inside diameter with square root of 2 elliptical bulkheads on either end. Two main structural rings help join the elliptical and cylindrical tanks sections, and also provide attachment sites for interfaces fore and aft. The tank cylindrical length is sized for the amount of fuel needed to complete the HERRO Mars mission, and the core stage element mass is less than $140 \mathrm{mt}$. It is further assumed that the overall wall thickness of the shells is $10 \mathrm{~cm}$, including structural skin, foam, MLI, MMOD protection and dynamic clearance for liftoff. Therefore, the outer mold line was assumed to be a $10 \mathrm{~m}$ diameter.

The tank materials and structure were assumed to be the current state-of-the-art. The tank was modeled after the Titan launch vehicle tanks. They were assumed to be skin stringer designed all made from Al Li. Unlike launch vehicles, which expend their fuel during flight; the NTR tanks were sized fully loaded from liftoff to orbit.

Other tank features include additional volume, $3 \%$ ullage and $0.3 \%$ manufacturing tolerance. The tank also has internal components such as a liquid acquisition device, a cooler to decrease boil off, as well as plumbing and valving to complete the fuel system. The core stage tank is also the only tank whose aft dome has additional insulation to keep the warmer NTR from transferring its heat to the tank.

\section{In-Line Element}

The inline stage is the simplest structural element of the four launch elements. It is comprised of the inline tank and all its subsystems, a fore and aft cylindrical skirt with the associated stiffening rings that also provide an interface for docking, as illustrated in Figure 47.

The inline tank and skirts are made with skin/stringer construction. They are entirely made from Al Li just like the core tank. The skirt provides more than enough surface area for the tank cooling radiators. Both skirts are assumed identical mirror images of each other. For launch, an expendable payload adapter attaches to the aft tank ring, such that the skirt is only under the load of its own hanging weight and does not have to be strengthened to hold any other mass at launch. 


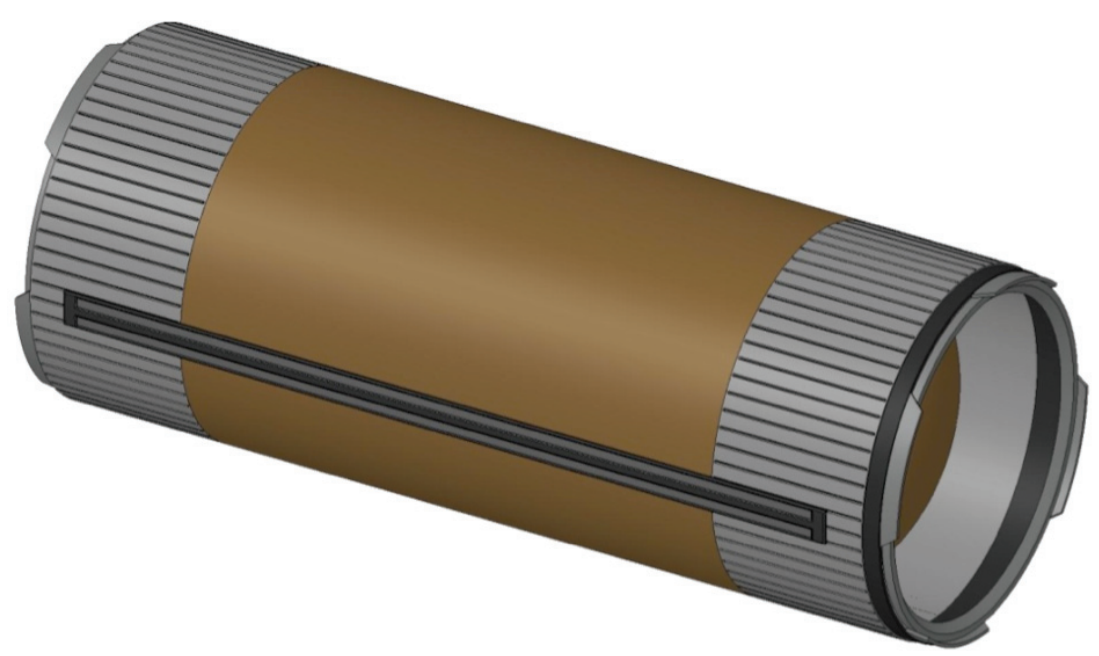

Figure 47. Inline tank launch element with end skirts.

The inline tank is sized with the same assumptions as the core tank. Additional $3 \%$ ullage and $0.3 \%$ manufacturing tolerance volume is provided. The tank also has similar internal components such as a liquid acquisition device, a cooler to decrease boil off, as well as plumbing and valving. Because of its simplicity, the inline stage can have a much longer tank than the core stage before reaching the length limit of $30 \mathrm{~m}$ or the mass limit of $140 \mathrm{mt}$.

\section{Saddle Tank Element}

One of the more interesting launch elements is known as the saddle tank stage. This element has basically two main pieces of structure, the saddle truss and drop tank. Smaller structural elements are a fore and aft ring for docking interface. In order to minimize the total initial mass of the entire vehicle, the drop tank should be sized as large as possible as long as the $30 \mathrm{~m}$ length limit and 140-mt mass limits are maintained. This is because the drop tank is jettisoned early in the mission so that overall fuel and mass savings can be achieved. Figure 48 shows the saddle tank element within its launch shroud.

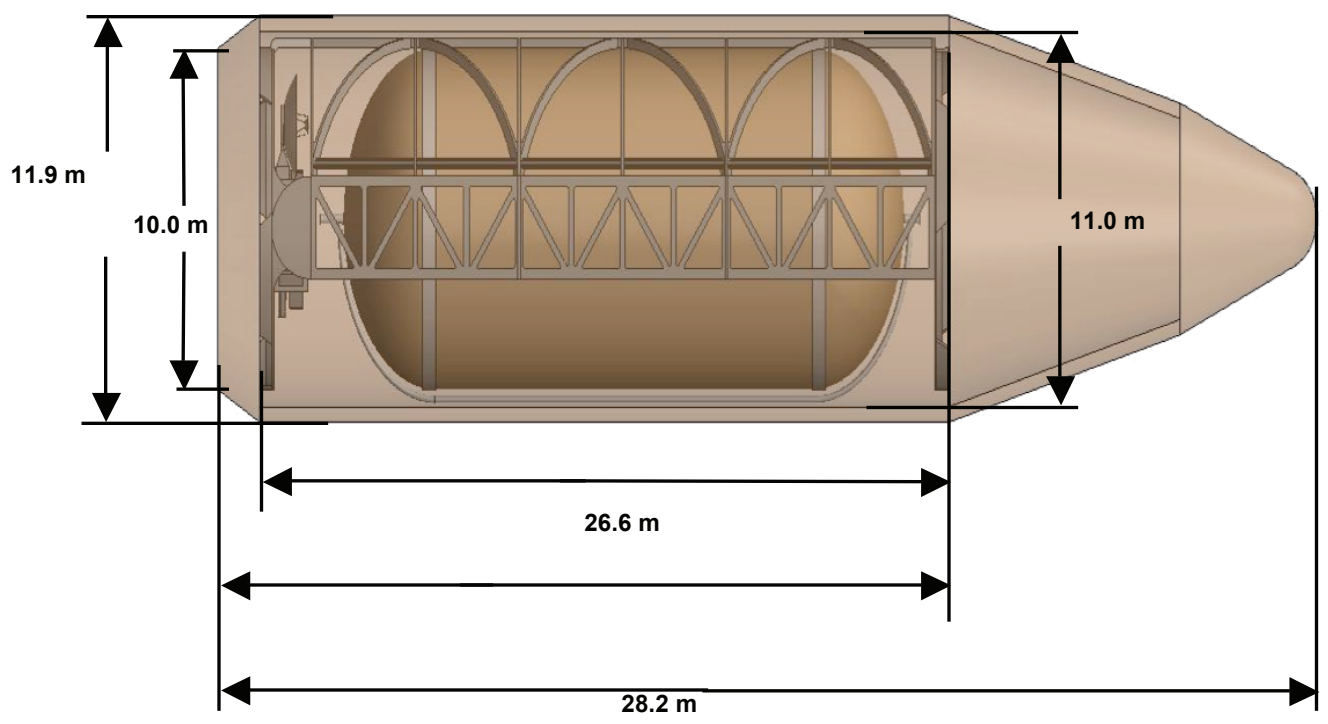

Figure 48. Saddle tank launch element.

The saddle truss is so named because it is U-shaped, just like a saddle as shown in Figure 49. A lightweight composite material was assumed to be used for construction of the truss. The truss structure was sized such that it is made to carry its own weight. This requires the use of expendable payload adapters that support the drop tank to the launch vehicle for liftoff. The drop tank is attached to the truss fore and aft by a separation mechanism. As such, the 
drop tank has two main functions: to carry its fuel to orbit and provide lateral stiffness to the truss. The drop tank is also equipped with separation motors because push off springs should not be used on a long, low frequency type structure.

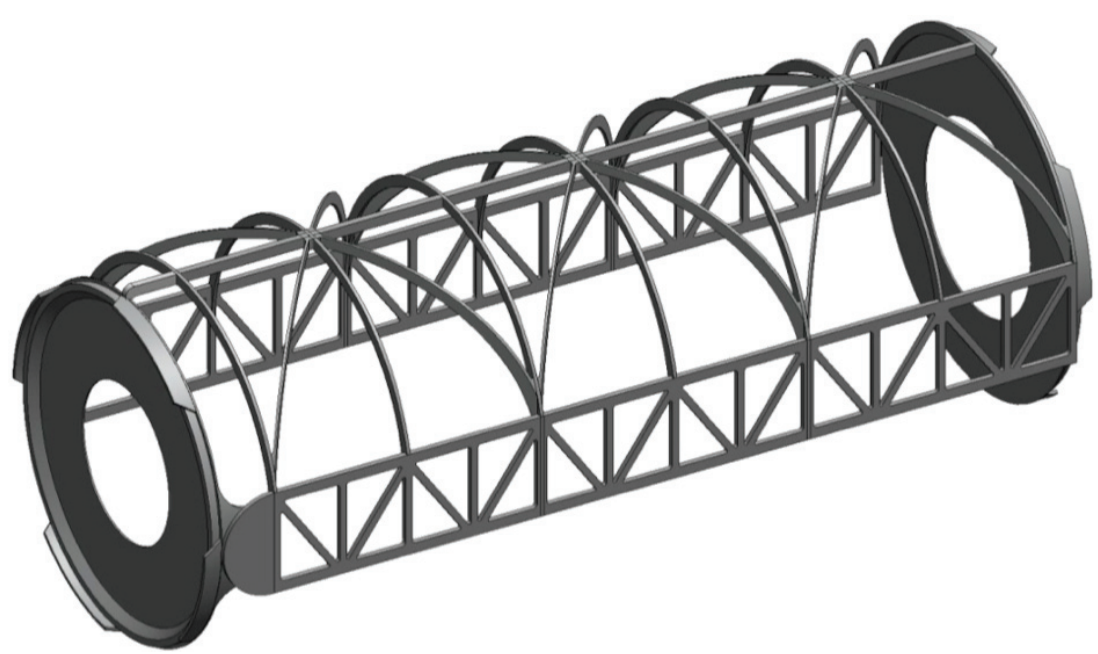

Figure 49. View of the saddle truss without the tank.

The drop tank is made from the same material and construction as the core and inline tanks. However, the drop tank is the only tank that does not use either a fore or aft skirt. The diameter of the tank is assumed to be the same as the other two tanks, even though the truss structure uses a significant portion of the shroud volume. Further refinements to this vehicle model should include a reduced drop tank diameter to account for the truss thickness.

4. Structures and Mechanisms Trades

One structures and mechanisms risk is that fine control of the RCS system is necessary when long and relatively flexible elements are used. This is especially true for the spin-up and spin-down operations for artificial gravity as well as the midcourse corrections. A long narrow and low natural frequency structure maybe unstable in bending and torsionally vibration mode. This should be investigated as a future issue.

\section{Summary and Comparison to DRA 5.0}

This document described the conceptual design of the Crew Telerobotics Control Vehicle (CTCV) that provides astronauts with a platform to operate the landed rovers (trucks and the Rockhounds) as well as transport the crew to/from Mars and protect them from the space radiation and microgravity environments. The design concept shown in Figure 50, starts from the Mars Design Reference Architecture (DRA) 5.0 (NASA/SP-2009-566) crew transfer vehicle using nuclear thermal rockets and an inflatable TransHabitat (TransHab). In addition to the high data rates to provide control and High Definition Television (HDTV) video from the rovers, the CTCV will need the proper radiation shielding and artificial gravity to ensure crew health. The radiation protection for the astronauts will come from water (14 mt) strategically surrounding only the sleeping and working areas of the vehicle where $2 / 3$ of their day are spent. (This trade saves over $30 \mathrm{mt}$ of shielding water that would be needed for the whole TransHab). (Other radiation protection options include plastic spacecraft materials, using the hydrogen propellant to protect the crew and use of electromagnetic shields). Health and fitness of the astronauts will be aided by artificial gravity $(0.38 \mathrm{~g}$, Mars' gravity) created by spinning the CTCV at $2.7 \mathrm{rpm}$ during the 500-d Mars stay (other options which should be explored include advanced exercise techniques to be developed on International Space Station or small centrifuges).

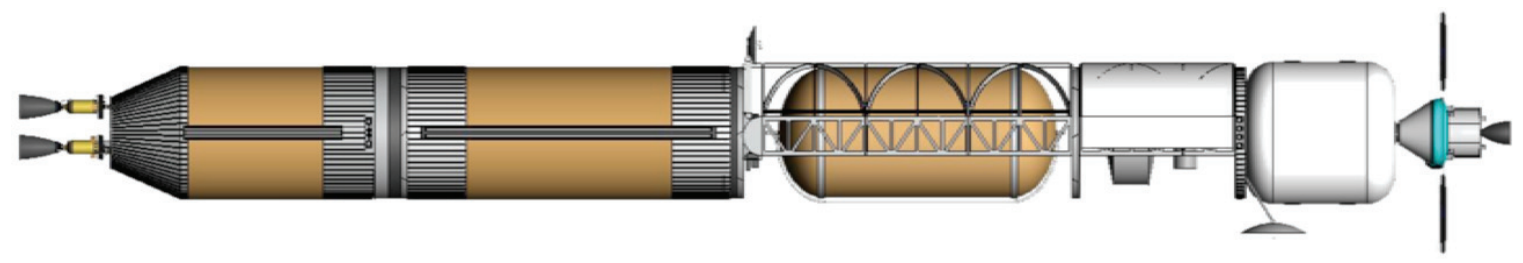

Figure 50. CTCV concept vehicle. 
The HERRO science orbit about Mars utilizes a $12 \mathrm{hr}, 116^{\circ}$ inclined Molniya type orbit to keep the high part of the orbit over the sunlit side of Mars for the $500 \mathrm{~d}$ stay. Using this orbit, two shifts of scientist/teleoperators can explore each side of Mars (using Truck/Rockhounds landed far apart) during each Mars day. Thus the teleoperations equipment will be in use for two 8-hr shifts each Mars day. Compared to the previously completed NASA DRA 5.0 the HERRO concept can perform simultaneous science at three separate sites. The DRA 5.0 required three different campaigns (along with associated crew vehicles, landers, surface reactors etc.) to three different Mars orbital locations to perform what one HERRO campaign could complete. This is partially due to the additional time setting up and maintaining an outpost and caches to support piloted rovers. The HERRO concept should be able to explore the entire globe, whereas the crew may be kept from the poles for the DRA 5.0 mission due to planetary protection concerns. Only in the mass of returned samples does the DRA 5.0 outperform the HERRO concept. The launch vehicle fleet needed for the HERRO approach is also much reduced with only four Ares V class launches and six Evolved Expendable Launch Vehicles (EELV) launches instead of the 21 Ares V class launches for the three DRA 5.0 campaigns. A tabulated comparison of DRA 5.0 and the HERRO concept is shown in Table C.1 to Table C.3Error! Reference source not found. in Appendix C.

The HERRO concept also greatly reduces the needed technologies when compared to the DRA 5.0 which needs additional technologies to land, support a crew on the surface and return to orbit. Keeping the crew in orbit only requires technologies in the areas of long duration crew spaceflight (radiation/artificial gravity), nuclear thermal rockets, long duration cryogenic propellant storage, and telerobotic systems with high definition communication links.

Table 25. Mission and Systems Summary: CTCV

\begin{tabular}{|c|c|}
\hline Subsystem area & Details \\
\hline Top level system & $\begin{array}{l}\text { Transport crew to/from Mars. Provide telerobotics platform for controlling surface science telerobots from } \\
\text { orbit. Provide artificial gravity and radiation protection (below } 75 \text { REM using water) for crew during } 500 \\
\text { day orbital stay. }\end{array}$ \\
\hline $\begin{array}{l}\text { Mission, operations, } \\
\text { guidance, navigation \& } \\
\text { control }(\mathbf{G N \& C )}\end{array}$ & $\begin{array}{l}2033 \text { Earth Mars Opportunity with a } 500 \text { day orbital stay. Retrograde, } 12 \text { hr Molniya orbit to provide } \\
\text { daylight coverage of each side of Mars for two separate science teleoperations shifts. Spin stabilized ( } 2.7 \\
\text { rpm), sun pointed for artificial gravity during Mars orbit. Gimballed NTR for departure/capture burns. }\end{array}$ \\
\hline $\begin{array}{l}\text { Attitude Control System } \\
\text { (ACS) }\end{array}$ & $\begin{array}{l}32 \mathrm{MMH} / \mathrm{NTO} 200 \mathrm{lbf} \text { thrusters for thrusting control, CMGs to damp out precession. Star-trackers, IMUs, } \\
\text { Sunsensors for attitude knowledge. }\end{array}$ \\
\hline Launch & Four Ares V (with Orion launched by Ares I) \\
\hline Science & Four geologist teleoperators for interface with Mars through 6 Rockhounds and 3 trucks \\
\hline Power & $50 \mathrm{~kW}$ fixed solar arrays, batteries for short shadow durations/burn maneuvers \\
\hline Propulsion & $\begin{array}{l}\text { Three } 25 \mathrm{kN} \text { nuclear thermal rockets using hydrogen propellant. } 32 \mathrm{MMH} / \mathrm{NTO} 200 \mathrm{lbf} \text { thrusters for } \\
\text { midcourse corrections and ACS }\end{array}$ \\
\hline Structures and mechanisms & Hydrogen Tank or truss designs for carrying spinning and NTR thrusting loads. \\
\hline Communications & $\mathrm{S}, \mathrm{X}$, and Ka-Band (20 Mbps back to $70 \mathrm{~m} \mathrm{DSN}$ ) \\
\hline $\begin{array}{l}\text { Command \& data handling } \\
\text { (C\&DH) }\end{array}$ & $\begin{array}{l}\text { Triple redundant command system using RAD750 based computers and providing }>10 \text { TB solid state } \\
\text { memory, Two telerobotics control stations }\end{array}$ \\
\hline Environmental & $\begin{array}{l}12 \mathrm{mT} \text { of water to protect crew during work and sleep shifts. Minimize dosage to } 75 \text { rem. Body mounted } \\
\text { radiators. }\end{array}$ \\
\hline
\end{tabular}

\section{Acknowledgments}

The authors would like to acknowledge the COMPASS Team: Les Balkanyi, Stan Borowski, Laura Burke, David Chato, Tony Colozza, Jon Drexler, Ian Dux, James Fincannon, Jim Fittje, John Gyekenyesi, Mike Krasowski, Geoff Landis, Mike Martini, Dave McCurdy, Tom Packard, Carl Sandifer, Tim Sarver-Verhey, George Schmidt, Joe Warner, David Wettergreen, and Glenn Williams.

\section{Appendix A-Acronyms and Abbreviations}

$\begin{array}{llll}\text { AIAA } & \begin{array}{l}\text { American Institute of Astronautics } \\ \text { and Aeronautics } \\ \text { aluminum }\end{array} & \text { ASTEP } & \begin{array}{l}\text { Astrobiology Science and } \\ \text { Technology Program for Exploring } \\ \text { Planets }\end{array} \\ \text { Al } & \begin{array}{l}\text { Advanced Material Bipropellant } \\ \text { AMBR }\end{array} & \text { ATCS } & \begin{array}{l}\text { Active Thermal Control System } \\ \text { astronomical unit }\end{array} \\ \text { AO } & \text { Announcement of Opportunity } & \text { AU } & \text { American Wire Gauge }\end{array}$




\begin{tabular}{|c|c|c|c|}
\hline BER & bit error rate & $\mathrm{LH}_{2}$ & liquid hydrogen \\
\hline C\&DH & Command and Data Handing & $\mathrm{Li}$ & lithium \\
\hline CBE & current best estimate & LMO & low Mars orbit \\
\hline CER & cost estimating relationships & LOx & liquid oxygen \\
\hline CEV & Crew Exploration Vehicle & LSP & Launch Service Program \\
\hline CMG & Control Moment Gyro & LSTO & Launch Service Task Order \\
\hline Comm & Communications & MAC & Media Access Control \\
\hline \multirow[t]{3}{*}{ COMPASS } & COncurrent Multidiciplinary & MEL & Master Equipment List \\
\hline & Parametric Assessment of Space & MER & Mass Estimating Relationship \\
\hline & Systems & MGA & Mass Growth Allowance \\
\hline \multirow[t]{2}{*}{ COPV } & Composite Overwrapped Pressure & MMOD & Micrometeoroid Orbital Debris \\
\hline & Vessel & MOC & Mars orbit capture \\
\hline COTS & commercial off the shelf & MOI & Mars orbit insertion \\
\hline cPCI & Peripheral Component Interconnect & MPU & Makeup Power Unit \\
\hline $\mathrm{CPU}$ & central processing unit & NASA & National Aeronautics and Space \\
\hline CTCV & Crew Telerobotic Control Vehicle & & Administration \\
\hline DCV & Direct Current Voltage & $\mathrm{Nav}$ & navigation \\
\hline DMR & Design for Minimum Risk & NERVA & Nuclear Engine for Rocket Vehicle \\
\hline DOE & Department of Energy & & Application \\
\hline DRA & Design Reference Architecture & NIST & National Institute of Standards and \\
\hline DSN & Deep Space Network & & Technology \\
\hline DTE & direct to Earth & NTO & nitrogen tetroxide \\
\hline \multirow{2}{*}{ ECLSS } & Environmental Control \& Life & NTR & Nuclear Thermal Rocket \\
\hline & Support Systems & OME & Orbital Maneuvering Engine \\
\hline \multirow[t]{2}{*}{ EELV } & Evolved Expendable Launch & OQPSK & Offset Quadratic Phase Shift Key \\
\hline & Vehicle & PEL & Power Equipment List \\
\hline ELV & Expendable Launch Vehicle & PMAD & Power Management and \\
\hline FEA & finite element analysis & & Distribution \\
\hline FOM & figure of merit & PMC & PCI Mezzanine Card \\
\hline FPGA & Flight Programmable Gate Arrays & QPSK & Quadratic Phase Shift Key \\
\hline FT & Fault Tolerant & RCS & Reaction Control System \\
\hline FY & fiscal year & SADA & Solar Array Drive Assembly \\
\hline GCR & Galactic Cosmic Ray & SLASR & Stretched Lens Array SquareRigger \\
\hline \multirow[t]{2}{*}{ GLIDE } & GLobal Integrated Design & SLOC & source lines of code \\
\hline & Environment & SN & signal-to-noise \\
\hline GN\&C & Guidance, Navigation and Control & SNRE & Small Nuclear Rocket Engine \\
\hline GRC & NASA Glenn Research Center & SOFI & Spray-On Foam Insulation \\
\hline hab & habitat & SOAP & Satellite Orbit Analysis Program \\
\hline HERRO & $\begin{array}{l}\text { Human Exploration using Real- } \\
\text { time Robotic Operations }\end{array}$ & SPACE & $\begin{array}{l}\text { System Power Analysis for } \\
\text { Capability Evaluation }\end{array}$ \\
\hline HQ & NASA Headquarters & SPU & Solar Power Unit \\
\hline IEM & integrated electronics modules & $\mathrm{TCM}$ & trajectory correction maneuvers \\
\hline IMDC & I M Design Center & TEI & trans Earth injection \\
\hline IMLEO & Initial Mass in Low Earth Orbit & TMI & trans Mars injection \\
\hline IP & internet protocol & TRL & Technology Readiness Level \\
\hline JPL & NASA Jet Propulsion Laboratory & TWTA & Traveling Wave Tube Amplifier \\
\hline LDPC & Low Density Parity Check & WBS & work breakdown structure \\
\hline LEO & low Earth orbit & & \\
\hline
\end{tabular}




\section{Appendix B-HERRO Technology and Demonstration Roadmap}

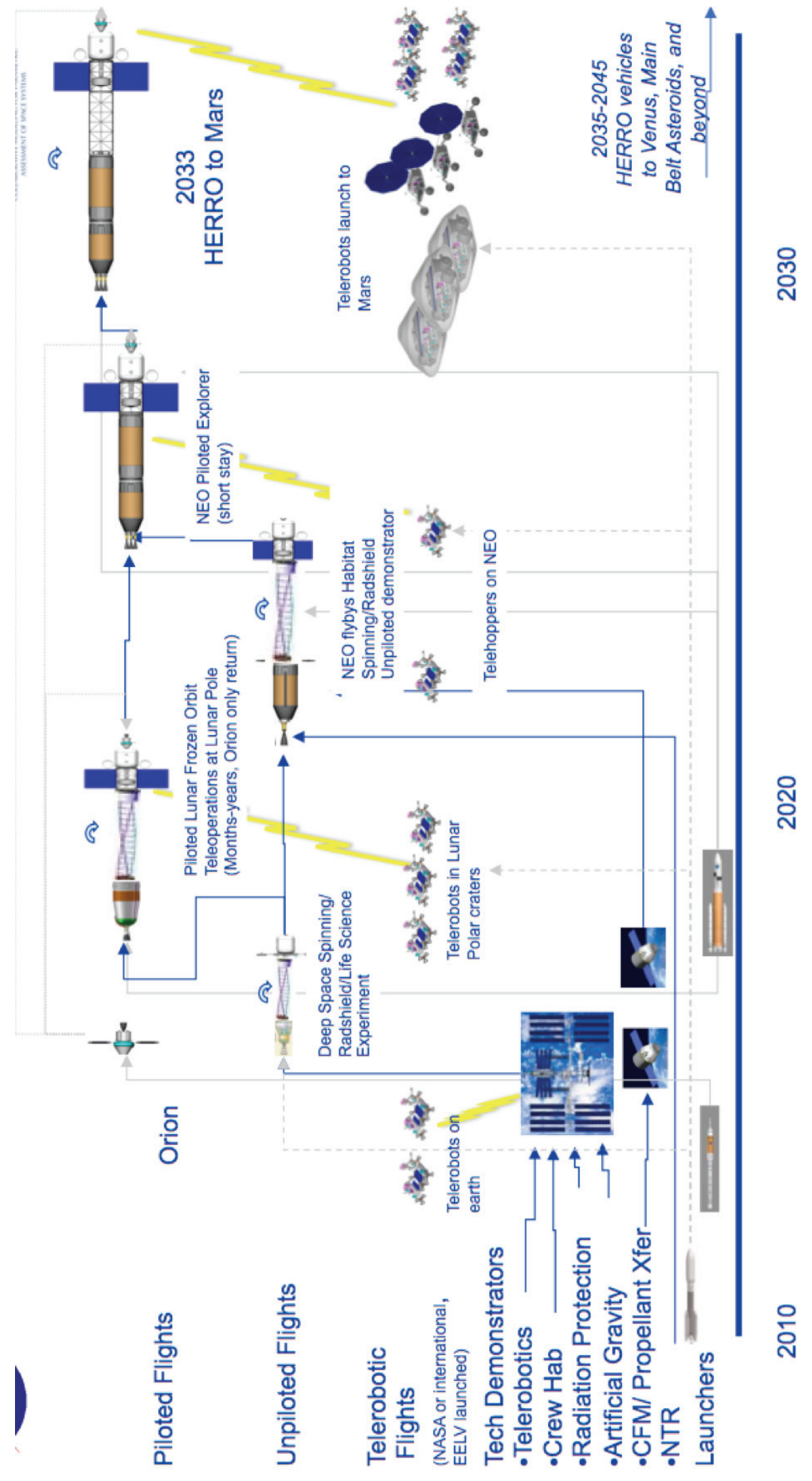




\section{Appendix C-HERRO Compared To DRA 5.0}

\section{Table C.1. DRM Versus HERRO Architecture Comparison}

\begin{tabular}{|c|c|c|}
\hline Criterion & DRM & HERRO \\
\hline $\begin{array}{l}\text { Science Campaign: } \\
\text { three } 100 \mathrm{~km} \text { radius, } \\
\text { widely separated } \\
\text { regions }\end{array}$ & $\begin{array}{l}\text { Three separate manned landed missions, landing in } \\
\text { three locations, pre-position cargo one opportunity } \\
\text { early }\end{array}$ & $\begin{array}{l}\text { One manned orbiting mission, telerobotically exploring } \\
\text { three locations, pre-position telerobots one opportunity } \\
\text { early }\end{array}$ \\
\hline Location/duration & Three $500 \mathrm{~d}$ stays, each at a $100 \mathrm{~km}$ radius region & $\begin{array}{l}\text { Three } 100 \mathrm{~km} \text { radius regions, simultaneous telerobotic } \\
\text { exploration }\end{array}$ \\
\hline $\begin{array}{l}\text { Launches } \\
\text { (entire campaign) }\end{array}$ & 21 Ares V+six Ares 1 & $\begin{array}{l}\text { Four Ares V, two Ares 1, seven EELVs } \\
\text { Four heavy lift + two Ares } 1+\text { three rovers = three EELVs } \\
+ \text { three sample return to LMO = three EELVs }+ \text { one sample } \\
\text { rendezvous (LMO to Manned Vehicle) }\end{array}$ \\
\hline $\begin{array}{l}\text { Vehicles } \\
\text { (entire campaign) }\end{array}$ & $\begin{array}{l}\text { Three Mars Transfer Vehicles, six Orion, three cargo } \\
\text { lander, three cargo habitat; three hab lander, three } \\
\text { ascent vehicle, three habitat, six pressurized manned } \\
\text { rovers, six unpressurized manned rovers ( } 27 \text { NTR } \\
\text { engines) }\end{array}$ & $\begin{array}{l}\text { One piloted teleoperation control vehicle (propulsion, } \\
\text { habitat, teleoperation center, Orion), three telerobot truck } \\
\text { carriers, six telerobot Rockhounds, three sample ascent } \\
\text { systems, one sample rendezvous system, } \\
\text { (three NTR engines) }\end{array}$ \\
\hline $\begin{array}{l}\text { Crew } \\
\text { (entire campaign) }\end{array}$ & Three crews of six & Six, four geologists teleoperators (two shifts), two support \\
\hline $\begin{array}{l}\text { Technology } \\
\text { development }\end{array}$ & $\begin{array}{l}\text { Long duration crew on-orbit habitat, cryofluid } \\
\text { management and propellant transfer, Nuclear } \\
\text { thermal rockets, Radiation protection, aerocapture } \\
\text { (cargo) Landing descent, Landing ascent systems, } \\
\text { Mars unique habitats/manned systems, Manned } \\
\text { rovers, Surface suits, Surface reactor, In-situ } \\
\text { propellant production for ascent system }\end{array}$ & $\begin{array}{l}\text { Long duration crew on-orbit habitat, Cryofluid } \\
\text { management and propellant transfer, Nuclear thermal } \\
\text { rockets Radiation protection, Artificial gravity, } \\
\text { Telerobotics, Teleoperated rovers, Sample ascent system, } \\
\text { Teleoperated sample rendezvous system }\end{array}$ \\
\hline Cost and Risk & TBD & TBD \\
\hline
\end{tabular}

Table C.2. DRM Versus HERRO Science Region Exploration Comparison

\begin{tabular}{|c|c|c|}
\hline Criterion & DRM & HERRO \\
\hline Regions & One $100-\mathrm{km}$ region explored per mission & $\begin{array}{l}\text { Three widely-separated } 100 \mathrm{~km} \text { regions explored per } \\
\text { mission }\end{array}$ \\
\hline Traverses & 14 science sites, at $2 \mathrm{wk}$ on site per traverse & $\begin{array}{l}30 \text { science sites explored per region, } 2 \text { wk per site, } x \text { three } \\
\text { region }\end{array}$ \\
\hline $\begin{array}{l}\text { Exploration period in } \\
\text { 8-hr EVA }\end{array}$ & $\begin{array}{l}4.8 \mathrm{hr} \text { of human exploration per day }(1 \mathrm{hr} / \mathrm{d} \\
\text { required for suiting/desuiting, plus } 20 \% \text { of time } \\
\text { spent moving to site*) }\end{array}$ & $\begin{array}{l}16 \mathrm{hr} \text { of effective exploration per day (two shifts). No } \\
\text { suiting; telerobots already on site. }\end{array}$ \\
\hline Crew & $\begin{array}{l}\text { Four geologists on surface, plus two astronaut } \\
\text { pilots/support }\end{array}$ & $\begin{array}{l}\text { Four geologists (two shifts) teleoperating six Rockhounds, } \\
\text { plus two astronaut pilots/support }\end{array}$ \\
\hline Sites & $\begin{array}{l}\text { Science sites must be within rover drive of high- } \\
\text { safety landing spot }\end{array}$ & $\begin{array}{l}\text { Difficult landing sites do not result in risk to humans; wide } \\
\text { variety of sites possible }\end{array}$ \\
\hline Latitude & $\begin{array}{l}\text { Mid-latitudes only } \\
\text { to avoid 6-months of darkness }\end{array}$ & All latitudes, including polar regions \\
\hline
\end{tabular}

Table C.3. DRM Versus HERRO Planetary Protection, Science, Public Outreach Comparison

\begin{tabular}{|c|c|c|}
\hline Mission & DRM & HERRO \\
\hline Planetary Protection & $\begin{array}{l}\text { Difficult planetary protection due to human } \\
\text { effluent; no human contact with "special regions" }\end{array}$ & $\begin{array}{l}\text { Planetary protection possible, no human effluent. } \\
\text { Exploration of "special regions" possible }\end{array}$ \\
\hline Sample Return & Large sample mass and volume returned & Small mass of samples returned \\
\hline Scientific instruments & Variety of highly capable scientific instruments & Variety of widely capable scientific instruments \\
\hline Drilling capability & $\begin{array}{l}\text { drilling capability TBD } \\
\text { ( } 100 \text { to } 1000 \mathrm{~m} \text { is desired, but design for this drill } \\
\text { is speculative) }\end{array}$ & $\begin{array}{l}\text { Drilling capability } 10 \mathrm{~m} \text { at multiple sites } \\
\text { (drill design exists, and has been tested) }\end{array}$ \\
\hline Public engagement & High public interested in humans & High public interest in both humans and robots \\
\hline Public outreach & $\begin{array}{l}\text { High definition video shot when astronauts feel } \\
\text { like it }\end{array}$ & High definition video of entire surface mission \\
\hline
\end{tabular}




\section{References}

${ }^{1}$ Borowski, S.K.; McCurdy, D.R.; and Packard, T.W.: Nuclear Thermal Rocket/Vehicle Characteristics and Sensitivity Trades for NASA's Mars Design Reference Architecture (DRA) 5.0 Study. Paper 203599, Nuclear and Emerging Technologies for Space 2009, Atlanta, GA, June 2009.

${ }^{2}$ Seeking a Human Spaceflight program worth of a Great Nation, Review of U.S. Human Spaceflight Plans Committee. October 2009. $283 \mathrm{http}: / /$ www.nasa.gov/pdf/396093main_HSF_Cmte_FinalReport.pdf

${ }^{3}$ AIAA S-120-2006, AIAA Standard Mass Properties Control for Space Systems.

${ }^{4}$ ANSI/AIAA R-020A-1999, Recommended Practice for Mass Properties Control for Satellites, Missiles, and Launch Vehicles

${ }^{5}$ C.S. Guernsey, R.S. Baker, D. Plachta, P. Kittel, R.J. Christie, J. Jurns, “Cryogenic Propulsion With Zero Boil-Off Storage Applied To Outer Planetary Exploration,” JPL D-31783, April 2005

${ }^{6}$ D. Plachta, P. Kittel, “An Updated Zero Boil-Off Cryogenic Propellant Storage Analysis Applied to Upper Stages or Depots in an LEO Environment,” NASA/TM-2003-211691, 2002 AIAA Joint Propulsion Conference, Indianapolis, IN, July 8, 2002.

${ }^{7}$ Plachta, D.W. et al. "Cryogenic Propellant Boil-off Reduction System” Advances in Cryogenics, Vol. 53, 2008.

\section{Bibliography}

ARC/Honeybee page on DAME drill: http://marte.arc.nasa.gov/drill.htm field trip demonstrated 8.3-m depth achieved with Mars "flightlike" power levels $(<100 \mathrm{~W})$.

B. Kent Joosten, "Preliminary Assessment of Artificial Gravity Impacts to Deep-Space Vehicle Design,” JSC-63743, Feb. 2007.

Bejan, A. and Kraus, A.D., Heat Transfer Handbook, John Wiley \& Sons, 2003.

Borowski, S., McGuire, M., and Beke, "Nuclear Thermal Rocket/Vehicle Design Options for Future NASA Missions to the Moon and Mars," NASA TM-107071, 1993.

Carrico, John P., Jon D. Strizzi, Joshua M. Kutrieb, and Paul E. Damphousse, "Trajectory Sensitivities for Sun-Mars Libration Point Missions," AAS 01-327.

Christiansen, E.L., "Meteoroid/Debris Shielding,” NASA/TP_2003-210788, Aug. 2003.

Colozza, A.J., "Spacecraft Thermal Sizing for Trade Study Analysis,” NASA CR Publication Pending, Sep. 2009.

Das et al 1999: H. Das, X. Bao, Y. Bar-Cohen, R. Bonitz, R. Lindemann, M. Maimone, I. Nesnas, C. Voorhees, "Robot manipulator technologies for planetary exploration," Proceedings of the 6th Annual International Symposium on Smart Structures and Materials, 1-5 March 1999, Newport Beach, CA. Paper No. 3668-17.

Durham. F. P., "Nuclear Engine Definition Study Preliminary Report, Volume 2-Supporting Studies," Los Alamos National Lab., Rept. LA-5044-MS Vol. 2, Sept 1972.

Fittje, J.E. and Buehrle, R.J., "Conceptual Engine System Design for NERVA derived 66.7 KN and 111.2 KN Thrust Nuclear Thermal Rockets," Space Technology and Applications International Forum [CD-ROM], Vol. 813, AIP, Melville, NY, 2006.

Fittje, James E., "Upgrades to the Nuclear Engine System Simulation (NESS) Code," AIAA-2007-5620, July 2007

G. A. Briggs, H. Cannon, S. Domville, B. Glass, C. McKay, J. George, B. Derkowski, R. Fincher, G. Cooper, K. Zacny, W. Pollard, S. Clifford, "Mars Deep Drill Prototype: An automated, low mass, low power drill for acquiring subsurface samples of ground ice for astrobiology studies on Earth and on Mars" http://www.maxsimul.com/Publications/NASAlpaper.pdf.

Gilmore, David G. ed., Spacecraft Thermal Control Handbook: Volume 1 Fundamental Technologies, AIAA, 2002.

Hyder, A.J., Wiley, R.L., Halpert, G., Flood, D.J. And Sabripour, S. Spacecraft Power Technologies, Imperial College Press, 2000.

Images of the Honeybee "DAME" drill (Drilling Automation for Mars Exploration): http://www.nasa.gov/centers/ames/multimedia/ images/2006/marsdrill.html, http://www.marsonearth.org/reports/07.31.04.field.update.html.

Incopera, F.P. and DeWitt, D.P., Fundamentals of Heat and Mass Transfer, John Wiley \& Sons, 1990.

Koenig, D.R., "Experience Gained from the Space Nuclear Rocket Program (Rover)," Los Alamos National Lab., Report LA-10062-H, May 1986.

Larson, Wiley J. and Linda K. Pranke, Human Spaceflight: Mission Analysis and Design, McGraw-Hill.

Liu 2008: Liu, H., Wu, K., Meusel, P., Hirzinger, G., Jin, M.H., Liu, Y.W., Fan, S.W., Lan, T., Chen, Z.P., “A dexterous humanoid fivefingered robotic hand," 17th IEEE International Symposium on Robot and Human Interactive Communication, RO-MAN 2008, 13 Aug. 2008, pp. 371-376, 10.1109/ROMAN.2008.4600694

Mewaldt, R.A., Davis, A.J., Binns, W.R., deNolfo, G.A., George, J.S., Isreal, M.H., Leske, R.A. Stone, E.C., Wiedenbeck, M.E. and von Rosenvinge, T.T., "The Cosmic Ray Radiation Dose in Interplanetary Space-Present D and Worst-Case Evaluations," 29th International Cosmic Ray Conference, 2005.

Pelaccio, Schiel, and Petrosky, "Nuclear Engine System Simulation (NESS): Version 2.0," NASA CR-191081, 1993.

Schimmerling, W., Wilson, J.W., Nealy, J.E., Thibeault, S.A., Cucinotta, F.A., Shinn, J.L., Kim, M., and Kiefer, R., "Shielding Against Galactic Cosmic Rays," Adv. Space Res., Vol. 17, No. 2, pp 31-36, 1996.

Schnitzler, B., and Borowski, S., "Nuetronics Models and Analysis of the Small Nuclear Rocket Engine (SNRE)," AIAA-2007-5618, July 2007. Durham, F.P., "Nuclear Engine Definition Study Preliminary Report, Volume 1—Engine Description," Los Alamos National Laboratory, Report LA-5044-MS Vol 1, Sept. 1972.

Schnitzler, Bruce G., Borowski, Stanley K., and Fittje, James E., "25,000-lbf Thrust Engine Options Based on the Small Nuclear Rocket Engine Design,” AIAA-2009-5239, August 2009.

Sylvia L. Miller, John C. Essmiller, and David W. Beaty, “Mars Deep Drill—A Mission Concept for the Next Decade,” paper 2004-042701 http://trs-new.jpl.nasa.gov/dspace/bitstream/2014/41083/1/04-2701.pdf.

Watson, C.W., "Nuclear Rockets: High-Performance Propulsion for Mars," Los Alamos National Lab. Report LA-12784-MS, May, 1994. Wiley J. Larson and James R. Wertz (eds.), Space Mission Analysis and Design, 3rd edition (Space Technology Library), Oct. 1999. 